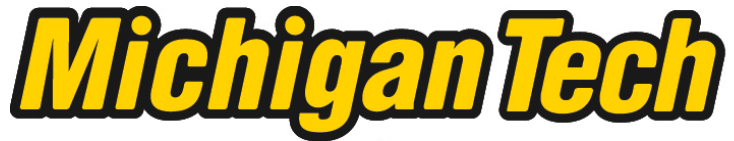 \\ Michigan Technological University Create the Future Digital Commons @ Michigan Tech
}

\section{Analyzing the effects of vertical acceleration and deceleration in multi-phase, debris-flow sediment-column experiments / by Christine Marie Williams.}

Christine Marie Williams

Michigan Technological University

Follow this and additional works at: https://digitalcommons.mtu.edu/etds

Part of the Geology Commons

Copyright 2006 Christine Marie Williams

\section{Recommended Citation}

Williams, Christine Marie, "Analyzing the effects of vertical acceleration and deceleration in multi-phase, debris-flow sediment-column experiments / by Christine Marie Williams.", Master's Thesis, Michigan Technological University, 2006.

https://doi.org/10.37099/mtu.dc.etds/342

Follow this and additional works at: https://digitalcommons.mtu.edu/etds

Part of the Geology Commons 
ANALYZING THE EFFECTS OF VERTICAL ACCELERATION AND DECELERATION IN MULTI-PHASE, DEBRIS-FLOW SEDIMENT-COLUMN EXPERIMENTS

By

CHRISTINE MARIE WILLIAMS

\author{
A THESIS \\ Submitted in partial fulfillment of the \\ requirements for the degree of \\ MASTER OF SCIENCE IN GEOLOGY \\ MICHIGAN TECHNOLOGICAL UNIVERSITY \\ 2006
}

Copyright $($ Christine M. Williams 2006 
This thesis, "Analyzing the Effects of Vertical Acceleration and Deceleration in Multi-Phase, Debris-Flow Sediment-Column Experiments",

is hereby approved in partial fulfillment of the requirements for the Degree of MASTER OF SCIENCE IN GEOLOGY.

DEPARTMENT: Geological and Mining Engineering and Sciences

Thesis Advisor: Dr. James Vallance

Department Chair: Dr. Wayne Pennington

Committee Members: Dr. Alex Mayer, Dr. Wayne Pennington, Dr. Tamara Olson 


\section{Abstract}

Water-saturated debris flows are among some of the most destructive mass movements. Their complex nature presents a challenge for quantitative description and modeling. In order to improve understanding of the dynamics of these flows, it is important to seek a simplified dynamic system underlying their behavior. Models currently in use to describe the motion of debris flows employ depth-averaged equations of motion, typically assuming negligible effects from vertical acceleration. However, in many cases debris flows experience significant vertical acceleration as they move across irregular surfaces, and it has been proposed that friction associated with vertical forces and liquefaction merit inclusion in any comprehensive mechanical model. The intent of this work is to determine the effect of vertical acceleration through a series of laboratory experiments designed to simulate debris flows, testing a recent model for debris flows experimentally. In the experiments, a mass of water-saturated sediment is released suddenly from a holding container, and parameters including rate of collapse, pore-fluid pressure, and bed load are monitored. Experiments are simplified to axial geometry so that variables act solely in the vertical dimension. Steady state equations to infer motion of the moving sediment mass are not sufficient to model accurately the independent solid and fluid constituents in these experiments. The model developed in this work more accurately predicts the bed-normal stress of a saturated sediment mass in motion and illustrates the importance of acceleration and deceleration.

Author: Christine M. Williams

January 12,2007 


\section{Acknowledgments}

Completion of this thesis marks the end of a long journey for me. I am grateful to everyone at Michigan Tech who has assisted me during this lengthy process. There are many people who took time out of their busy schedules in an effort to see this project to the end. I will always appreciate and remember their support.

This all began with a chance meeting between myself and Dr. William Rose at the University of Washington that led me to apply to graduate school at Michigan Tech. Shortly after arriving at Tech I was introduced to Dr. James Vallance who was looking for a graduate student to work on a project he and Dr. Richard Iverson were developing. That introduction was the catalyst for this project. I thank both Dr. Vallance and Dr. Iverson for their support and guidance throughout this project.

The project involved running experiments, all of which were conducted at the Cascades Volcano Observatory (CVO) in Vancouver, WA. I spent several months over 3 summers working at CVO, during which time there were many people who helped me whenever I needed it. These folks were instrumental in the success of this project. Their support in building the experimental apparatus, designing and understanding the data acquisition system, and supplying various supplemental equipment was important to the projects success. I thank Winston Stokes, Richard LaHusen, Tony Bequette, and Jon Major.

Completion of the experiments launched me into the daunting task of reducing data, writing code, and plotting results. There were a number of people who helped me through this process by answering questions and providing guidance within their areas of expertise. I thank Doug Hull for 
all his help in Matlab coding and data processing. I thank Dr. Charles Young, Dr. Timothy Schultz, and Ms. Shannon Pipik for sharing their digital signal processing expertise and advice.

Many revisions of this thesis have existed through the years and each time reviewers were there to take a look at yet another draft. I owe a huge thank you to Dr. Charles Young, Mr. Michael Dolan, Ms. Christine Houts, Mr. James Moore and Mrs. Nancy Moore, and Mr. Ted Soldan. A very special thank you goes out to Dr. Wayne Pennington for his thorough and enlightening editing of the final thesis draft. His patience and willingness to sit with me and discuss changes that would enhance my document were invaluable. I will always remember his dedication and support.

I would like to thank my committee members Dr. Alex Mayer and Dr. Tamara Olson, for their reviews, thoughts, and support.

During the summers I was out in Washington conducting experiments my family and friends opened their homes to me and for that I am forever grateful. My mother provided me and my dog Patches a comfortable place to stay during the first summer. I truly appreciated her home cooked meals and companionship. I owe a special thank you to my dear friend, Mr. Jay Turner, who opened up his home during the second summer of experiments. He not only provided me with a place to stay but made me smile and laugh during some rough times.

When it came time to write the final draft of this thesis it was critical for me to be close to my advisor, who was out in Washington at CVO. This time my brother offered me a room in his house for as long as I needed it. Five months later, I had the final draft written and was ready to head back home to Michigan. I owe my brother an enormous thank you for providing me with a comfortable and quiet place to stay during those five months. I am also grateful for his companionship and friendship during the most difficult phase of the project. 
A special thank you goes out to my sister Tracy, my personal cheerleader. Tracy never seemed to tire of hearing me say, "I'm almost done". Her words of encouragement were necessary and appreciated every time she offered them.

Finally, I want to thank Michael Dolan from the bottom of my heart for his unwavering support through the years. He has been along on this ride from the very first day and has supported me every step along the way. I could not have finished this project without his friendship, patience, and kindness. His support through it all will forever be appreciated and I will never forget how lucky I have been for having such a wonderful person by my side. 


\section{Table of Contents}

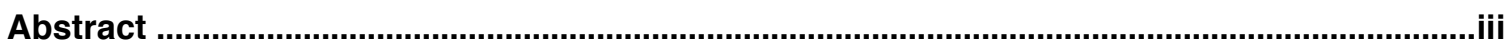

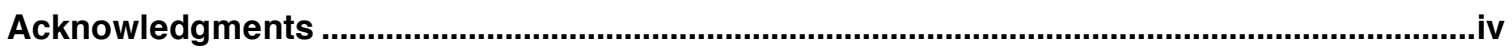

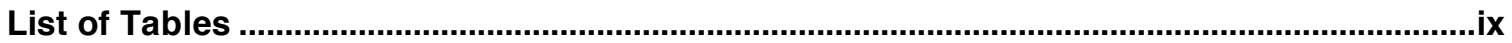

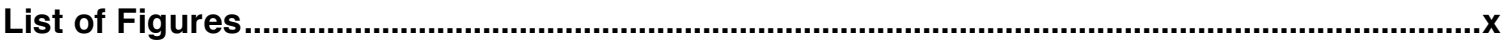

Variable Listing

1. Introduction

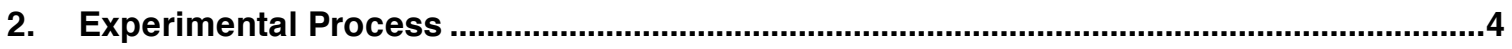

3. Theory

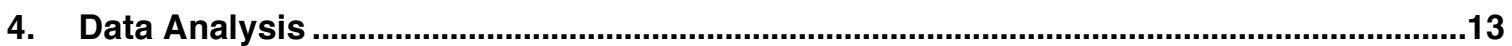

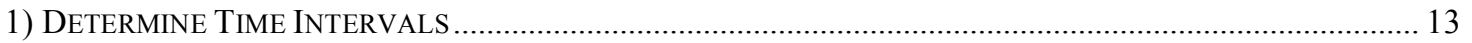

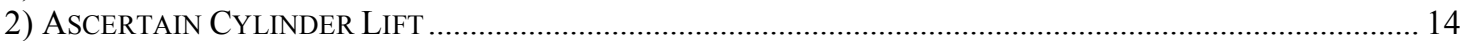

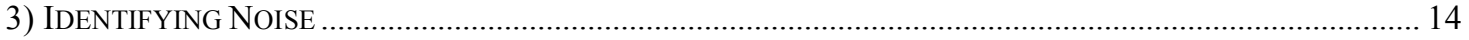

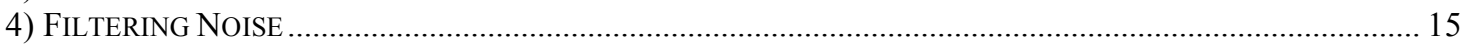

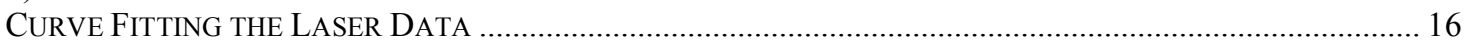

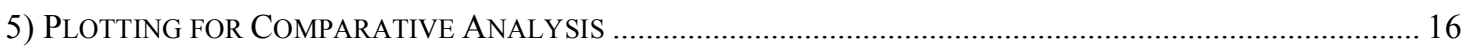

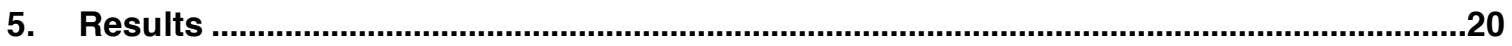

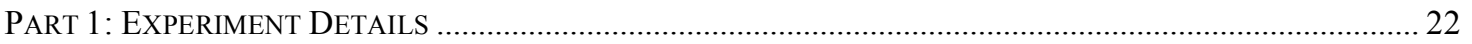

DODSON DEBris Flow, Columbia RIVER Gorge, DodSON, OREGON, 1997.......................................... 22

OSCEOLA MUDFLOW, MT. RAINIER, WASHINGTON, CIRCA 5700 B.P. ..................................................... 24

North Fork TOUTLE River Mudflow, Mount St. Helens, WASHINGTON, 1980 ............................... 26

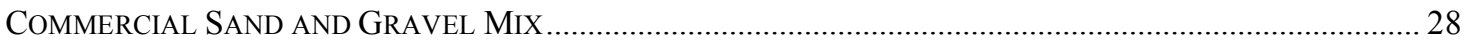

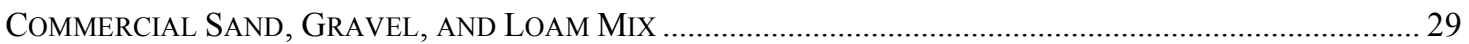

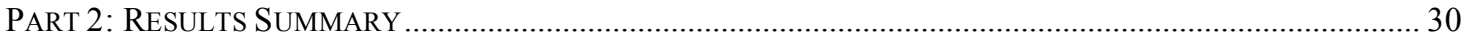

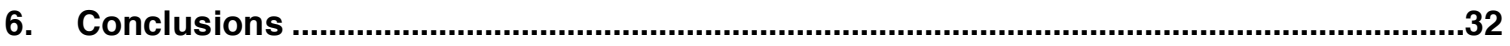

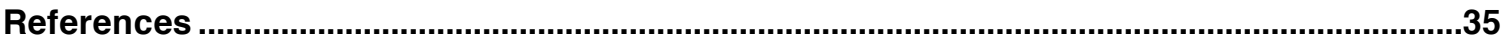

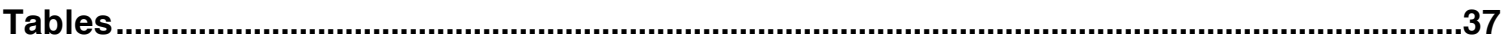

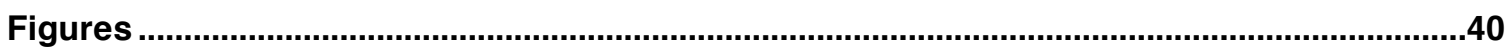

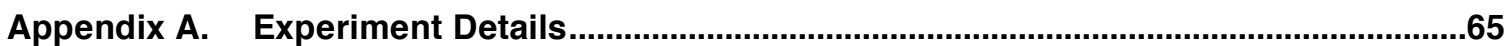

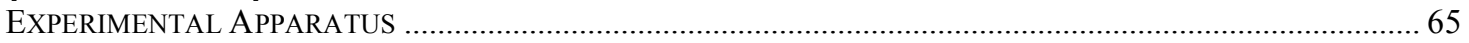

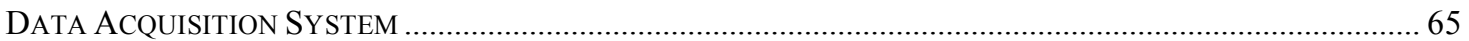

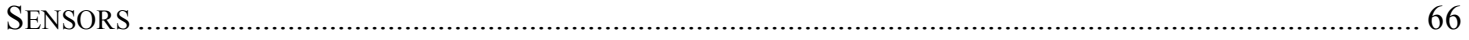

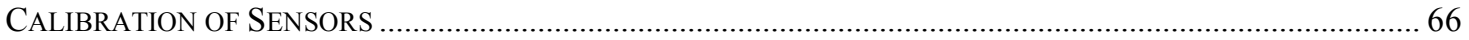

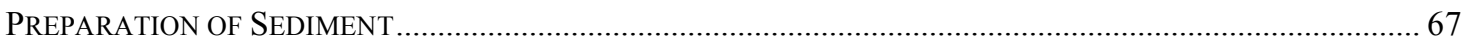

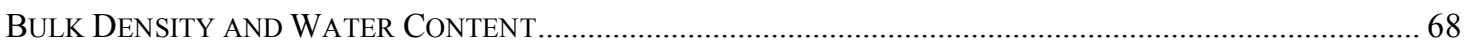

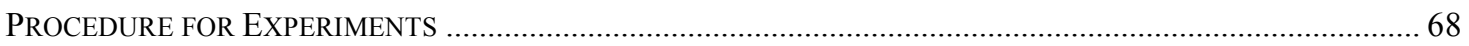

Appendix B. Normalization and Dimensional Analysis ........................................................ 


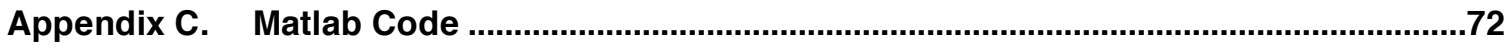

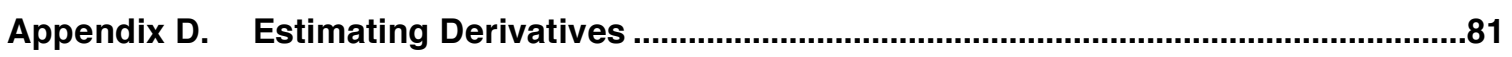

Appendix E. Calculating the Mean Square Error (MSE) ...................................................

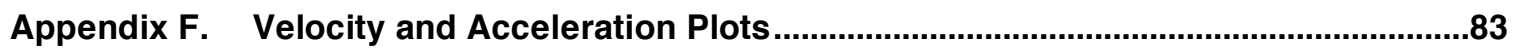

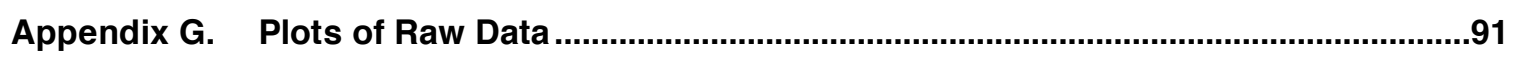

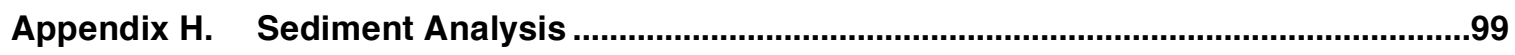




\section{List of Tables}

Table 1: Sediment summary of the grain size analysis and variable definitions. ........................... 37

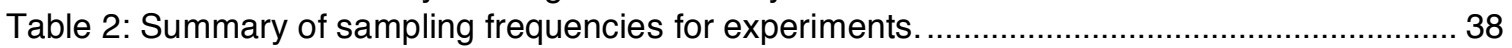

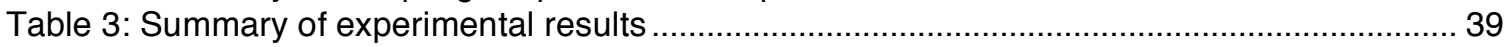




\section{List of Figures}

Figure 1: LaConchita, CA. The left image shows the 1995 slump in the hillside behind the coastal community of LaConchita. No injuries were recorded in this event but there was substantial property loss. The image to the right shows the 2005 debris flow that mobilized from the 1995 slump after 72 consecutive hours of rainfall. In this event, 10 people lost their lives. Photos courtesy of Bruce Perry, California State University Long Beach, Department of Geological Sciences.

Figure 2: Drawing showing cylinder being lifted to allow sediment slurry to flow. Sediment column starts at rest confined in the cylinder, then is rapidly released where it again comes to rest. The visible light laser records mass flow rate during the lift. Pressure transducers used in the experiments are shown at the base of the container and labeled \#1 and \#4. The load cell is centered with pressure sensor \#1 and records the bed-normal stress. Pressure sensor \#4 records the arrival of the sediment at the sidewall of the container. Pressure sensor \#1 records the centerline pore-fluid pressure.

Figure 3: Experimental apparatus shows the large holding container (blue) with the tall cylinder inside and in the center. The cylinder is housed in stability framework. A visible light laser is suspended above and in the centerline of the cylinder. Pressure transducers are affixed to the base and sidewall of the holding container. The yellow ropes seen attached to the horizontal bars at the top of the cylinder are a part of a pulley system, which vertically lifts the cylinder at a constant rate when a counter weight is applied. Video cameras record the experiments.

Figure 4: a) Pressure transducer locations looking down into the holding container. The load cell plate is represented by the circle around the centerline pressure sensor. The bottom of the container has 4 pressure transducers radiating from the center and 2 transducers on the sidewall (upper area of image). Each pressure transducer is protected from entrance of fine particles by a 230-mesh screen. b) Shows the exterior of the container with the 4 pressure transducers at the base and 2 on the sidewall attached as they are during experiments. The clear tubing is pre-filled with water before each experiment. The transducers are housed in PVC tubing to protect them from vibrations and superfluous noise. c) Shows the S-beam style load cell mounted under the container. There is a $5 \mathrm{~cm}$ diameter plate mounted on the base of the container, above the load cell, which records bed-normal stress in the centerline of the cylinder. On the following page: d) Schematic drawing of the apparatus and sensor locations. The drawing shows a side view and plan view of the apparatus. The laser measures change in column height $(h)$, load cell measures bed-normal stress $(\sigma)$, and pressure sensors measure pore-fluid pressure $(p)$

Figure 5: Diagram showing the cylinder and centerline. A simple coordinate system shows $z \uparrow^{+}$. Pressure sensor \#1, the load cell, and the visible light laser are located in this centerline. Sediment mixture is made up of solids and fluid (water) and is at rest prior to lifting the cylinder.

Figure 6: Histograms of sediments used in these experiments. Three samples were analyzed for both the Dodson debris flow sediment and the sand and gravel mixture. Sand/gravel/loam mixture is represented by $(S / G / L)$ and the sand/gravel mixture is represented by $(S / G) \ldots . .46$

Figure 7: Histograms from hydrometer tests representing Osceola mudflow sediments courtesy of Dr. James Vallance (1996) and North Fork Toutle River mudflow sediment courtesy of Dr. Jon Major (1997). 46

Figure 8: Aerial photograph showing collection site from the 1996 Dodson debris flow, Dodson, OR, Columbia River Gorge. The white circle with the $\mathrm{x}$ indicates the site where sediment was removed to a depth of $1 \mathrm{~m}$. The Royse house that was inundated by the flowing debris is just to the right in the photo. The house is buried to the second story windows. Photo courtesy of K. Cruikshank, Portland State University, Portland, Oregon. 
Figure 9: Osceola mudflow collection site, indicated by red circle. Located on Huckleberry Creek, on the northeast side of Mt. Rainier, south of Greenwater, WA

Figure 10: Toutle River mudflow from Mount St. Helen's 1980 eruption. The collection site is near the Kidd Valley Bridge on Highway 504. The sediment collection site is represented by the red circle in the graphic. Sediment was collected at about 3 meters above the Toutle River.

Figure 11: Example of noisy raw data. The x-axis is time in seconds and the $y$-axis is analog digital units (adu). The example shows the load cell sensor during the lift portion of the experiment. Note that from $0-.5$ and from $\sim 1.7$-end noise is easily identified as oscillating around a mean value.

Figure 12: Example of power spectral density plots showing sinusoids identifying the primary signal and noise. The y axis represents decibel units $(\mathrm{dB})$. The primary signal is in the low frequency range $(<20 \mathrm{~Hz})$. The noise in the signal oscillates around a mean of about -20 $\mathrm{dB}$ and is identified by the relative plane in which it resides, i.e., a horizontal line can be drawn through the sinusoids. This example plot is representative of all PSD's for the experiments.

Figure 13: Power spectral density plot showing frequency peaks at $60 \mathrm{~Hz}$ and $120 \mathrm{~Hz}$. The $37.15 \mathrm{~Hz}$ peak is presumably caused by aliasing of the $3^{\text {rd }}$ harmonic of the power spectrum.

Figure 14: Example of lowpass Butterworth filter. The green horizontal double lines define the maximum and minimum desired values for the frequency response across the passband. The vertical separation of the lines indicates the magnitude of the passband ripple, the larger the ripple the further apart the bands. The single green horizontal line defines the stopband. The blue line defines the frequency response and plots the magnitude of the filter's frequency response in decibels $\left(20^{*} \log 10\right.$ (magnitude)).

Figure 15: Example of comparison plot showing the filtered and raw data. The raw data are shown in light blue and the filtered data are in red. The y axis represents analog digital units and the $x$ axis is time in seconds. This example is representative of all filtering that is done for both the load cell and the pressure sensors.

Figure 16: Example of curve fitting laser data. Several curves were fit to the data before settling on the smoothing spline. The inset plots show detail at the start of flow and the end of the flow. This example is representative of all curve fitting of the laser data for all experiments.

Figure 17: The figure shows a subplot with five plots, a-b-c-d-e. The header of the plot defines the sediment name, bulk density, initial height, and water content. The y-axis are normalized and represents stress for plots a-d. Plot (a) shows the measured normal stress compared to the.

Figure 18: Experiment \#1 - Dodson debris flow, Dodson, Oregon, Columbia River Gorge, 1997. The sediment mixture has a water content of $43 \%$, initial column height of $.33 \mathrm{~m}$, and bulk density.....

Figure 19: Experiment \#2 - Dodson debris flow, Dodson, Oregon, Columbia River Gorge, 1997. The sediment mixture has a water content of $47 \%$, initial column height of $.43 \mathrm{~m}$, and bulk density of $1876 \mathrm{~kg} / \mathrm{m}^{3}$. Refer to Figure 18 for plot details.

Figure 20: Experiment \#1 - Osceola mudflow, Mt. Rainier, WA, 5600 years ago. The sediment mixture has a water content of $40 \%$, initial column height of $.43 \mathrm{~m}$, and bulk density of 1993 $\mathrm{kg} / \mathrm{m}^{3}$. Refer to Figure 18 for plot details.

Figure 21: Experiment \#2 - Osceola mudflow, Mt. Rainier, WA, 5600 years ago. The sediment mixture has a water content of $43 \%$, initial column height of $.39 \mathrm{~m}$, and bulk density of 1943 $\mathrm{kg} / \mathrm{m}^{3}$. Refer to Figure 18 for plot details.

Figure 22: Experiment \#1 - North Fork Toutle River mudflow, Mount St. Helens, WA, 1980. The sediment mixture has a water content of $44 \%$, initial column height of $.37 \mathrm{~m}$, and bulk density of $1891 \mathrm{~kg} / \mathrm{m}^{3}$. Refer to Figure 18 for plot details. 
Figure 23: Experiment \#2 - North Fork Toutle River mudflow, Mount St. Helens, WA, 1980. The sediment mixture has a water content of $47 \%$, initial column height of $.40 \mathrm{~m}$, and bulk density of $1841 \mathrm{~kg} / \mathrm{m}^{3}$. Refer to Figure 18 for plot details.

Figure 24: Experiment \#1 - Commercial sand and gravel mixture. The sediment mixture has a water content of $29 \%$, initial column height of $.58 \mathrm{~m}$, and bulk density of $2211 \mathrm{~kg} / \mathrm{m}^{3}$. Refer to Figure 18 for plot details.

Figure 25: Experiment \#1 - Commercial sand, gravel, and loam mixture. The sediment mixture has a water content of $39 \%$, initial column height of $.31 \mathrm{~m}$, and bulk density of $2000 \mathrm{~kg} / \mathrm{m}^{3}$. Refer to Figure 18 for plot details.

Figure 26: Experiment \#1 - Dodson debris flow, Dodson, Oregon, Columbia River Gorge, 1997. The sediment mixture has a water content of $43 \%$, initial column height of $.33 \mathrm{~m}$, and bulk density of $1939 \mathrm{~kg} / \mathrm{m}^{3}$.

Figure 27: Experiment \#2 - Dodson debris flow, Dodson, Oregon, Columbia River Gorge, 1997. The sediment mixture has a water content of $47 \%$, initial column height of $.43 \mathrm{~m}$, and bulk density of $1876 \mathrm{~kg} / \mathrm{m}^{3}$.

Figure 28: Experiment \#1 - Osceola mudflow, Mt. Rainier, WA, 5600 years ago. The sediment mixture has a water content of $40 \%$, initial column height of $.43 \mathrm{~m}$, and bulk density of 1993 $\mathrm{kg} / \mathrm{m}^{3}$.

Figure 29: Experiment \#2 - Osceola mudflow, Mt. Rainier, WA, 5600 years ago. The sediment mixture has a water content of $43 \%$, initial column height of $.39 \mathrm{~m}$, and bulk density of 1943 $\mathrm{kg} / \mathrm{m}^{3}$

Figure 30: Experiment \#1 - North Fork Toutle River mudflow, Mount St. Helens, WA, 1980. The sediment mixture has a water content of $44 \%$, initial column height of $.37 \mathrm{~m}$, and bulk density of $1891 \mathrm{~kg} / \mathrm{m}^{3}$.

Figure 31: Experiment \#2 - North Fork Toutle River mudflow, Mount St. Helens, WA, 1980. The sediment mixture has a water content of $47 \%$, initial column height of $.40 \mathrm{~m}$, and bulk density of $1841 \mathrm{~kg} / \mathrm{m}^{3}$...

Figure 32: Experiment \#1 - Commercial sand and gravel mixture. The sediment mixture has a water content of $29 \%$, initial column height of $.58 \mathrm{~m}$, and bulk density of $2211 \mathrm{~kg} / \mathrm{m}^{3} \ldots \ldots \ldots . .89$

Figure 33: Experiment \#1 - Commercial sand, gravel, and loam mixture. The sediment mixture has a water content of $39 \%$, initial column height of $.31 \mathrm{~m}$, and bulk density of $2000 \mathrm{~kg} / \mathrm{m}^{3}$.

Figure 34: Dodson debris flow, Dodson, Oregon, Columbia River Gorge, 1997. The sediment mixture has a water content of $43 \%$, initial column height of $.33 \mathrm{~m}$, and bulk density of 1939 $\mathrm{kg} / \mathrm{m}^{3}$. The plot shows all sensors for the duration of the run.

Figure 35: Dodson debris flow, Dodson, Oregon, Columbia River Gorge, 1997. The sediment mixture has a water content of $47 \%$, initial column height of $.43 \mathrm{~m}$, and bulk density of 1876 $\mathrm{kg} / \mathrm{m}^{3}$. The plot shows all sensors for the duration of the run.

Figure 36: Osceola mudflow, Mt. Rainier, WA, 5600 years ago. The sediment mixture has a water content of $40 \%$, initial column height of $.43 \mathrm{~m}$, and bulk density of $1993 \mathrm{~kg} / \mathrm{m}^{3}$. The plot shows all sensors for the duration of the run.

Figure 37: Osceola mudflow, Mt. Rainier, WA, 5600 years ago. The sediment mixture has a water content of $43 \%$, initial column height of $.39 \mathrm{~m}$, and bulk density of $1943 \mathrm{~kg} / \mathrm{m}^{3}$. The plot shows all sensors for the duration of the run.

Figure 38: North Fork Toutle River mudflow, Mount St. Helens, WA, 1980. The sediment mixture has a water content of $44 \%$, initial column height of $.37 \mathrm{~m}$, and bulk density of $1891 \mathrm{~kg} / \mathrm{m}^{3}$. The plot shows all sensors for the duration of the run. 95

Figure 39: North Fork Toutle River mudflow, Mount St. Helens, WA, 1980. The sediment mixture has a water content of $47 \%$, initial column height of $.40 \mathrm{~m}$, and bulk density of $1841 \mathrm{~kg} / \mathrm{m}^{3}$. The plot shows all sensors for the duration of the run.

Figure 40: Commercial sand and gravel mixture. The sediment mixture has a water content of $29 \%$, initial column height of $.58 \mathrm{~m}$, and bulk density of $2211 \mathrm{~kg} / \mathrm{m}^{3}$. The plot shows all sensors for the duration of the run. 
Figure 41: Commercial sand, gravel, and loam mixture. The sediment mixture has a water content of $39 \%$, initial column height of $.31 \mathrm{~m}$, and bulk density of $2000 \mathrm{~kg} / \mathrm{m}^{3}$. The plot shows all sensors for the duration of the run. 


\section{Variable Listing}

$g_{z}=-g \quad$ gravitational constant due to Earth's mass

$\rho_{b} \quad$ bulk density

$\rho_{s} \quad$ solids density

$\rho_{f} \quad$ fluid density

$\tau_{i j} \quad$ total stress tensor

$r \quad$ radial coordinate

$t \quad$ time

$m \quad$ mass

$z \quad$ vertical coordinate in the centerline of sediment column (positive upward)

$h \quad$ sediment column height in the $z$ direction

$v_{z} \quad$ velocity vector in the $z$ direction

$\bar{v}_{z} \quad$ mean velocity averaged through the sediment mass

$\sigma \quad$ bed-normal stress (positive in compression)

$\alpha \quad$ ratio of the velocity averaged through the sediment column to the surface velocity

$p \quad$ pore-fluid pressure

$S \quad$ sidewall friction

W weight of sediment mass 


\section{Introduction}

Water-saturated debris flows are among the most destructive of naturally occurring mass movements. Debris flows can begin with little warning and move rapidly. They can travel great distances down valleys, in some cases, far enough that people living in the vicinity neither understand nor expect danger from such flows. The concrete-like consistency and the large boulders they carry permit debris flows to bury or smash anything in their paths.

Debris flows can have dire consequences in populated areas that they inundate. They ruin crops, destroy buildings, bury animals, and kill unwary humans. In 1985, an eruption of Nevado del Ruiz

in Colombia generated debris flows that traveled up to $100 \mathrm{~km}$ down valleys, inundated more than $50 \mathrm{~km}^{2}$, killed more than 23,000 people, and destroyed the town of Armero. Smaller debris flows are more common and less infamous. A more typical example of debris-flow-induced tragedy occurred in La Conchita, CA, January 2005. Heavy persistent rainfall triggered failure of a slope that had previously slumped in 1995, and mobilized a debris flow, which inundated a neighborhood downslope. The 1995 event destroyed property but spared residents. Unfortunately, during the 2005 debris flow, residents were less fortunate, and ten perished (Figure 1).

Debris flows exhibit complex flow mechanics, include both solid and fluid constituents, and change their physical properties as they flow. The solids in debris flows include sediment that ranges in grain size from clay to boulders. A high solids concentration can provide internal strength sufficient to support very large objects such as boulders, trees, cars, and even houses within the flow. The fluid in debris flows is typically water or muddy water and usually originates as rainfall, rapid melting of snow or ice, accretion from rivers and lakes, or some combination of these. The complex nature of such flows presents a challenge for their quantitative description 
and modeling; therefore, in order to improve understanding of the dynamics of these flows, it is useful to simplify the mechanics of the system geometrically.

Debris flows routinely encounter topography and obstacles, such as channel walls and large objects; these topographic barriers cause sudden acceleration and deceleration of the sedimentwater mixtures that influence liquefaction of the mixture and friction of the mixture at its boundary. Current models used to describe debris flows in motion employ depth-averaged equations of motion which account for acceleration in the downstream direction (horizontal), but typically assume negligible effects from vertical acceleration. In many cases, however, debris flows experience significant vertical acceleration as they move across irregular surfaces.

The purpose of this work is to perform axially symmetric experiments in order to test a recent model for debris flows. Axially symmetry limits variables to the vertical dimension. The model includes the possibly important, commonly overlooked effects of vertical acceleration. Acceleration normal to the bed (assumed here to be vertical) is potentially important because it affects the vertical force exerted by the debris (its apparent weight), which in turn, affects the frictional resisting force as the debris slides across its bed. Vertical acceleration can potentially affect pore-fluid pressure within debris flows. As pore-fluid pressure increases in the sediment mass the contact forces between solid particles decreases. If the pressure changes are abrupt then liquefaction of the sediment mass can occur. Therefore, vertical acceleration may control strength of the mass, liquefaction, and mobility.

Accounting for vertical acceleration in debris-flow motion raises several questions. To what degree does vertical acceleration affect the total force? Can simple one-dimensional theories predict that force? How does vertical acceleration influence basal pore-fluid pressure and therefore the effective basal normal force (or stress)? Does the pore-fluid pressure vary independently of the total force (or stress), such that the effective stress and degree of 
liquefaction change as a consequence of vertical acceleration? These questions provide the impetus for this work, which seeks to specify the effects of vertical acceleration normal to the bed of moving saturated sediment. It is through a series of laboratory experiments designed to evaluate the dynamics of simulated debris flows that these questions are addressed. 


\section{Experimental Process}

Assessment of vertical acceleration normal to the bed of moving saturated sediment is accomplished through a series of laboratory experiments designed to simulate debris flows. An important component of testing the model is the independent measurements of the solid and fluid phases, enabling an examination of the role between bed-normal stress and pore-fluid pressure in saturated sediments.

The experimental apparatus consists of a holding container, a tall cylinder, and eight sensors (Figure 2). The cylinder sits inside and at the center of the container. The base of the cylinder is fitted with a flange and sealed with a gasket. Stabilization framework is fastened to the container, bracing the cylinder to ensure no rotation or lateral movement when the cylinder is vertically displaced (Figure 3). Saturated sediment is added to the cylinder at the start of each experiment. Sensors are housed in the cylinder to record stress and pressure while the cylinder is at rest and during rapid motion. The cylinder is then lifted very quickly to release the slurry into the holding container. Fluid pressure and bed-normal stress are measured as the sediment flows and settles. In particular, the container is a modified 55-gallon drum and the cylinder is manufactured from smooth stainless steel (Appendix A).

Several independent measurements are taken during both the static pre-lift period and the dynamic flow period of the experiments. The container has six pressure transducers, four mounted in the base and two on the sidewall. One of the pressure transducers is located in the center of the container and the remaining transducers radiate in a line from the center out to and up the sidewall (Figure $4 \mathrm{a}, \mathrm{b}$ ). Only the centerline pressure transducer is used in quantitative analysis. A 5-cm-diameter circular plate is in the center of the container and has an "S" style load 
cell mounted below (Figure $4 \mathrm{c}, \mathrm{d}$ ). A visible light laser is suspended above the cylinder with its beam centered on the surface of the sediment column.

Three distinct types of sensors independently record the stress and motion of the sediment column as the experiments progress. The pressure transducers measure the pore-fluid pressure in the saturated sediment (Figure 5) and the load cell measures the vertical force on the plate as the mixture comes in contact with the base of the container. The laser measures the change in height of the sediment column as it falls downward, away from the laser when the cylinder is lifted and the sediment flows freely.

Sediments selected for these experiments cover a broad spectrum of naturally occurring debris flows, as well as commercial soils (Table 1). The varying physical characteristics of these sediments provide the framework for comparisons between sediments that contain fine material and those that do not (Figure 6 and Figure 7). Granular fines-poor sediments include two types: a sand/gravel mixture and a sand/gravel/loam mixture. Fines-rich sediments consist of naturally occurring debris-flow materials collected from field locations (Figure 8, Figure 9, and Figure 10). Many of these samples are essentially identical to those used in earlier research by Iverson and Vallance (2001), Major (1999), and Iverson (1997). The main advantage of the experimental setup described here is the isolation of vertical forces (acceleration) and the separation of fluid pressure from total stress.

The experiments were conducted in a systematic three step process. First, the soil sample was reconstituted with water in a commercial grade mixer, and the sample was mixed until fully liquefied, ensuring hydrostatic pressure within the sediment column. Next, the saturated soil was added to the cylinder to a sufficient height. Lastly, the data acquisition is started and the cylinder lifted to allow the saturated soil column to flow freely into the holding container. 


\section{Theory}

A model developed in this section is a special case of the model given in Iverson [2005] for multiphase debris flows which accounts for the interactions between solid and fluid phases and for acceleration within the flowing sediment mass. The special model developed here assumes that centerline bed-normal stress and pore-fluid pressure are not equal to each other during flow. The theory focuses on the idea that a saturated sediment mass does not behave like a single-phase solid mass where the solids and fluids act in unison. Instead, it describes motion in which solid and fluid phases can act independently of one another and have a significant effect on each other.

The theory given in Iverson [2005] presents three-dimensional equations of motion for debris-flow mixtures, but in the simplified theory presented here axial symmetry about a vertical axis allows simplification to one-dimensional motion, normal to the bed and along the centerline of the experimental apparatus.

The equations presented here cover centerline bed-normal stress of the sediment column. These can also be used to describe centerline pore-fluid pressure by replacing the bulk density with fluid density in each of the equations.

The fundamental equation of motion, stated in the $z$ direction, is

$\rho_{b}\left(\frac{\partial v_{z}}{\partial t}+v_{z} \frac{\partial v_{z}}{\partial z}\right)=-\frac{\partial \tau_{z z}}{\partial z}-\frac{\partial \tau_{r z}}{\partial r}+\rho_{b} g_{z}$ 
where $\rho_{b}$ is the bulk density of the material, $\tau_{z z}$ is the vertical normal stress defined as positive in compression, $\tau_{r z}$ is the shear stress on planes normal to $r, g_{z}$ is the component of gravitational acceleration in the $z$ direction $\left(g_{z}=-g\right.$, where $g$ is the gravitational constant due to the Earth's mass), $v_{z}$ is the vertical velocity (positive upward), $t$ is time, $r$ is the radial direction, and $z$ is the vertical coordinate, defined as positive upward with an origin at the base of the sediment column. Because the sediment column is in motion and its height is changing analysis begins with integration of the equation of motion over the height of the column,

$$
\int_{z=0}^{z=h} \rho_{b}\left(\frac{\partial v_{z}}{\partial t}+v_{z} \frac{\partial v_{z}}{\partial z}\right) d z=\int_{z=0}^{z=h}\left(-\frac{\partial \tau_{z z}}{\partial z}-\frac{\partial \tau_{r z}}{\partial r}+\rho_{b} g_{z}\right) d z
$$

The experimental apparatus will induce horizontal friction between the sidewalls of the cylinder and the sediment mass that is unaccounted for here. Three-dimensional analysis would account for the horizontal forces associated with sidewall friction. Therefore, let the sidewall friction between the cylinder and the sediment mass be represented by a variable defined as $S$,

$$
-\int_{z=0}^{z=h} \frac{\partial \tau_{r z}}{\partial r} d z=S
$$

The value of $S$ is not directly measured in these experiments; however, $S$ will be zero at the beginning of an experiment if the sediment mixture is liquefied, will have some value as the sediment column begins to flow, and will return to zero after the sediment column has evacuated the cylinder.

Consider only the centerline bed-normal stress, then rearrange and put the stress term on the left hand side, 
$\int_{z=0}^{z=h} \frac{\partial \tau_{z z}}{\partial z} d z=\rho_{b} g h-S+\int_{z=0}^{z=h} \rho_{b}\left(\frac{\partial v_{z}}{\partial t}+v_{z} \frac{\partial v_{z}}{\partial z}\right) d z$

Evaluating the stress term at the base of the column where $z=0$ can be written as

$$
\int_{z=0}^{z=h} \frac{\partial \tau_{z z}}{\partial z} d z=\tau_{z z \mid z=0}
$$

At the surface of the sediment column where $z=h$, the normal stress is zero (free open surface), and

$$
\int_{z=0}^{z=h} \frac{\partial \tau_{z z}}{\partial z} d z=\tau_{z z \mid z=h}=0
$$

Since the analysis applies only along the centerline, where shear stresses vanish, the stress term at the base of the column can simply be rewritten as,

$$
\tau_{z z \mid z=0}=\sigma
$$

\section{Equation (3.4) can be rewritten as}

$$
\sigma=\rho_{b} g h-S+\int_{z=0}^{z=h} \rho_{b}\left(\frac{\partial v_{z}}{\partial t}+v_{z} \frac{\partial v_{z}}{\partial z}\right) d z
$$


Equation (3.8) is evaluated in these experiments under two conditions. First, the static condition in which the velocity $\left(v_{z}\right)$ and sidewall friction $(S)$ are zero resulting in the simple static equation,

$$
\sigma=\rho_{b} g h
$$

The second condition is when the sediment column is in motion. This condition requires evaluation of the integral in equation (3.8), which is separated into two parts to aid in evaluation. The first part can be solved using Leibniz' theorem (Savage and Hutter, 1989),

$\rho_{b} \int_{z=0}^{z=h} \frac{\partial v_{z}}{\partial t} d z=\rho_{b}\left[\frac{\partial}{\partial t} \int_{z=0}^{z=h} v_{z} d z-v_{z \mid z=h}\left(\frac{\partial h}{\partial t}\right)\right]$

The second part is simply evaluated and reduces to

$\rho_{b} \int_{z=0}^{z=h} v_{z} \frac{\partial v_{z}}{\partial z} d z=\rho_{b} \int_{z=0}^{z=h} \frac{1}{2} \frac{\partial v_{z}^{2}}{\partial z} d z=\frac{1}{2} \rho_{b} v_{z \mid z=h}^{2}$

If the sediment column were to exhibit constant velocity, with no acceleration $\left(\frac{\partial v_{z}}{\partial t}=0\right)$ and no sidewall friction $(S=0)$, then the centerline bed-normal stress at the base of the sediment column would be defined by the equation,

$\sigma=\rho_{b} g h+\frac{1}{2} \rho_{b} v_{z \mid z=h}^{2}$ 
However, a typical scenario includes acceleration and deceleration $\left(\frac{\partial v_{z}}{\partial t} \neq 0\right)$. In this case, the motion of the sediment column cannot be defined using constant velocity; instead, the velocity variations through the column from $z=0$ to $z=h$ must be accounted for, and the following identifications are advanced to simplify equation (3.10),

$$
\frac{\partial}{\partial t} \int_{z=0}^{z=h} v_{z} d z=\frac{\partial}{\partial t}\left(\bar{v}_{z} h\right)=h \frac{\partial \bar{v}_{z}}{\partial t}+\bar{v}_{z} \frac{\partial h}{\partial t} \quad \text { and } \quad \frac{\partial h}{\partial t}=v_{z \mid z=h}
$$

where $\bar{v}_{z}$ is the mean value of $v_{z}$ through the sediment column from $z=0$ to $z=h$ as the height of the column changes. Combining equations (3.10) and $(3.13 a, b)$ results in

$\rho_{b} \int_{z=0}^{z=h} \frac{\partial v_{z}}{\partial t} d z=\rho_{b} h \frac{\partial \bar{v}_{z}}{\partial t}+\rho_{b} v_{z \mid z=h}\left(\bar{v}_{z}-v_{z \mid z=h}\right)$

In a rapidly moving sediment mass, velocity is not expected to be uniform and steady throughout, and the second part of equation (3.14) accounts for that variation.

At this point, the analysis shows that four factors contribute to centerline bed-normal stress at the base of the sediment column; hydrostatic stress $\left(\rho_{b} g h\right)$ due to the weight of the sediment column, sidewall friction $(S)$ between the sediment mass and the cylinder walls, free-fall acceleration $\left(\rho_{b} v_{z} \frac{\partial \bar{v}_{z}}{\partial t}\right)$ of the sediment mass, and momentum flux $\left(\rho_{b} v_{z \mid z=h}\left(\bar{v}_{z}-\frac{1}{2} v_{z \mid z=h}\right)\right)$. Combining these factors, from equation (3.8) through equation (3.14), into a single equation that describes centerline bed-normal stress for these experiments gives 
$\sigma=\rho_{b} g h-S+\rho_{b} h \frac{\partial \bar{v}_{z}}{\partial t}+\rho_{b} v_{z \mid z=h}\left(\bar{v}_{z}-\frac{1}{2} v_{z \mid z=h}\right)$

The last issue of concern is how to relate the velocity at the upper surface $\left(v_{\left.z\right|_{z=h}}\right)$ to the mean

velocity $\left(\bar{v}_{z}\right)$ averaged through the sediment column. Thus, a new term $\alpha$ is introduced, where

$\alpha=\frac{\bar{v}_{z}}{v_{z \mid z=h}}$.

A value of $\alpha$ other than 1 indicates the surface velocity and the mean velocity averaged through the sediment column differ as the mass moves. Evaluating the effects of $\alpha$ around the value of 1 is an important aspect in this study. If $\alpha=1$, then the surface velocity of the sediment column equals the velocity averaged throughout the column and the mass behaves like a rigid solid. If $\alpha \neq 1$, the sediment column is deforming. A basic assumption is that the solid and fluid constituents behave independently of one another. If $\alpha>1$, the sediment column dilates, and pore-fluid pressure decreases relative to the normal stress. If $\alpha<1$, the sediment column contracts, and pore-fluid pressure increases relative to normal stress. Most likely the sediment mass will both contract and dilate throughout its motion. In this case, an interesting question arises; when does the sediment column contract and when does it dilate, and what affect do these changes have on the flowing sediment mass?

The new variable $\alpha$ is inserted into equation (3.15) and yields

$\sigma=\rho_{b} g h-S+\alpha \rho_{b} h \frac{\partial v_{z \mid z=h}}{\partial t}+\rho_{b} v_{z \mid z=h}^{2}\left(\alpha-\frac{1}{2}\right)$ 
Equation (3.17) is the fundamental equation defining the centerline bed-normal stress of the saturated sediment columns for use in reducing data from one-dimensional experiments. Equation (3.17) predicts values of bed-normal stress, pore-fluid pressure, and effective stress, using specific values for $\alpha$. These values can then be compared with measured values from the experiments.

Effective stress, $\sigma^{\prime}$, is the difference between the bed-normal stress, $\sigma$, and the pore-fluid pressure, $p$,

$\sigma^{\prime}=\sigma-p$

The effective stress is calculated using the measured pore-fluid pressure and measured bednormal stress. Evaluation of the effective stress provides the framework to ascertain whether excess pore-fluid pressure occurs during sediment mass collapse.

In order to employ equations (3.17) and (3.18) the following measurements are made.

1) A visible light laser records the change in sediment column height $(h)$.

2) A load cell records the bed-normal stress in the centerline of the sediment column $(\sigma)$.

3) A centerline differential pressure sensor measures pore-fluid pressure $(p)$,

4) Independent measurements of dried sediment and water prior to mixing allows calculation of the bulk density of the mixture $\left(\rho_{b}\right)$.

5) Sensor sampling rate yields the time-step interval $(\Delta t)$. 


\section{Data Analysis}

Careful analysis of recorded signals is required to distinguish noise and to prepare data for mathematical computations and model comparisons. Experimental data always contain some noise, introduced into the signal by a variety of sources, including, in this case, external electrical noise, internal wiring configurations, vibrations, external light sources, and sensor interference. Noise in a signal can obscure local minima and maxima, distort peak widths, and make calculations using the data difficult, if not impossible to perform reliably.

These experiments make use of three dissimilar types of sensors; a load cell, pressure transducers, and a visible light laser. Each sensor records both a primary signal and a unique array of noise. A "one size fits all" approach to filtering noise is unlikely to succeed. In particular, the laser data involves computation of the second derivative, requiring data to be as clean as possible in order to avoid amplification of the noise by differentiation.

The process of data preparation is broken into five steps, summarized below. A detailed discussion of each step follows the summary list:

1) Determine time intervals for each experiment.

2) Plot data to ascertain the onset of cylinder lift, extracting only the meaningful time sequence.

3) Plot spectra and review: differentiate primary signal from noise.

4) Design filters and apply them to reduce noise.

5) Plot filtered data for analysis.

\section{1) Determine Time Intervals}

The data acquisition system (DAS) writes directly to disk in a proprietary binary format, which is then converted to useable ASCII format through a translation program ${ }^{1}$. The sensors are

\footnotetext{
${ }^{1}$ Streamer, Keithley MetraByte Corporation, 440 Myles Standish Blvd. Tauton, MA 02780, 508.880.3000.
} 
connected to the DAS in parallel and data are written from each sensor during each timing cycle. Sampling frequencies varied among the experiments (Table 2), but were identical within each experiment for the 7 channels of data: laser, load cell, and 5 pressure sensors. The DAS collected data at a set rate, cycling among the various input channels sequentially at that rate. Therefore, to obtain the sample rate for each sensor, the DAS sample rate is divided by the number of channels. For example, an experiment with a sample rate of $2000 \mathrm{~Hz}$ and 7 channels resulted in a sample rate of $\sim 285.7 \mathrm{~Hz}$ for each sensor, corresponding to a time interval of .0035 seconds. Time intervals were also verified qualitatively by reviewing video recordings of the experiments and counting the $1 / 30^{\text {th }}$-of-a-second video frames.

\section{2) Ascertain Cylinder Lift}

The total recorded time for each experiment is greater than the time span of interest (Appendix G). Each experiment contains a small subset within the entire run that represents the lift of the cylinder and release of the sediment column mass. Total experiment times range from 143 to 358 seconds, while extracted time periods of interest (the "lift portions") are 1.6-2.0 seconds. Extracting the lift portion of the data is accomplished by plotting the entire run for each experiment (using Matlab ${ }^{2}$ ) to identify the lift region, which is then extracted and used in all subsequent analysis. The extracted time sequence is reset to zero-time.

\section{3) Identifying Noise}

In noisy data there often appear regular, repeating oscillations around a mean value (Figure 11, during the first 0.5 seconds) and can be easily identified as background noise. Figure 11 is an example from one experiment and depicts the raw data for the load cell. However, during the lift ( 0.5 to 1.5 seconds) it is more difficult to discern noise from the primary signal. This higher amplitude noise is due to small localized perturbations, or turbulence, as the mass flows over the load cell. After the mass has evacuated the cylinder the noise is again identified as background noise.

\footnotetext{
${ }^{2}$ Plotting, signal processing, and some mathematics were performed in Matlab and its associated toolboxes.
} 
Each data set was evaluated in the frequency domain to facilitate further identification of the primary signal and noise. In particular, the Welch method within Matlab is used to obtain power spectral density (PSD) plots, revealing a clear-cut separation between primary signal and noise (Figure 12). In the example shown in Figure 12, the primary signal is evident at very low frequencies with high power, rolling off to noise, in this example, at about $15-20 \mathrm{~Hz}$, when the power is down by $70 \mathrm{~dB}$ from the maximum. The primary source of noise is concentrated around the frequency associated with the U.S. power transmission $(60 / 120 / 180 \mathrm{~Hz})$, but many experiments also contain noise in the $37.15 \mathrm{~Hz}$ range, presumably caused by aliasing of the $3^{\text {rd }}$ harmonic of the power spectrum (Figure 13). The next step is to filter this noise from the primary signal.

\section{4) Filtering Noise}

A clear representation of noise in the primary signal has been established in the frequency domain, making it possible to design filters to eliminate frequencies associated with noise while maintaining the integrity of the primary signal. A filter acts as a signal conditioner and functions by accepting an input signal, blocking specified frequency ranges, and passing the original signal without those blocked ranges to the output signal (Wagner 2002). Here, the filtering was done in the frequency domain. Discrete-time infinite impulse response (IIR) lowpass filters were designed for the pressure sensor and load cell data (Figure 14). Filtering of the laser data presented a unique challenge and is discussed later in this section.

Butterworth filters provide theoretically infinite attenuation in the stopband (higher frequencies in this case), which makes them a good fit for filtering of these data. The Butterworth IIR filter algorithm within Matlab is designed by using a maximally flat (Taylor series) approximation to the desired frequency response from $0 \mathrm{~Hz}$ to $\mathrm{F}_{\mathrm{s}} / 2$, where $\mathrm{F}_{\mathrm{s}}$ is the sampling frequency. The passband frequency range allows signal at those frequencies through the filter and, here, is 
applied as a low-pass filter allowing frequencies up to about $25 \mathrm{~Hz}$ in most cases. Both the amplitude and frequency range of the passband can be specified, the passband ripple (or maximum permissible passband loss) can also be adjusted. The higher frequency stopband, which totally attenuates the frequencies associated with noise can also be specified. In these experiments the stopband typically starts around $25 \mathrm{~Hz}$, but can start anywhere from $6 \mathrm{~Hz}$ to 40 Hz. In order to correct for phase shifts resulting from the type of filter used, a zero phase IIR algorithm is applied.

The final process in filtering the pressure sensor and load cell data is to ensure that the process performed as expected by plotting the filtered signal against the raw data and comparing the fit (Figure 15).

\section{Curve Fitting the Laser Data}

The laser data, representing the changing height of the sediment column, presented a unique challenge in filtering because of persistent low frequency $(\sim 11 \mathrm{~Hz})$ noise, within the range of the primary signal. The low frequency data are recorded as the sediment column sits at rest but as the height of the sediment column changes rapidly high frequency data is recorded. Filtering resulted in loss of important data in the high frequency (steep part of curve) range. Instead of filtering, a curve was fit to the laser data which resulted in a smooth and practical curve on which mathematical computations could be performed. Several curve fit methods were tried and the fits visually inspected in key areas (Figure 16) before settling on the smoothing spline method.

\section{5) Plotting for Comparative Analysis}

The model predictions are compared to data sets graphically. Data are plotted on a pressure (Pa) vs. time (seconds) scale, by converting the sediment column height, $h$ (determined by the laser observations), to pressure ( $\left.\rho_{b} g h\right)$. The fundamental equation (3.17) is then normalized to facilitate the analysis process (Appendix B). 
The normalized fundamental equation (4.1) is broken into four individual terms for programming purposes (represented as T1-T4), each of which is calculated independently prior to evaluating the equation as a whole (Appendix C).

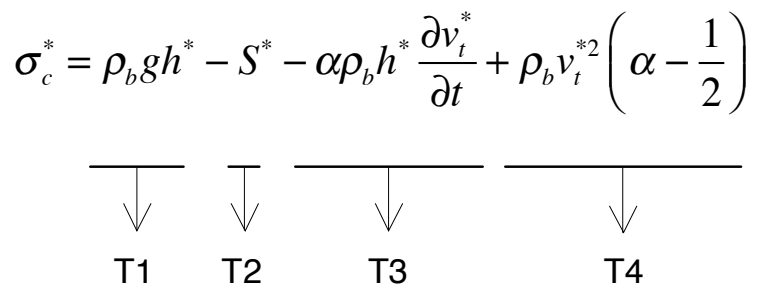

In terms T3 and T4 the numerical derivatives are estimated using Matlab's central difference method (Appendix D). A sample experiment is used here (Figure 17) to describe the process of observing the differences between measured $\left(\sigma_{m}^{*}\right)$ and calculated $\left(\sigma_{c}^{*}\right)$ stress. The measured stress is simply that which was measured by the load cell. The calculated stress is the solution to equation (4.1).

Equation (4.1), the calculated bed-normal stress $\left(\sigma_{c}^{*}\right)$ is solved by determining the values for each individual term. In particular, the laser-determined sediment height and the bulk density of the sediment mixture are used to solve for the first term (T1). The sidewall friction term $S^{*}$ (T2), is calculated from the mean difference between the hydrostatic stress and the measured bednormal stress over the time from the initial lifting of the cylinder to the time the sediment has evacuated the cylinder. Outside of this timeframe $S^{*}$ is set to 0 . The change in height (determined from the laser) is used to calculate the acceleration and velocity components in terms T3 and T4, respectively. The $\alpha$ term in T3 and T4 is a number that is approximately 1 but is not directly measured or calculated. One independent value of $\alpha$ cannot provide a fit throughout the experiment. The values of $\alpha$ that will provide a reasonable fit during acceleration 
and deceleration are determined to be greater than one or less than one by visual inspection of the plots using several test values. The apparent values indicate that the sediment is contracting or dilating at any given moment, specifically during acceleration and deceleration.

Using Figure 17 as an example, a discussion of the comparisons is made in each of the subplots:

(Plot a) Compares the simple hydrostatic stress $\left(\rho_{b} g h^{*}\right)$ predicted from sediment height (using the laser data) to the measured bed-normal stress $\left(\sigma_{m}^{*}\right)$ obtained from the load cell (Figure 17, a).

(Plot b) Compares the calculated bed-normal stress $\left(\sigma_{c}^{*}\right)$ to both the measured bed-normal stress $\left(\sigma_{m}^{*}\right)$ and the simple hydrostatic stress prediction $\left(\rho_{b} g h^{*}\right)$ from plot (a). This plot also shows the values of terms T3 and T4 of the normalized equation with $\alpha$ set equal to 1 and the calculated $S^{*}$ value. Plotting the terms independently allows us to evaluate acceleration and deceleration of the sediment mass (Figure 17, b).

(Plot $\mathrm{c}$ ) This plot shows the calculated bed-normal stress $\left(\sigma_{c}^{*}\right)$ using values of $\alpha$ bracketing 1 (Figure 17, c). The five chosen values for $\alpha$ are shown in the legend, along with the calculated mean square error (MSE) (Appendix E) for each $\alpha$ value. The MSE is calculated from the difference between the measured bed-normal stress and the calculated bed-normal stress.

(Plot d) In this plot the calculated effective stress $\left(\sigma^{\prime}\right)$ is shown along with the measured bednormal stress $\left(\sigma_{m}^{*}\right)$ and measured pore-fluid pressure $\left(p_{m}^{*}\right)$, the effective stress is the difference between the two. Negative effective stress indicates excess pore-fluid pressure (Figure 17, d). 
(Plot e) This last plot is used to show the residuals between the calculated bed-normal stress equation $\left(\sigma_{c}^{*}\right)$ (model) and the measured bed-normal stress $\left(\sigma_{m}^{*}\right)$ with the five values of $\alpha$ (Figure 17, e). As the residual lines approach zero (horizontal) the fit between the two is improving. The small oscillations in the residual lines are due to the small amount of noise still present in the data. The plot also shows the general trend of dilation and contraction as the sediment mass flows. 


\section{Results}

In this series of experiments, measured bed-normal stress and pore-fluid pressure are analyzed independently. The model developed in the Theory is then employed to calculate bed-normal stress which is compared to the measured bed-normal stress from the experiments.

At the base of a saturated sediment column sitting at rest with a free surface, the bed-normal stress is equal to the simple hydrostatic stress $\left(\rho_{b} g h^{*}\right)$, where $h^{*}$ is the normalized initial sediment column height (Appendix B) and $\rho_{b}$ is the bulk density of the sediment mixture (assumed constant). The hydrostatic stress is used to calibrate the initial stress values for each experiment, removing the effect of the long-term drift of the load cell and pressure sensors.

In the fundamental equation (3.17) the term $S^{*}$ accounts for sidewall friction between the saturated sediment mass and the cylinder walls. When the counter weight is applied to the slurry filled cylinder there is an immediate decrease in bed-normal stress which rebounds when the sediment mass has completely evacuated the cylinder. This departure can be attributed to sidewall friction, which produces non-zero $S^{*}$. The mean of the differences between the hydrostatic stress and the measured bed-normal stress from the time the counter weight is applied to the time the sediment has evacuated the cylinder is used to estimate $S^{*}$. The value of $S^{*}$ is set to zero outside of this time frame.

In this discussion, the experiments are presented independently before summarizing and identifying correlations. Each experiment is identified by a characteristic name based on the sediment type, followed by the characteristics of the sediment (water content, percent fines, bulk density, and initial height). For the naturally occurring debris-flow sediments (3), two independent experiments were carried out, for a total of six experiments. For the sand/gravel and 
sand/gravel/loam sediments two experiments were conducted, but only one for each sediment is discussed here; because one experiment for each resulted in sensors problems. The $100 \%$ sand and $100 \%$ gravel experiments are not discussed for the following reasons. The $100 \%$ sand experiment resulted in a rigid plug that stood on its own and did not flow. During the $100 \%$ gravel experiment, significant sediment bridging occurred, and the gravel exited the cylinder in a series of collapses, as the bridges collapsed piecemeal.

In an effort to understand the factors relating to observable behavior, the results presented for each experiment are included in the following discussion and summarized in Table 3. The discussion presents,

- the consistency of the sediment mixture,

- the length of time the sediment sat after preparation, prior to lifting of the cylinder,

- the time required for the sediment to evacuate the cylinder, and the estimated, non-zero $S^{*}$ value during this time,

- the values of $\alpha$ that provide the best apparent fit during acceleration and deceleration and whether the sediment mass is contracting $(\alpha<1)$ or dilating $(\alpha>1)$,

- the time it takes the sediment column to completely collapse and come to rest,

- the characteristics of the pore-fluid pressure and whether excess pore-fluid pressure exists,

- $\quad$ and whether the calculated bed-normal stress $\left(\sigma_{c}^{*}\right)$ (the model) fits the measured bednormal stress $\left(\sigma_{m}^{*}\right)$ better during acceleration or deceleration.

One characteristic is common to all experiments. The bed-normal stress, measured by the central load cell, immediately decreases as the counter weight is applied to the system in preparation for lifting the cylinder (identified on the plots as "cw") and recovers slightly just before 
the cylinder begins to move vertically (identified on the plots as "column collapses"). This change in stress is a result of the apparatus design. The cylinder is tightly held in place while the sediment is added, but is then loosened in preparation for the lift. This release at the base of the cylinder has an obvious effect on the sediment mass and is recorded in the sensors. A portion of this decreased stress is accounted for in the sidewall friction term $S^{*}$.

\section{Part 1: Experiment Details}

\section{Dodson Debris Flow, Columbia River Gorge, Dodson, Oregon, 1997}

Experiment \#1 (Figure 18): water content $43 \%$, fines $28.8 \%$, bulk density $1939 \mathrm{~kg} / \mathrm{m}^{3}$, initial height $.33 \mathrm{~m}$

The sediment mixture consistency is similar to wet cement with a thick, paste-like texture. The mixture sat in the cylinder for 1 hour prior to lifting. The counter weight is applied to the system at 0.40 seconds and the cylinder begins to move upward at 0.50 seconds releasing the sediment mixture (Figure 18, a). The mixture is completely free from the cylinder by 0.55 seconds. During this time $S^{*}$ is calculated to be 0.00813 . As the sediment continues to collapse (but free from the cylinder) $S^{*}$ is set to zero.

The sediment mass begins to accelerate from the time the counter weight is applied at .40 seconds and continues to accelerate to 0.88 seconds (Figure 18, b). From 0.40 to 0.75 seconds the apparent fit for $\alpha$ is greater than 1 (dilating). At 0.75 seconds the apparent fit values for $\alpha$ drop below 1 (contracting) which may be due to momentum flux with the bed. At 0.88 seconds the mass begins to decelerate and for the remaining time the $\alpha$ apparent fit values remain less than 1. Momentum flux with the bed ceases at 1.00 second even though the mass continues to settle for another 0.05 seconds. The sediment has fully collapsed and comes to rest at $\sim 1.10$ seconds, resulting in a total collapse time of 0.60 seconds (Figure 18, b and c). Negative effective stress (excess pore-fluid pressure) exists during acceleration but increases to 0 as the mass begins to decelerate. The effective stress remains 0 or is a minor positive value until 0.95 
seconds. At which time there is a very short duration ( 0.05 seconds) when the effective stress decreases before sharply rising again at 1.00 second (Figure 18, d). The pore-fluid pressure equals the hydrostatic stress for the first 0.20 seconds of the experiment. After which the porefluid pressure mimics but remains greater than the bed-normal stress until deceleration. As the sediment mass slows, the pore-fluid pressure remains elevated over the bed-normal stress.

Overall, apparent fit $\alpha$ values are greater than 1 during acceleration and less than 1 during deceleration (Figure 18, e).

Experiment \#2 (Figure 19): water content 47\%, fines $14.2 \%$, bulk density $1876 \mathrm{~kg} / \mathrm{m}^{3}$, initial height $.43 \mathrm{~m}$

The sediment mixture consistency is very thin and watery. The mixture sat in the cylinder for just a few minutes prior to lifting. The counter weight is applied to the system at 0.35 seconds and the cylinder begins to move upward at 0.70 seconds releasing the sediment mixture (Figure 19, a).

The mixture is completely free from the cylinder by 0.79 seconds. During this time the estimated value of $S^{*}$ is equal to 0.0246 . As the sediment continues to collapse (but free from the cylinder) $S^{*}$ is set to 0 . The significant drop in bed-normal stress and pore-fluid pressure before the cylinder is lifted is the result of watery fluid draining, or leaking, from the base of the cylinder just prior to lifting ( 0.50 seconds to 0.70 seconds).

The sediment mass begins to accelerate as the column starts to collapse at 0.72 seconds and continues to accelerate to 1.07 seconds (Figure 19, b). From 0.72 to 0.90 seconds the apparent fit for $\alpha$ is greater than 1 (dilating) but could approach 1 if leaking had not occurred. At 0.90 seconds the apparent fit value for $\alpha$ equals 1 (neither dilating nor contracting), but the trend is $\alpha$ less than 1 (contracting). At 1.07 seconds the mass begins to decelerate and the apparent fit $\alpha$ values decrease to less than 1 . The remainder of the time the $\alpha$ values are less than 1 . The sediment has fully collapsed at $\sim 1.22$ seconds, resulting in a total collapse time of 0.52 seconds 
(Figure 19, b and c). Negative effective stress (excess pore-fluid pressure) exists momentarily during initial acceleration. The effective stress increases rapidly and remains positive throughout the experiment except near maximum acceleration when the pore-fluid pressure and bed-normal stress are nearly equal (Figure 19, d).

Overall, apparent fit $\alpha$ values are greater than 1 during acceleration and much less than 1 during deceleration (Figure 19, e).

Osceola Mudflow, Mt. Rainier, Washington, circa 5700 B.P. Experiment \#1 (Figure 20): water content 40\%, fines 16.6\%, bulk density $1993 \mathrm{~kg} / \mathrm{m}^{3}$, initial height $.43 \mathrm{~m}$

The sediment mixture consistency is thin but very sticky. The mixture sat in the cylinder for just a few minutes prior to lifting. The counter weight is applied to the system at 0.35 seconds and the cylinder begins to move upward at 0.55 seconds releasing the sediment mixture (Figure 20, a). The mixture is completely free from the cylinder by 0.57 seconds. During this time the estimated value of $S^{*}$ is equal to 0.00285 . As the sediment continues to collapse (but free from the cylinder) $S^{*}$ is set to 0 .

The sediment mass begins to accelerate from the time the counter weight is applied at .355 seconds to 1.07 second (Figure 20, b). From 0.35 to 0.83 seconds the apparent fit for $\alpha$ is 1 (unison). At 0.83 seconds $\alpha$ values drop below 1 (contracting). At 0.90 seconds the mass begins to dilate and at 1.07 seconds the mass begins to decelerate. During deceleration the apparent fit for $\alpha$ is less than 1. Momentum flux with the bed occurs from 0.85 seconds to 1.20 seconds. The sediment has fully collapsed at $\sim 1.20$ seconds, resulting in a total collapse time of 0.65 seconds (Figure 20, b and c). Negative effective stress (excess pore-fluid pressure) exists throughout the experiment. There is a slight decrease in pore-fluid pressure just before maximum deceleration (Figure 20, d). 
Overall, the apparent fit $\alpha$ value is 1 during acceleration and just less than 1 during deceleration (Figure 20, e).

Experiment \#2 (Figure 21): water content 43\%, fines 16.6\%, bulk density $1943 \mathrm{~kg} / \mathrm{m}^{3}$, initial height $.39 \mathrm{~m}$

The sediment used in this experiment was dried from the previous experiment (\#1). The sediment mixture consistency is exceptionally thin and watery. The mixture sat in the cylinder for just a few minutes prior to lifting. The counter weight is applied to the system at 0.35 seconds and the cylinder begins to move upward at 0.41 seconds releasing the sediment mixture (Figure 21 , a). The mixture is completely free from the cylinder by 0.44 seconds. During this time the estimated value of $S^{*}$ is equal to 0.00485 . As the sediment continues to collapse (but free from the cylinder) $S^{*}$ is set to 0 .

The sediment mass begins to accelerate at the time the counter weight is applied at .35 seconds to .64 seconds (Figure 21, b). From 0.35 to 0.60 seconds the apparent fit for $\alpha$ is less than 1 (contracting). At 0.60 seconds the apparent fit values for $\alpha$ exceeds 1 (dilating) but for just 0.04 seconds, this is also the time in which maximum momentum flux with the bed occurs. By 0.64 seconds, the apparent fit $\alpha$ values decrease to less than 1 and remain so for the rest of the experiment. Momentum flux with the bed occurs between 0.47 seconds and 0.77 seconds. The sediment has fully collapsed and comes to rest at $\sim 0.80$ seconds, resulting in a total collapse time of 0.39 seconds (Figure 21, b and c). Negative effective stress (excess pore-fluid pressure) exists from the time counter weight is applied to maximum acceleration ( 0.53 seconds). From 0.53 seconds to 0.71 seconds the effective stress fluctuates but is always positive. The effective stress then drops below zero and remains as the experiment ends (Figure 21, d). The pore-fluid pressure is less responsive to the counter weight and remains elevated until the sediment mass actually starts to collapse. 
Overall, the apparent fit $\alpha$ values are less than 1 during both acceleration and deceleration (Figure 21, e).

North Fork Toutle River Mudflow, Mount St. Helens, Washington, 1980

Experiment \#1 (Figure 22): water content 44\%, fines $14.2 \%$, bulk density $1891 \mathrm{~kg} / \mathrm{m}^{3}$, initial height $.37 \mathrm{~m}$

The sediment mixture consistency is similar to wet cement with a thick, pastey texture. The mixture sat in the cylinder for 12 hours prior to lifting. This extended time may have caused very fine particles to penetrate the mesh screen that protects the pore-fluid pressure sensors resulting in pore-fluid pressure results that are not reliable. The counter weight is applied to the system at .42 seconds and the cylinder begins to move upward at .81 seconds releasing the sediment mixture (Figure 22, a). The delay between the counter weight and the cylinder lifting was due to a slight malfunction in the pulley system. The mixture is completely free from the cylinder by 0.89 seconds. During this time the estimated value of $S^{*}$ is equal to 0.0182 . As the sediment continues to collapse (but free from the cylinder) $S^{*}$ is set to 0 .

The sediment mass does not start to accelerate when the counter weight is applied at 0.42 seconds, instead acceleration starts at 0.75 seconds, 0.06 seconds before the sediment mass starts to collapse (Figure 22, b). From 0.85 to 0.95 seconds the apparent fit for $\alpha$ is less than 1 (contracting). For the remaining time in which the sediment mass is accelerating ( 0.90 seconds to 1.22 seconds) the apparent fit $\alpha$ values are greater than 1 (dilating). From 1.22 seconds to 1.39 seconds the mass decelerates and the apparent fit $\alpha$ value is less than 1 (contracting). Momentum flux with the bed is minimal but occurs between 1.05 seconds and 1.35 seconds. The sediment has fully collapsed and comes to rest at $\sim 1.39$ seconds, resulting in a total collapse time of 0.58 seconds (Figure 22, b and c). Negative effective stress (excess pore-fluid pressure) 
exists throughout the experiment. However, there are large fluctuations in the negative effective stress values. The effective stress values in this experiment are highly suspect (Figure 22, d).

Overall, the apparent fit for $\alpha$ values are greater than 1 during acceleration and less than 1 during deceleration (Figure 22, e).

Experiment \#2 (Figure 23): water content 47\%, fines $14.2 \%$, bulk density $1841 \mathrm{~kg} / \mathrm{m}^{3}$, initial height $.40 \mathrm{~m}$

The sediment used in this experiment was dried and re-used from experiment \#1. The sediment mixture consistency is similar to wet cement with a thick, pastey texture. The mixture sat in the cylinder for 5 minutes prior to lifting. The counter weight is applied to the system at 0.16 seconds and the cylinder begins to move upward at 0.50 seconds releasing the sediment mixture (Figure 23, a). The mixture is completely free from the cylinder by 0.80 seconds. During this time the estimated value of $S^{*}$ is equal to 0.0196 . As the sediment continues to collapse (but free from the cylinder) $S^{*}$ is set to 0 . The sediment mass stood momentarily after the cylinder was lifted before flowing. This can be seen as a gentle slope in the hydrostatic pressure from 0.80 seconds to 0.95 seconds.

The sediment mass begins to accelerate around 0.50 seconds but decelerates and returns to 0 at 0.80 seconds (Figure 23, b). As the sediment mass again accelerates from 0.95 seconds to 1.34 seconds the apparent fit for $\alpha$ is greater than 1 (dilating). At 1.27 seconds the apparent fit values for $\alpha$ drop below 1 (contracting). At 1.34 seconds the mass begins to decelerate and only briefly ( 1.27 seconds to 1.34 seconds) do the apparent fit $\alpha$ values increase beyond 1 , the remainder of the time the $\alpha$ values remain less than 1 . Momentum flux with the bed is minimal but sustained for an extended period of time ( 1.15 to 1.45 seconds). The sediment has fully collapsed and comes to rest at $\sim 1.48$ seconds, resulting in a total collapse time of .98 seconds (Figure 23, b and c). This collapse time is significantly longer than the other experiments and is 
likely the result of the initial conditions in which the sediment mass held the shape of the cylinder before slowly collapsing. Negative effective stress (excess pore-fluid pressure) exists, and is fairly consistent, throughout the experiment. However, at 1.37 seconds the effective stress drops dramatically for 0.08 seconds before sharply rising to nearly 0 . In addition, the pore-fluid pressure nearly mimics the hydrostatic stress from the onset of the experiment to $\sim 1.26$ seconds, which is near maximum acceleration. After 1.26 seconds the pore-fluid pressure deviates significantly from the hydrostatic stress and bed-normal stress (Figure 23, d).

Overall, the apparent fit $\alpha$ values are greater than 1 during acceleration and less than 1 during deceleration (Figure 23, e).

\section{Commercial Sand and Gravel Mix}

Experiment \#1 (Figure 24): water content 29\%, fines 1.5\%, bulk density $2211 \mathrm{~kg} / \mathrm{m}^{3}$, initial height $.58 \mathrm{~m}$

The sediment mixture consistency is thin and watery with standing water on the surface of the column. The sediment-water mixture was difficult to keep mixed. The mixture sat in the cylinder for just a few minutes prior to lifting. The sediment column created a suction effect inside of the cylinder making it difficult to lift. The counter weight is applied to the system at 0.30 seconds and the cylinder begins to move upward at 0.57 seconds releasing the sediment mixture (Figure 24, a). The mixture came out of the cylinder as a plug, with rigid sides and stood on its own for a brief moment. The mixture is completely free from the cylinder by .60 seconds. During this time the estimated value of $S^{*}$ is equal to 0.0109 . As the sediment continues to collapse (but free from the cylinder) $S^{*}$ is set to 0 .

The sediment mass accelerates from the time the column begins to collapse at .6 seconds to 1.00 seconds (Figure 24, b). During acceleration the apparent fit for $\alpha$ is much greater than 1 (dilating). During deceleration $\alpha$ drops below 1 (contracting) and persists as less than 1 for the 
remainder of the experiment. Momentum flux with the bed occurs between 0.75 seconds and 1.20 seconds. The sediment has fully collapsed and comes to rest at $\sim 1.20$ seconds, resulting in a total collapse time of 0.63 seconds (Figure 24, b and c). Negative effective stress (excess pore-fluid pressure) is recorded shortly after the counter weight is applied to the system but increases and is positive for the moment before ( 0.59 seconds) the column collapses. The effective stress is negative throughout the rest of the experiment but does fluctuate a significant amount as the sediment mass transitions from acceleration to deceleration (Figure 24, d).

Overall, the apparent fit $\alpha$ values are greater than 1 during acceleration and much less than 1 during deceleration (Figure 24, e).

\section{Commercial Sand, Gravel, and Loam Mix}

Experiment \#1 (Figure 25): water content 39\%, fines $7.4 \%$, bulk density $2000 \mathrm{~kg} / \mathrm{m}^{3}$, initial height $.31 \mathrm{~m}$

The sediment mixture consistency is watery and thin. The mixture sat in the cylinder for just a few minutes prior to lifting. The counter weight is applied to the system at 0.46 seconds and the cylinder begins to move upward at 0.59 seconds releasing the sediment mixture (Figure 25, a). The mixture is completely free from the cylinder by 0.62 seconds. During this time the estimated value of $S^{*}$ is equal to 0.0117 . As the sediment continues to collapse (but free from the cylinder) $S^{*}$ is set to 0 .

The sediment mass accelerates from the time the counter weight is applied at 0.46 seconds to 0.79 seconds (Figure 25, b). In this experiment the value of $\alpha$ is never greater than 1 . From 0.46 to 0.60 seconds the apparent fit for $\alpha$ is much less than 1 (contracting). From 0.60 to 0.79 $\alpha$ is less than 1 but a slightly higher value. During deceleration $\alpha$ remains less than 1 but is increasing. Momentum flux with the bed occurs between 0.60 and 0.95 seconds. The sediment has fully collapsed and comes to rest at $\sim 0.95$ seconds, resulting in a total collapse time of 0.36 
seconds (Figure 25, b and c). Negative effective stress (excess pore-fluid pressure) exists from the time the counter weight is applied to the system to the time the column starts to collapse. After this time the effective stress is positive to 0.85 seconds which correlates to maximum deceleration during acceleration but increases to 0 as the mass beings to decelerate. The effective stress is then negative again and remains negative for the rest of the experiment (Figure $25, d)$.

Overall, the apparent fit for $\alpha$ values are less than 1 for both acceleration and deceleration (Figure 25, e).

\section{Part 2: Results Summary}

In all experiments, the measured bed-normal stress deviates significantly from the simple hydrostatic stress when the sediment mass is in motion. The measured bed-normal stress is always less than the simple hydrostatic stress during acceleration and is greater during deceleration (with the minor exception of the sand-gravel experiment during the time that the counterweight was in place, prior to lifting).

The measured pore-fluid pressure is also less than the simple hydrostatic stress during acceleration and greater during deceleration (except in the Toutle experiment \#1, likely a sensor problem). As the structure collapses, the solids become more tightly packed increasing the pressure in the pore space. Therefore, when the sediment mass is contracting the pore-fluid pressure should increase. Instead, the results show that while the sediment mass is decelerating and contracting the pore-fluid pressure in some experiments is less than the bed-normal stress and in others it is greater than bed-normal stress. However, in the case where pore-fluid pressure is greater than bed-normal stress, the pore-fluid pressure never drops below the bed- 
normal stress throughout the experiment. Nevertheless, the pore-fluid pressure always exceeds bed-normal stress shortly after maximum deceleration is achieved.

In the naturally occurring debris-flow sediments the value of $S^{*}$ increased as the water content increased and the mixture density decreased, with the exception of the Dodson \#2 experiment. The mixture density of this experiment is $1876 \mathrm{~kg} / \mathrm{m}^{3}$ and a value of .0246 for $S^{*}$. The Toutle \#2 experiment, which follows the Dodson experiment in terms of $S^{*}$ value (.0196) has a density of $1841 \mathrm{~kg} / \mathrm{m}^{3}$, a difference of $35 \mathrm{~kg} / \mathrm{m}^{3}$. There does not appear to be any correlation between the percent fines in the sediment and the calculated value of $S^{*}$. 


\section{Conclusions}

The multi-phase model for debris flows presented in this study accounts for the interactions between the solid and fluid phases and for vertical acceleration within the flowing sediment mass. Comparing this model to experimental data required accurate measurements of both the bednormal stress and the pore-fluid pressure within the saturated sediment mass while in rapid motion. These two stresses were successfully measured independent of one another and resulted in individual time-dependent histories for the solid and fluid phases. These independent measurements allow for reasonable interpretation of the effective stress during the sediment column collapse (plot d, Figure 17 through Figure 25).

The bed-normal stress in the saturated sediment-column experiments is not accurately predicted by the simple hydrostatic stress, $\rho_{b} g h$, but instead is best described by the equation (3.17) that includes vertical acceleration and momentum flux with the bed. Using steady-state equations to infer motion of the moving sediment mass is not sufficient to define accurately the independent nature of the solid and fluid constituents in these column experiments. Accounting for the reaction forces exerted by the bed in response to bed-normal acceleration allows the model to more accurately predict the sediment mass dynamics. In real debris flows or large scale debrisflow experiments this inclusion could result in better prediction of downslope thinning (Delinger and Iverson, 2001). In conclusion, the model accurately predicts the bed-normal stress of a saturated sediment mass in motion and illustrates the importance of vertical acceleration and momentum flux (plot b, Figure 17 through Figure 25).

Solids in contact with the bed and one another transfer momentum and dissipate energy by bed friction (Pitman and Le, 2005; Iverson, 2001). The experimental results conclude that this momentum transfer produces much of the heightened stress during rapid motion. This increased 
force could result in increased friction at the bed. The nearly flat pore-fluid pressure recordings during momentum exchange signify that the majority of the force is exerted by the solids, and suggests that in real debris flows this could facilitate scouring of the bed.

Experiments with extended collapse times (i.e., the sediment mass takes more time to evacuate the cylinder) result in persistent excess pore-fluid pressure (Table 3). The fluid pressure facilitates solid-fluid interactions and the effective stress defines friction between the solids via contact points. Liquefaction (decreased pore-fluid pressure) occurs when the contact stress between the solids decreases. Extended collapse times should allow pore-fluid pressure to equalize rather than increase. This inconsistency may result from using a miniature flow which can show signs of viscous effects but little pore-fluid pressure effects, exactly the opposite of what is expected. Denlinger and Iverson [2001] showed that as sediment-water mixture experiments decrease in size the tendency for persistent high pore-fluid pressure increases, causing the fluid pressure to reduce the intergranular stresses and transfer stresses to the fluid. Fluid draining from the cylinder, more readily than the solids leaving the cylinder, could also cause excess pore-fluid pressure.

Bridging and sidewall friction resist evacuation of the sediment from the cylinder. These effects are evident in the experiments during which time $S^{*}$ is calculated and show up as a decrease in bed-normal stress while the sediment is evacuating. The value of $S^{*}$, which partially accounts for this sidewall friction and bridging, has no direct correlation to the physical attributes of the sediment or lift and collapse times (Table 3).

In all of the experiments bed-normal stress is less than the simple hydrostatic stress during acceleration and greater than the simple hydrostatic stress during deceleration. Momentum exchange with the bed creates excess stress during acceleration and that stress dissipates during deceleration (plot b, Figure 17 through Figure 25) (Major and Iverson 1999). Excess 
stress could be the result of some complex physical phenomenon whereby the vertical acceleration effectively changes the weight of the sediment mass (Iverson, 1997).

The variable $\alpha$, which relates the depth-averaged velocity to the surface velocity plays an important role. The values of $\alpha$ characterize the sediment mass during rapid motion. In the theory section the question was raised "when does the sediment column contract and when does it dilate, and what affect do these changes have on the flowing sediment column?" It is observed that during acceleration of the sediment mass, the apparent fit value of $\alpha$ can be greater than 1 , equal to 1 , and less than 1 and is not consistent from one experiment to another. However, during deceleration the apparent fit value of $\alpha$ is consistent and is always less than 1 . Data from these experiments suggest that the sediment mass both dilates and contracts during acceleration of the mass, but only contracts during deceleration. Contraction of the sediment column during deceleration implies that as the mass slows the solids move through the fluid and increasingly come in contact with one another, increasing grain-contact friction and bed-normal stress (Iverson and Vallance, 2001). In naturally occuring debris flows, increase in bed-normal stress increases friction along the bed and may cause deposition. Similarly, additional grain contact may add resistance to flow. Major and Iverson [1999], in their study of large-scale debris-flow experiments, concluded that debris flows cease movement because of grain-to-grain contacts along the perimeter of the flow. Results presented in this study support the theory that debrisflow deposition can occur locally owing to increases of grain-contact friction and bed friction. 


\section{References}

1. Cannon, S.H. and Ellen, S.D., 1985, Rainfall conditions for abundant debris avalanches, San Francisco Bay region, California: CALIFORNIA GEOLOGY, Vol. 38, No. 12, pp. 267-272.

2. Coussot, P. and Meunier, M., "Recognition, Classification, and Mechanical Description of Debris Flows", Earth-Science Reviews, Vol. 40, 1996, pp. 209-227.

3. Denlinger, R.P. and Iverson, R.M., "Flow of Variably Fluidized Granular Masses Across Three-Dimensional Terrain 2. Numerical Predictions and Experimental Tests", The Journal of Geophysical Research, Vol. 106, No. B1, 2001, pp. 553-566.

4. Frequency Devices, Inc., http://www.freqdev.com/guide/fullguide.html., 2003.

5. Hollingsworth, R. and Kovacs, G.S., 1981, Soil slips and debris flows, prediction and protection: Bulletin of the Association of Engineering Geologists, Vol. 18, No. 1, pp. 17-28.

6. Huntley, J. M., "Fluidization, Segregation and Stress Propagation in Granular Materials", Phil. Trans. R. Soc. Lond. A, Vol. 356, 1998, pp. 2569-2590.

7. Iverson, R.M. and Vallance, J.W., "New Views of Granular Mass Flows", Geology, Vol. 29, No. 2, 2001, pp. 115-118.

8. Iverson, R.M., Reid, M.E., et al, "Acute Sensitivity of Landslide Rates to Initial Soil Porosity", Science, Vol. 290, 2000, pp. 513-516.

9. Iverson, R.M., "Landslide Triggering by Rain Infiltration", Water Resources Research, Vol. 36, No. 7, 2000, pp. 1897-1910.

10. Iverson, R. M., "The Physics of Debris Flows", Reviews of Geophysics, Vol. 35, No. 3, August 1997, pp. 245-296.

11. Iverson, R.M., Debris-flow mechanics: in Jakob, M. and Hungr, O. (eds.), Debris-flow Hazards and Related Phenomena, Praxis Publishing Ltd., Chichester, UK, 2005, p. 105-158.

12. Iverson, R. M., "Hydraulic Modeling of Unsteady Debris-Flow Surges with Solid-Fluid Interactions, in Debris-Flow Hazards Mitigation: Mechanics, Prediction, and Assessment", C.L. Chen, ed., American Society of Civil Engineers, 1997, pp. 550-560.

13. Iverson, R. M., "A Constitutive Equation for Mass-Movement Behavior", Journal of Geology, Vol. 93, 1985, pp. 143-160.

14. Iverson, R. M., Reid, M.E., LaHusen, R. G., "Debris-Flow Mobilization from Landslides", Annual Review of the Earth Planetary Sciences, Vol. 25, 1997, pp. 85-138.

15. Kaczmarek, M and Hueckel, T., "Use of Porosity in Models of Consolidation", Journal of Engineering Mechanics, Vol. 124, February 1998, pp. 237-239.

16. Makino, K. and Kuramitsu, K., "Measurement of the Bulk Density Structure of Granular Materials in a Powder Vessel", Micromechanics of Granular Materials, Proceedings from the US/Japan Seminar, October 26-30, 1987, pp. 55-61.

17. Major, J.J., Iverson, R.M., et al., "Geotechnical Properties of Debris-Flow Sediments and Slurries, in Debris-Flow Hazards Mitigation: Mechanics, Prediction, and Assessment", C.L. Chen, ed., American Society of Civil Engineers, 1997, pp. 249-259.

18. Major, J. J., "Depositional Processes in Large-Scale Debris-Flow Experiments", The Journal of Geology, Vol. 105, 1997, pp. 345-366.

19. Major, J.J. and Iverson, R.M., "Debris-flow Deposition: Effects of Pore-fluid Pressure and Friction Concentrated at Flow Margins", GSA Bulletin, Vol. 111, No. 10, 1999, pp. 1424-1434. 
20. Oron, G. and Herrmann, H.J., "Exact Calculation of Force Networks in Granular Piles", Physical Review, Vol. 58, No. 2, 1998, pp. 2079-2089.

21. Pitman E. Bruce and Le, Long, "A Two-Fluid Model for Avalanche and Debris Flows", Philosophical Transactions of The Royal Society A, Vol. 363, 2005, pp. 1573-1601.

22. Pudasaini S. P., Wang Y., and Hutter K., "Modeling Debris Flows Down General Channels", Natural Hazards and Earth System Sciences, Vol. 5, 2005, pp. 799-819.

23. Radke, R. and Kulkarni, S., "An Integrated Matlab Suite for Introductory DSP Education", SPE Workshop, Department of Electrical Engineering, Princeton University.

24. Savage S.B. and Hutter K., "The Motion of a Finite Mass of Granular Material Down a Rough Incline", Journal of Fluid Mechanics, Vol. 199, 1989, pp. 177-215.

25. Savitzky A, Golay M J E. Smoothing and Differentiation of Data by Simplified Least Squares Procedures. Analytical Chemistry, Vol. 36, 1964, pp. 1627-1639.

26. Thong, Tran and McNames, James, "Nonlinear Reconstruction of Over-Sampled Coarsely Quantized Signals", http://www.bme.ogi.edu/ trant/2002mcas2.pdf.

27. Vallance, J. W., "The Osceola Mudflow from Mount Rainier: Sedimentology and Hazard Implications of a Huge Clay-Rich Debris-Flow", GSA Bulletin, Vol. 109, 1997.

28. Wakelin, S.L., "Variational Principles and the Finite Element Method for Channel Flows", PhD Thesis, University of Reading, UK, Department of Mathematics, Oct. 1993.

29. Wagner, B. and Barr, M., "Introduction to Digital Filters", Embedded Systems Glossary, http://www.netrino.com/Publications/Glossary/Filters.html. 


\section{Tables}

Table 1: Sediment summary of the grain size analysis and variable definitions.

\begin{tabular}{|c|c|c|c|c|c|c|c|c|}
\hline Type and Location & $\mathrm{G} / \mathrm{S} / \mathrm{S} / \mathrm{C}(\%)$ & $\delta(\mathrm{m})$ & Texture & $h_{i}(m)$ & $\rho_{s}\left(\mathbf{k g} / \mathrm{m}^{3}\right)$ & $\rho_{\mathrm{f}}\left(\mathbf{k g} / \mathrm{m}^{3}\right)$ & $\rho_{b}\left(\mathbf{k g} / \mathbf{m}^{3}\right)$ & wc(\%) \\
\hline \multirow{2}{*}{$\begin{array}{l}\text { Dodson Debris Flow } \\
\text { Columbia River Gorge, } \\
\text { Dodson, Oregon, } 1998\end{array}$} & \multirow{2}{*}{$\begin{array}{c}8.5 / 62.7 / 24.1 / 4.7 \\
36.5 / 49.3 / 12.0 / 2.2 \\
18.8 / 61.6 / 16.5 / 3.1\end{array}$} & \multirow{2}{*}{$\begin{array}{l}.00085 \\
.002 \\
.002\end{array}$} & Thin, watery & .43 & 2650 & 1000 & 1876 & 47 \\
\hline & & & Thick, pastey & .33 & 2650 & 1000 & 1939 & 43 \\
\hline \multirow{2}{*}{$\begin{array}{l}\text { Osceola Mudflow } \\
\text { Mt. Rainier, WA, } \\
\text { circa } 5700 \text { B.P. }\end{array}$} & \multirow[b]{2}{*}{ 17.7/65.7/13.9/2.7 } & \multirow[b]{2}{*}{.000425} & Thin, watery & .39 & 2650 & 1000 & 1943 & 43 \\
\hline & & & Thin, but sticky & .43 & 2650 & 1000 & 1993 & 40 \\
\hline \multirow{2}{*}{$\begin{array}{c}\text { North Fork Toutle River } \\
\text { Lahar } \\
\begin{array}{c}\text { Mount St. Helens, WA } \\
\text { Kidd Valley, } 1980\end{array}\end{array}$} & \multirow[b]{2}{*}{$12.5 / 73.3 / 14.2^{+}$} & \multirow[b]{2}{*}{.000425} & Thick, pastey & .40 & 2600 & 1000 & 1841 & 47 \\
\hline & & & Thick, pastey & .37 & 2600 & 1000 & 1891 & 44 \\
\hline $\begin{array}{c}\text { Sand/Gravel/Loam } \\
\text { H.J. Andrews Debris-Flow } \\
\text { Flume, USGS }\end{array}$ & $30.7 / 61.9 / 7.4^{+}$ & .000425 & Thin, watery & .31 & 2650 & 1000 & 2000 & 39 \\
\hline$\underset{\text { Engineered Soil }}{\text { Sand/Gravel }}$ & $\begin{array}{l}62.3 / 36.0 / 1.7 / 0.0 \\
71.8 / 27.0 / 1.2 / 0.0\end{array}$ & $\begin{array}{l}.0127 \\
.0127\end{array}$ & Thin, watery & .58 & 2700 & 1000 & 2211 & 29 \\
\hline $\begin{array}{l}\text { H.J. Andrews Debris-Flow } \\
\text { Flume, USGS }\end{array}$ & $\begin{array}{l}37.7 / 60.3 / 2.0 / 0.0 \\
40.5 / 56.1 / 3.4 / 0.0\end{array}$ & $\begin{array}{l}.000425 \\
.000425\end{array}$ & Thin, watery & .38 & 2700 & 1000 & 2012 & 40 \\
\hline$\frac{\text { Uniform Sand }}{\text { Engineered }}$ & \multirow[b]{2}{*}{$0.0 / 99.7 / .3 / 0.0$} & \multirow[b]{2}{*}{.000250} & Dry* & .66 & 2700 & 1 & 1224 & 0 \\
\hline Local retail purchase & & & Saturated* & .50 & 2700 & 1000 & 1313 & 80 \\
\hline \multirow{2}{*}{$\begin{array}{l}\text { Sandy Gravel } \\
\text { Local retail purchase }\end{array}$} & \multirow[b]{2}{*}{$41.7 / 58.3 / 0.0 / 0.0$} & \multirow[b]{2}{*}{.002} & Dry* & .39 & 2700 & 1 & 1688 & 0 \\
\hline & & & Saturated ${ }^{*}$ & .44 & 2700 & 1000 & 2198 & 25 \\
\hline 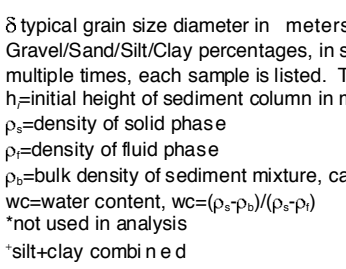 & $\begin{array}{l}\text { with } \leq 14 \% \text { silt + clay, hydr } \\
\text { TM Soil Classification was } ~\end{array}$ & $\begin{array}{l}\text { tests were } n \\
\text { define grain } \\
\text { ghts }\end{array}$ & $\begin{array}{l}\text { med and the last ve } \\
\text { avel }>.00475 \mathrm{~m}, \mathrm{~S}\end{array}$ & $\begin{array}{l}\text { reser } \\
775-.\end{array}$ & $\begin{array}{l}\text { It and clay c } \\
\text { Silt .000075 }\end{array}$ & $\begin{array}{l}\text { d. Dodson } \\
\text { 025m, and }\end{array}$ & $\begin{array}{l}\text { nd/gravel expe } \\
0000025 \mathrm{~m})\end{array}$ & were \\
\hline
\end{tabular}


Table 2: Summary of sampling frequencies for experiments.

\begin{tabular}{|c|c|c|c|c|c|}
\hline Sediment Type and Location & Experiment & Number of Samples & Sampling Rate $(\mathrm{Hz})$ & Time of Experiment (s) & Time Interval (s) \\
\hline $\begin{array}{c}\text { Dodson Debris Flow } \\
\text { Columbia River Gorge, Dodson, }\end{array}$ & $\# 1$ & 7168000 & 2000 & 358.4 & .0035 \\
\hline Oregon, 1998 & \#2 & 7168000 & 2000 & 358.4 & .0035 \\
\hline$\frac{\text { Osceola Mudflow }}{\text { Mt. Rainier, WA }}$ & $\# 1$ & 7168000 & 2000 & 358.4 & .0035 \\
\hline circa 5700 B.P. & $\# 2$ & 7168000 & 2000 & 358.4 & .0035 \\
\hline $\begin{array}{c}\text { North Fork Toutle River Lahar } \\
\text { Mount St. Helens, WA }\end{array}$ & \#2 & 7168000 & 2000 & 358.4 & .0035 \\
\hline Kidd Valley, 1980 & $\# 1$ & 7168000 & 5000 & 143.4 & .0014 \\
\hline $\begin{array}{c}\text { Sand/Gravel/Loam } \\
\text { H.J. Andrews Debris-Flow } \\
\text { Flume, USGS }\end{array}$ & $\# 1$ & 7168000 & 2000 & 358.4 & .0035 \\
\hline $\begin{array}{c}\text { Sand/Gravel } \\
\text { Engineered Soil } \\
\text { H.J. Andrews Debris-Flow }\end{array}$ & $\# 1$ & 256000 & 1000 & 256 & .007 \\
\hline $\begin{array}{l}\text { H.J. Andrews Deris-Flow } \\
\text { Flume, USGS }\end{array}$ & $\# 2^{*}$ & 7168000 & 2000 & 358.4 & .0035 \\
\hline$\frac{\text { Uniform Sand }}{\text { Engineered }}$ & $\# 1^{*}$ & 7168000 & 2000 & 358.4 & .0035 \\
\hline Local retail purchase & $\# 2^{*}$ & 256000 & 500 & 512 & .014 \\
\hline Sandy Gravel & $\# 1^{*}$ & 256000 & 500 & 512 & .014 \\
\hline Local retail purchase & $\# 2^{\star}$ & 256000 & 500 & 512 & .014 \\
\hline
\end{tabular}


Table 3: Summary of experimental results

\begin{tabular}{|c|c|c|c|c|c|c|c|c|c|c|c|c|c|c|c|}
\hline Experiment & $h(m)$ & wc(\%) & $\rho_{b}\left(\frac{k g}{m^{3}}\right)$ & Texture & $S^{*}$ & $\begin{array}{l}\text { Before } \\
\text { Lift } \\
\text { (sec) }\end{array}$ & $\begin{array}{l}\text { Lift } \\
\text { Time } \\
\text { (sec) }\end{array}$ & $\begin{array}{l}\text { Total } \\
\text { Collapse } \sigma^{\prime} \\
(\sec )\end{array}$ & $\begin{array}{l}(+ \text { or } \\
(\text { acc })\end{array}$ & $\begin{array}{c}-\sigma^{\prime}(+ \text { or } \\
\quad(\mathrm{dec})\end{array}$ & $\begin{array}{c}p \\
(\operatorname{acc})\end{array}$ & $\begin{array}{c}p \\
(\mathrm{mom})\end{array}$ & $\begin{array}{c}p \\
(\mathrm{dec})\end{array}$ & $\begin{array}{c}\alpha \\
(\mathrm{acc})\end{array}$ & $\begin{array}{c}\alpha \\
(\mathrm{dec})\end{array}$ \\
\hline Dodson \#1 & 0.33 & 43 & 1939 & $\begin{array}{l}\text { thick, } \\
\text { pastey }\end{array}$ & 0.00813 & 3600 & 0.05 & 0.60 & $+\&-$ & $+\&-$ & $p>\sigma$ & $p<\sigma$ & $p>\sigma$ & $>1$ & $<1$ \\
\hline Dodson \#2 & 0.43 & 47 & 1876 & $\begin{array}{l}\text { watery } \\
\text { thin, }\end{array}$ & 0.0246 & 300 & 0.09 & 0.52 & $+\&-$ & + & $p>\sigma \& p<\sigma$ & $p<\sigma$ & $p>\sigma$ & $>1$ & $<1$ \\
\hline Osceola \#1 & 0.43 & 40 & 1993 & $\begin{array}{l}\text { sticky } \\
\text { thin, }\end{array}$ & 0.00285 & 300 & 0.025 & 0.65 & - & - & $p>\sigma$ & $p>\sigma$ & $p>\sigma$ & $=1$ & $<1$ \\
\hline Osceola \#2 & 0.39 & 43 & 1943 & $\begin{array}{l}\text { watery } \\
\text { thick. }\end{array}$ & 0.00485 & 300 & 0.03 & 0.39 & $+\&$ & $+\&$ & $p>\sigma$ & $p<\sigma$ & $p>\sigma$ & $<1$ & $<1$ \\
\hline Toutle \#1 & 0.37 & 44 & 1891 & $\begin{array}{l}\text { pastey } \\
\text { thick. }\end{array}$ & 0.0182 & 43200 & 0.08 & 0.58 & NA & NA & NA & NA & NA & $>1$ & $<1$ \\
\hline Toutle \#2 & 0.40 & 47 & 1841 & $\begin{array}{l}\text { pastey } \\
\text { thin, }\end{array}$ & 0.0196 & 300 & 0.30 & 0.98 & - & - & $p>\sigma$ & $p>\sigma$ & $p>\sigma$ & $>1$ & $<1$ \\
\hline Sand/Gravel & 0.58 & 29 & 2211 & $\begin{array}{l}\text { watery } \\
\text { thin, }\end{array}$ & 0.0109 & 300 & 0.03 & 0.63 & - & - & $p>\sigma \& p<\sigma$ & $p \gg \sigma$ & $p \gg \sigma$ & $>1$ & $<1$ \\
\hline Sand/Gravel/Loam & 0.31 & 39 & 2000 & watery & 0.0117 & 300 & 0.03 & 0.36 & $+\&-$ & $+\&-$ & $p>\sigma \& p<\sigma$ & $p \ll \sigma$ & $p>\sigma$ & $<1$ & $<1$ \\
\hline \multicolumn{16}{|c|}{$\begin{array}{l}h, \text { initial height of sediment column in the cylinder } \\
\text { wc, water content of the sediment mixture } \\
\rho_{b}, \text { bulk density of the sediment mixture }\end{array}$} \\
\hline \multicolumn{16}{|c|}{$\begin{array}{l}S^{*}, \text { normalized sidewall friction calculation, this is an estimated value } \\
\text { Before Lift, the amount of time the sediment mass sat in the cylinder before lifting } \\
\text { Lift Time, is the amount of time it takes the sediment column to completely evacuate the cylinder } \\
\text { Total Collapse, is the amount of time it takes the sediment column to completely collapse }\end{array}$} \\
\hline \multicolumn{16}{|c|}{$\begin{array}{l}\sigma^{\prime}, \text { effective stress positive or negative during acceleration (acc) and deceleration (dec) } \\
\sigma \text {, bed-normal str es s }\end{array}$} \\
\hline \multicolumn{16}{|c|}{$\begin{array}{l}\sigma \text {, ped-normal stre } \mathrm{s} \text {, } \\
p \text {, pore-fluid pressure as it relates to bed-normal stress during acceleration, momentum exchange (mom), and deceleration }\end{array}$} \\
\hline & & 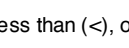 & & & & & & & & & & & & & \\
\hline
\end{tabular}




\section{Figures}
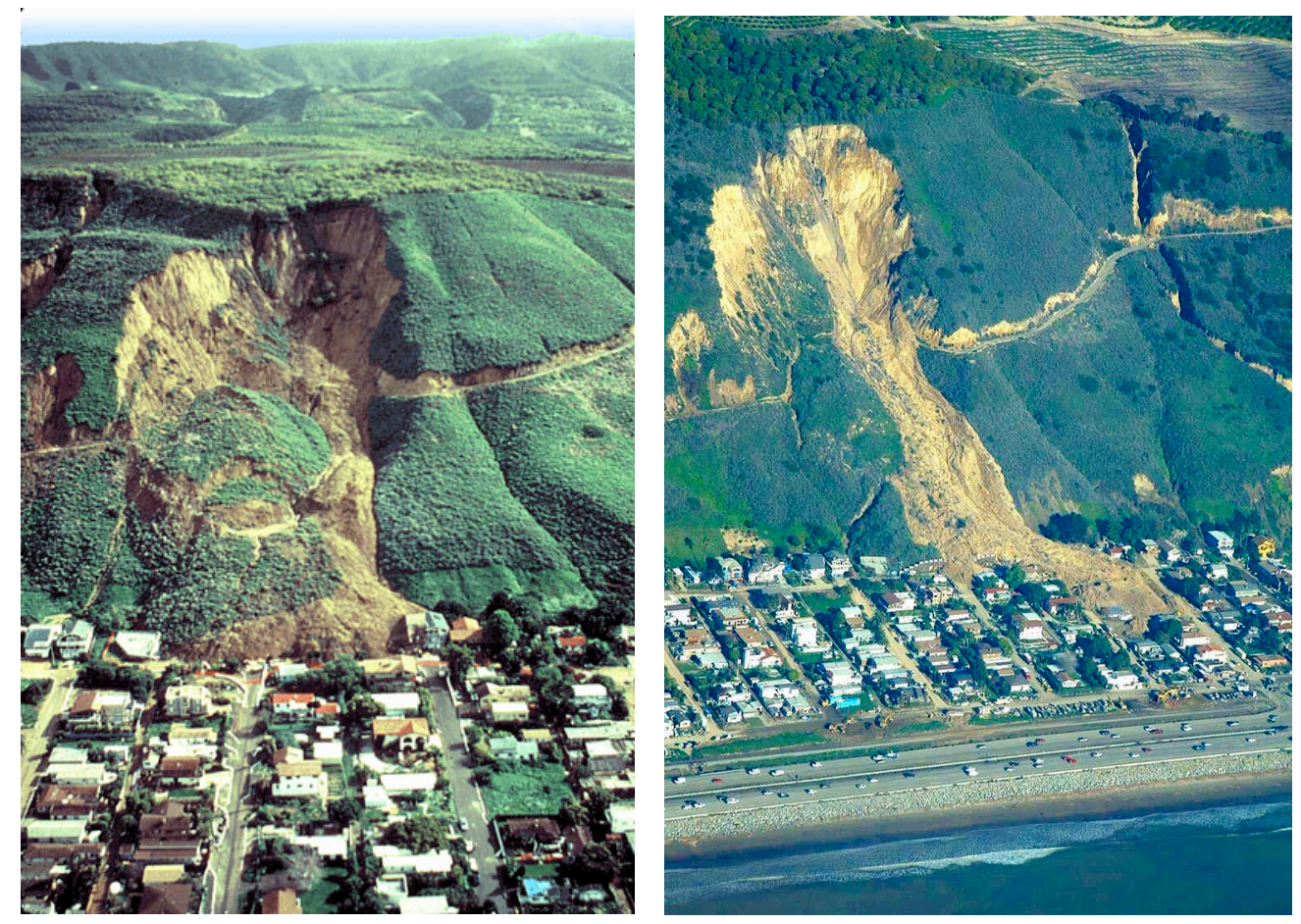

Figure 1: LaConchita, CA. The left image shows the 1995 slump in the hillside behind the coastal community of LaConchita. No injuries were recorded in this event but there was substantial property loss. The image to the right shows the 2005 debris flow that mobilized from the 1995 slump after 72 consecutive hours of rainfall. In this event, 10 people lost their lives. Photos courtesy of Bruce Perry, California State University Long Beach, Department of Geological Sciences. 


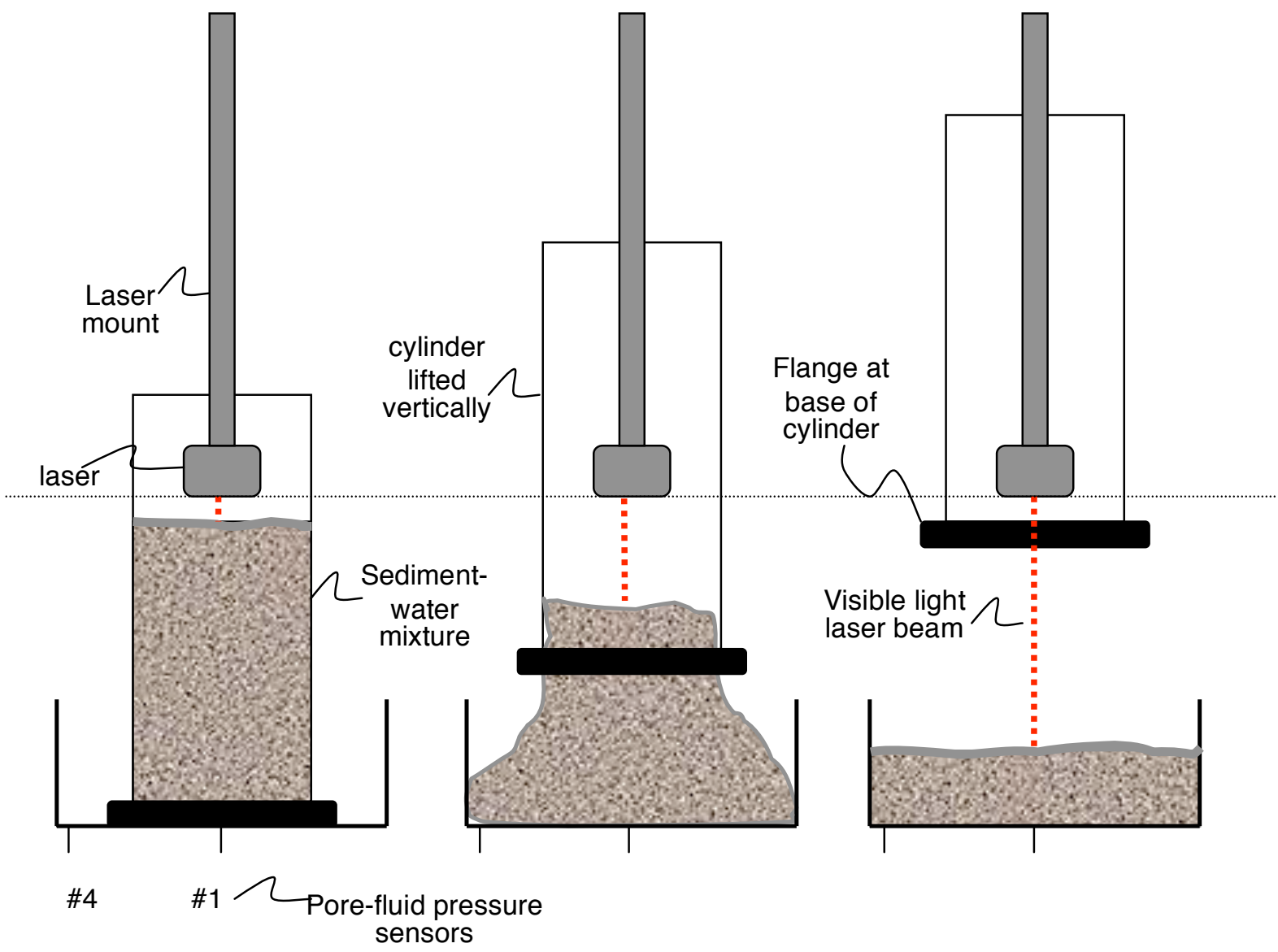

Figure 2: Drawing showing cylinder being lifted to allow sediment slurry to flow. Sediment column starts at rest confined in the cylinder, then is rapidly released where it again comes to rest. The visible light laser records mass flow rate during the lift. Pressure transducers used in the experiments are shown at the base of the container and labeled \#1 and \#4. The load cell is centered with pressure sensor \#1 and records the bed-normal stress. Pressure sensor \#4 records the arrival of the sediment at the sidewall of the container. Pressure sensor \#1 records the centerline pore-fluid pressure. 


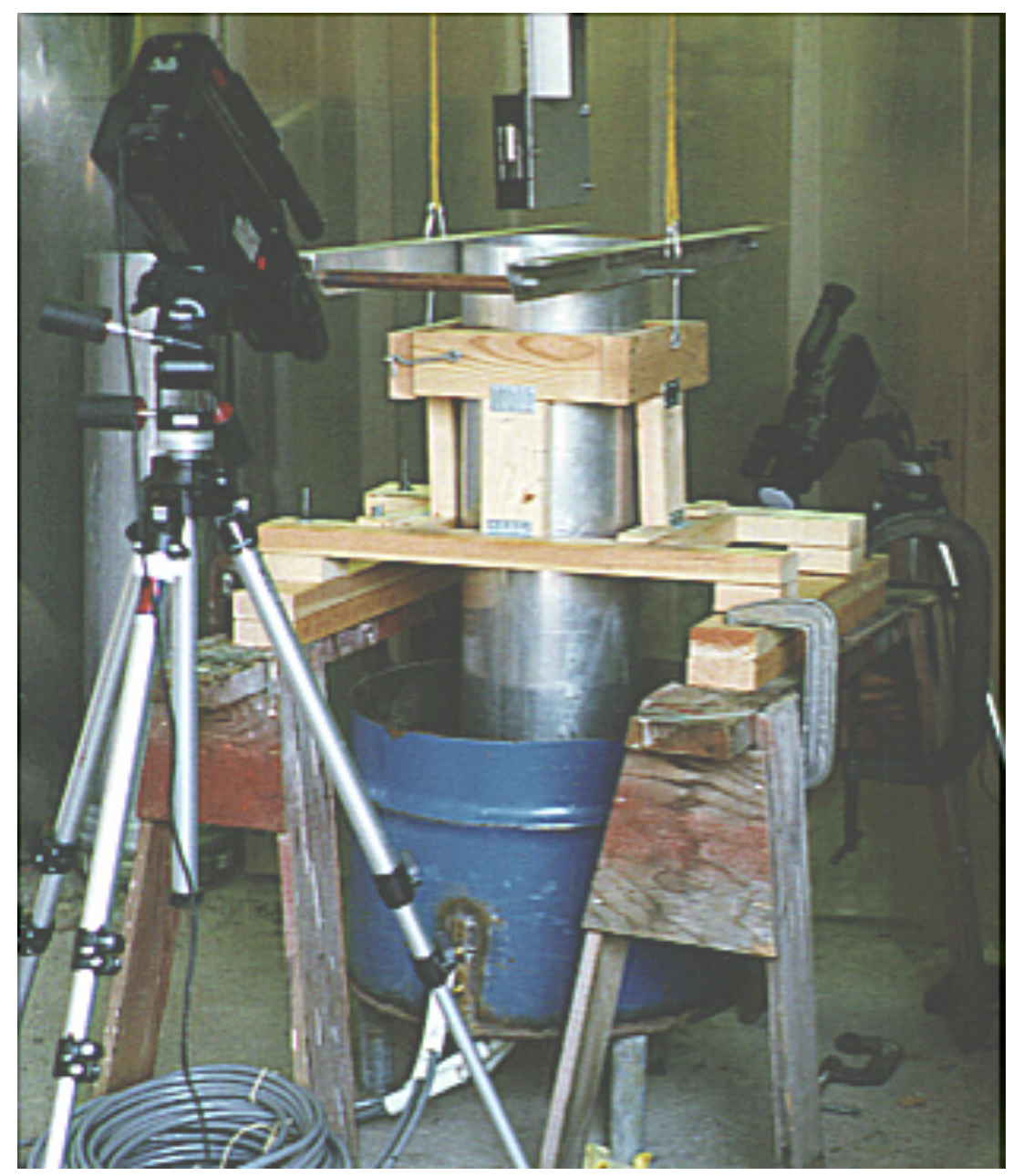

Figure 3: Experimental apparatus shows the large holding container (blue) with the tall cylinder inside and in the center. The cylinder is housed in stability framework. A visible light laser is suspended above and in the centerline of the cylinder. Pressure transducers are affixed to the base and sidewall of the holding container. The yellow ropes seen attached to the horizontal bars at the top of the cylinder are a part of a pulley system, which vertically lifts the cylinder at a constant rate when a counter weight is applied. Video cameras record the experiments. 

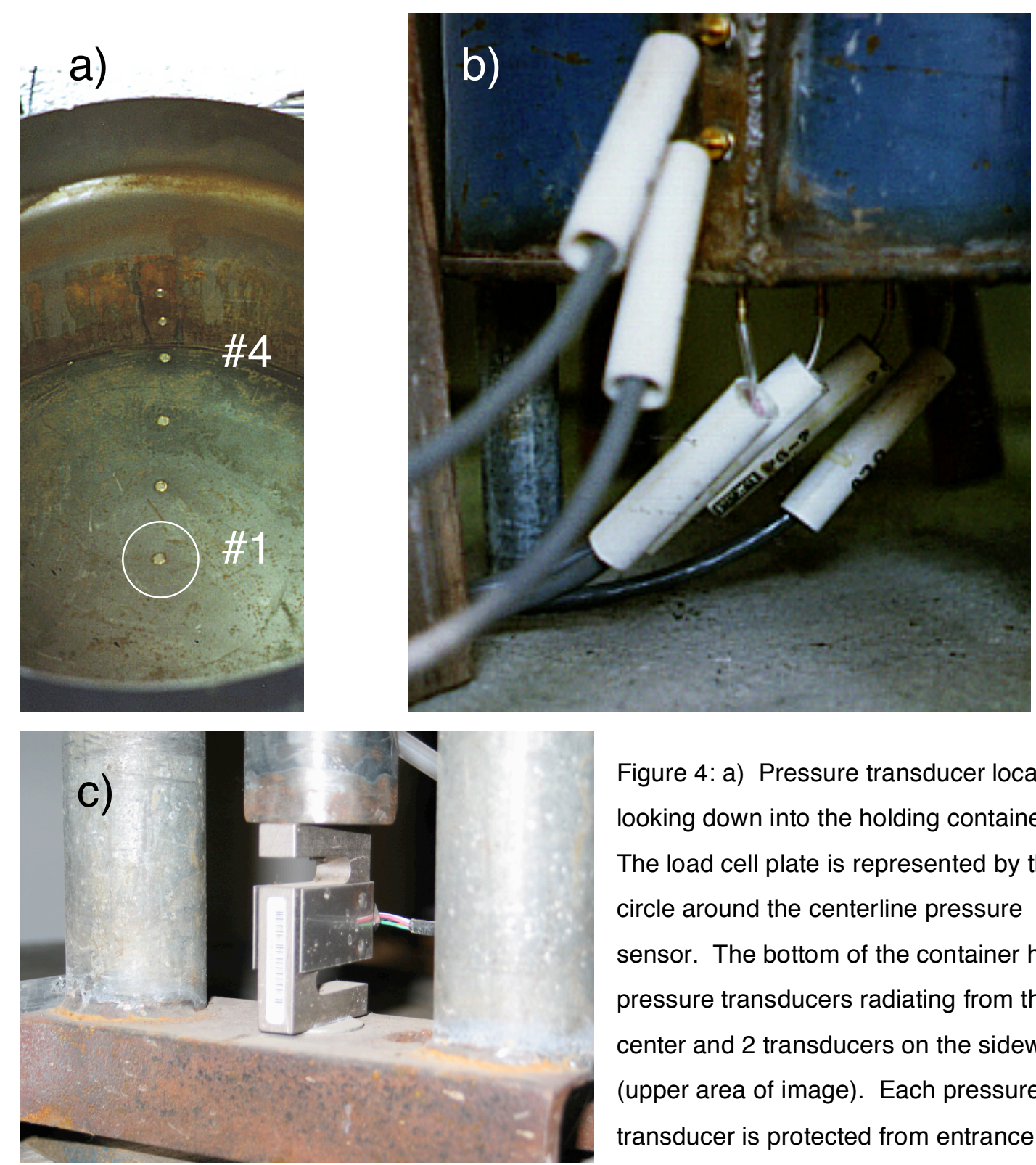

Figure 4: a) Pressure transducer locations looking down into the holding container. The load cell plate is represented by the circle around the centerline pressure sensor. The bottom of the container has 4 pressure transducers radiating from the center and 2 transducers on the sidewall (upper area of image). Each pressure transducer is protected from entrance of

fine particles by a 230-mesh screen. b) Shows the exterior of the container with the 4 pressure transducers at the base and 2 on the sidewall attached as they are during experiments. The clear tubing is pre-filled with water before each experiment. The transducers are housed in PVC tubing to protect them from vibrations and superfluous noise. c) Shows the S-beam style load cell mounted under the container. There is a $5 \mathrm{~cm}$ diameter plate mounted on the base of the container, above the load cell, which records bed-normal stress in the centerline of the cylinder. On the following page: d) Schematic drawing of the apparatus and sensor locations. The drawing shows a side view and plan view of the apparatus. The laser measures change in column height $(h)$, load cell measures bed-normal stress $(\sigma)$, and pressure sensors measure pore-fluid pressure $(p)$. 


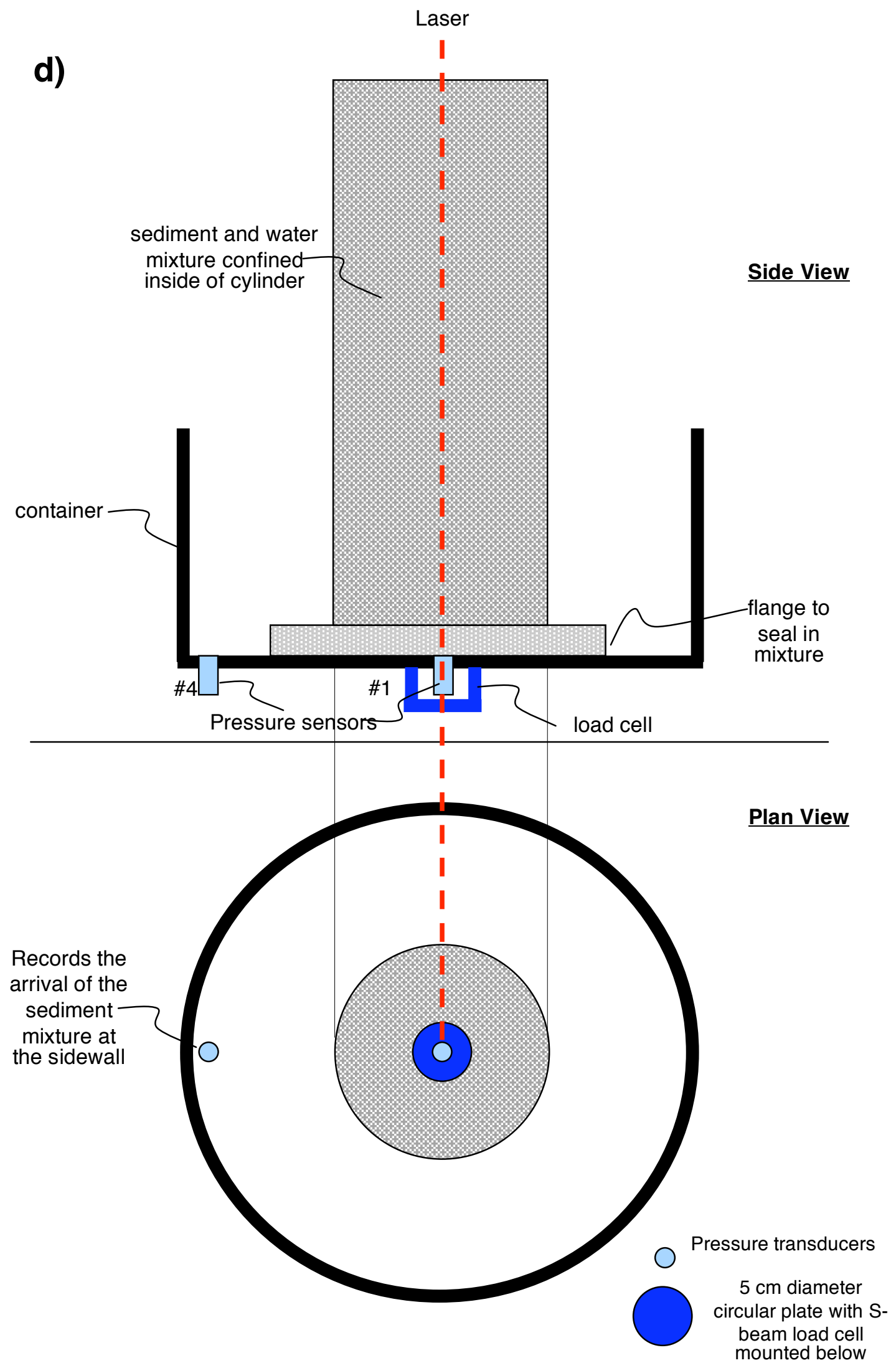




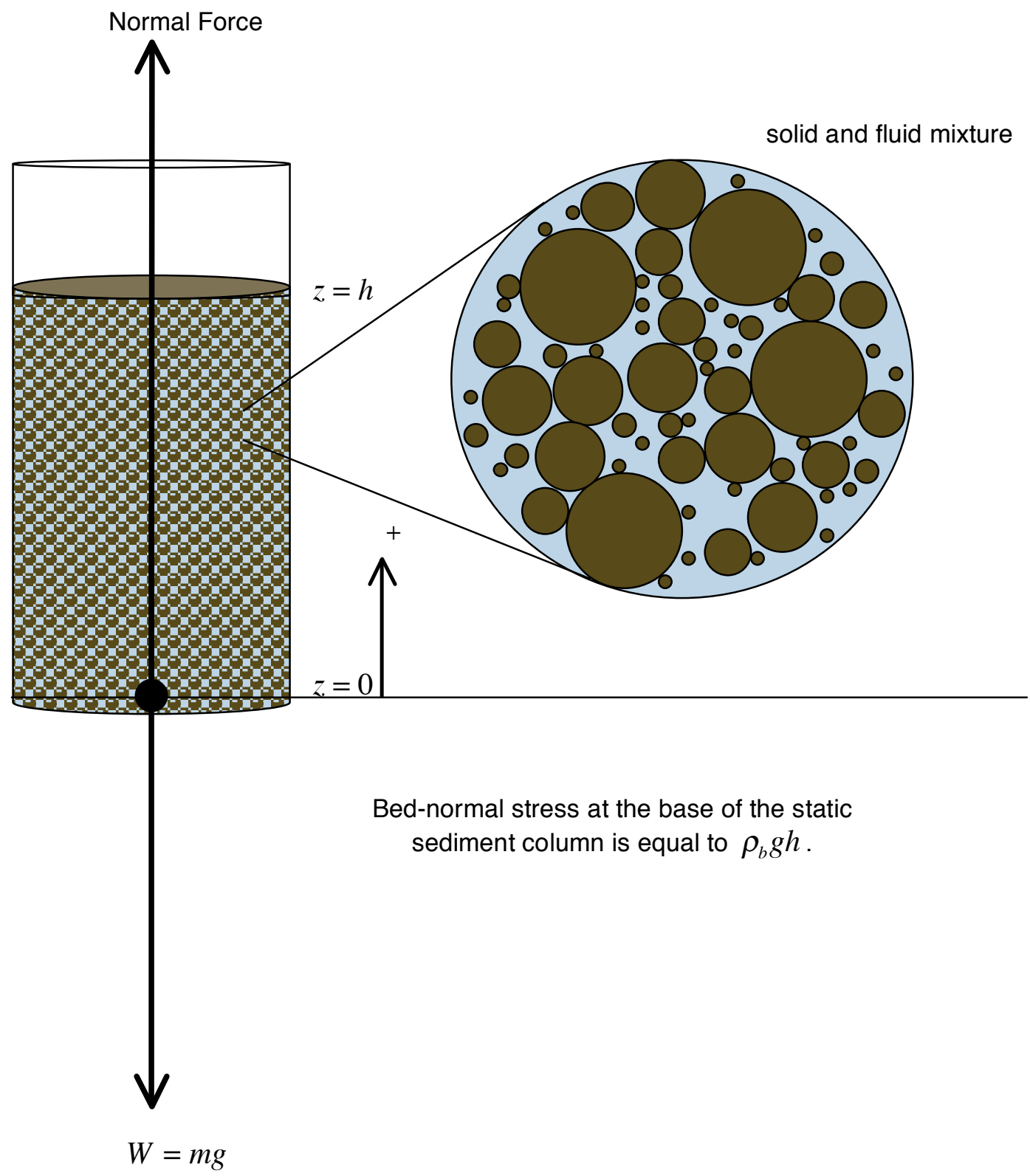

Figure 5: Diagram showing the cylinder and centerline. A simple coordinate system shows $z \uparrow^{+}$. Pressure sensor \#1, the load cell, and the visible light laser are located in this centerline. Sediment mixture is made up of solids and fluid (water) and is at rest prior to lifting the cylinder. 

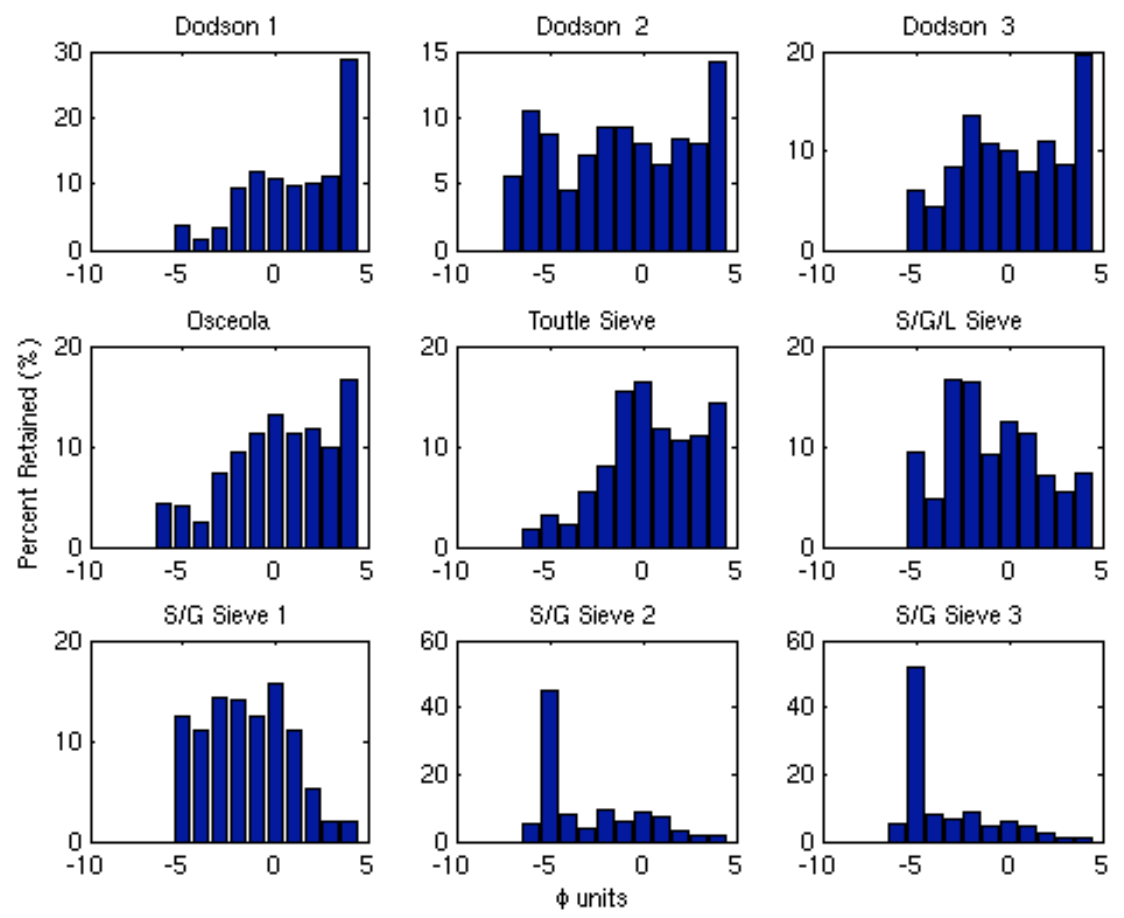

Figure 6: Histograms of sediments used in these experiments. Three samples were analyzed for both the Dodson debris flow sediment and the sand and gravel mixture. Sand/gravel/loam mixture is represented by $(S / G / L)$ and the sand/gravel mixture is represented by $(S / G)$.
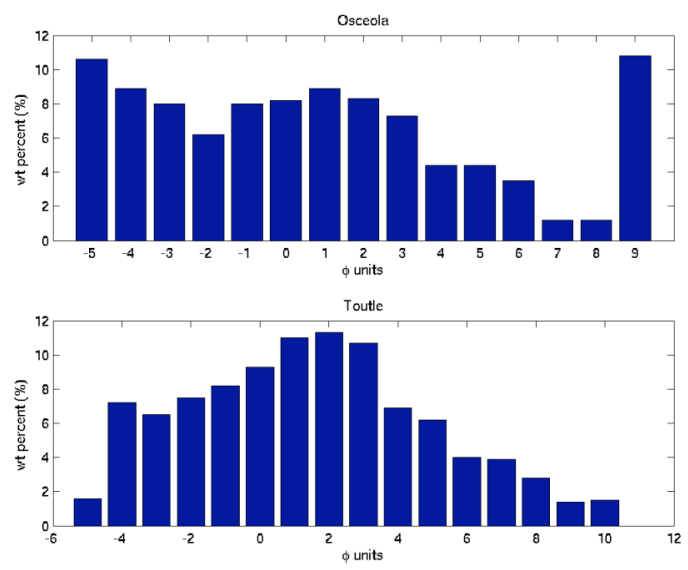

Figure 7: Histograms from hydrometer tests representing Osceola mudflow sediments courtesy of Dr. James Vallance (1996) and North Fork Toutle River mudflow sediment courtesy of Dr. Jon Major (1997). 


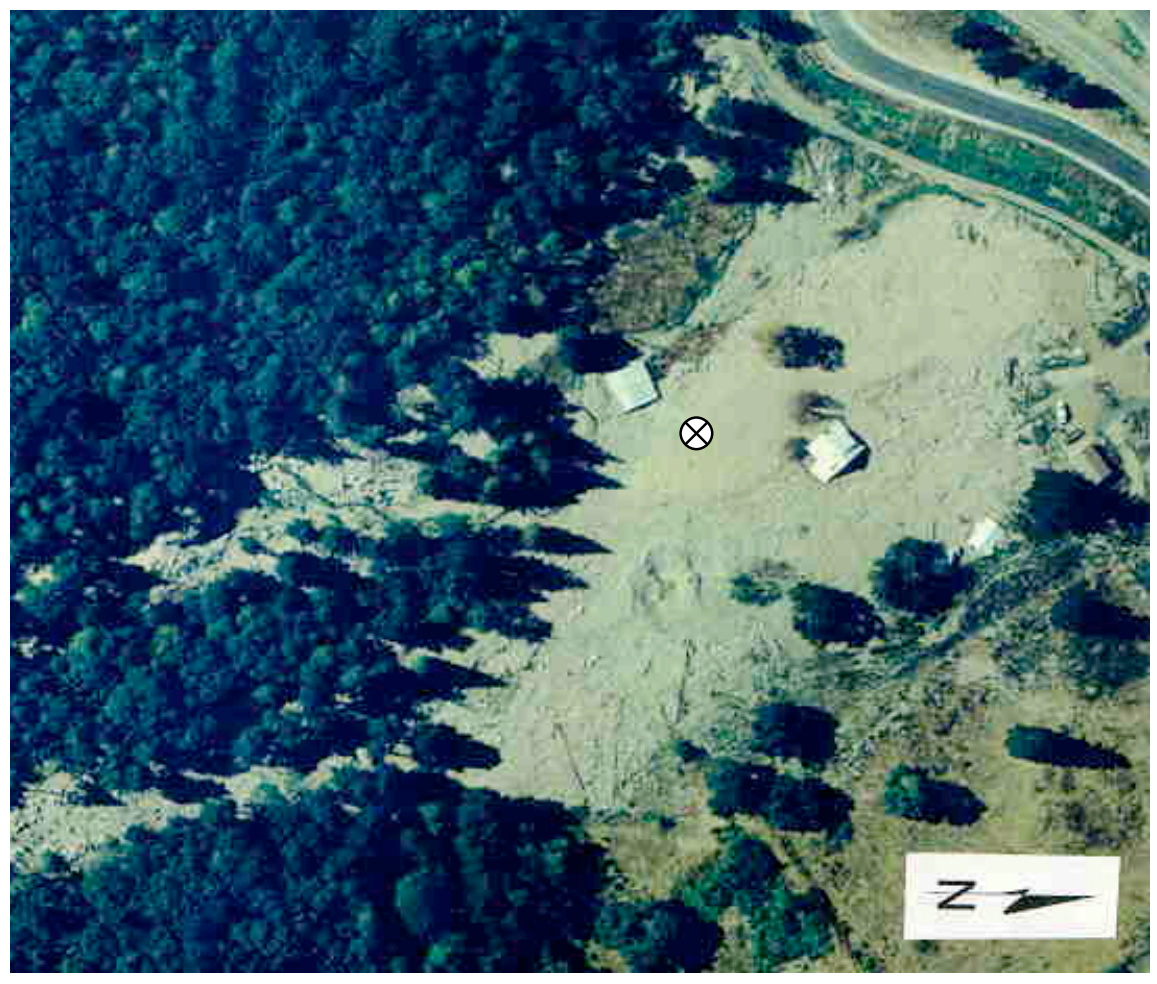

Figure 8: Aerial photograph showing collection site from the 1996 Dodson debris flow, Dodson, OR, Columbia River Gorge. The white circle with the $\mathrm{x}$ indicates the site where sediment was removed to a depth of $1 \mathrm{~m}$. The Royse house that was inundated by the flowing debris is just to the right in the photo. The house is buried to the second story windows. Photo courtesy of K. Cruikshank, Portland State University, Portland, Oregon. 


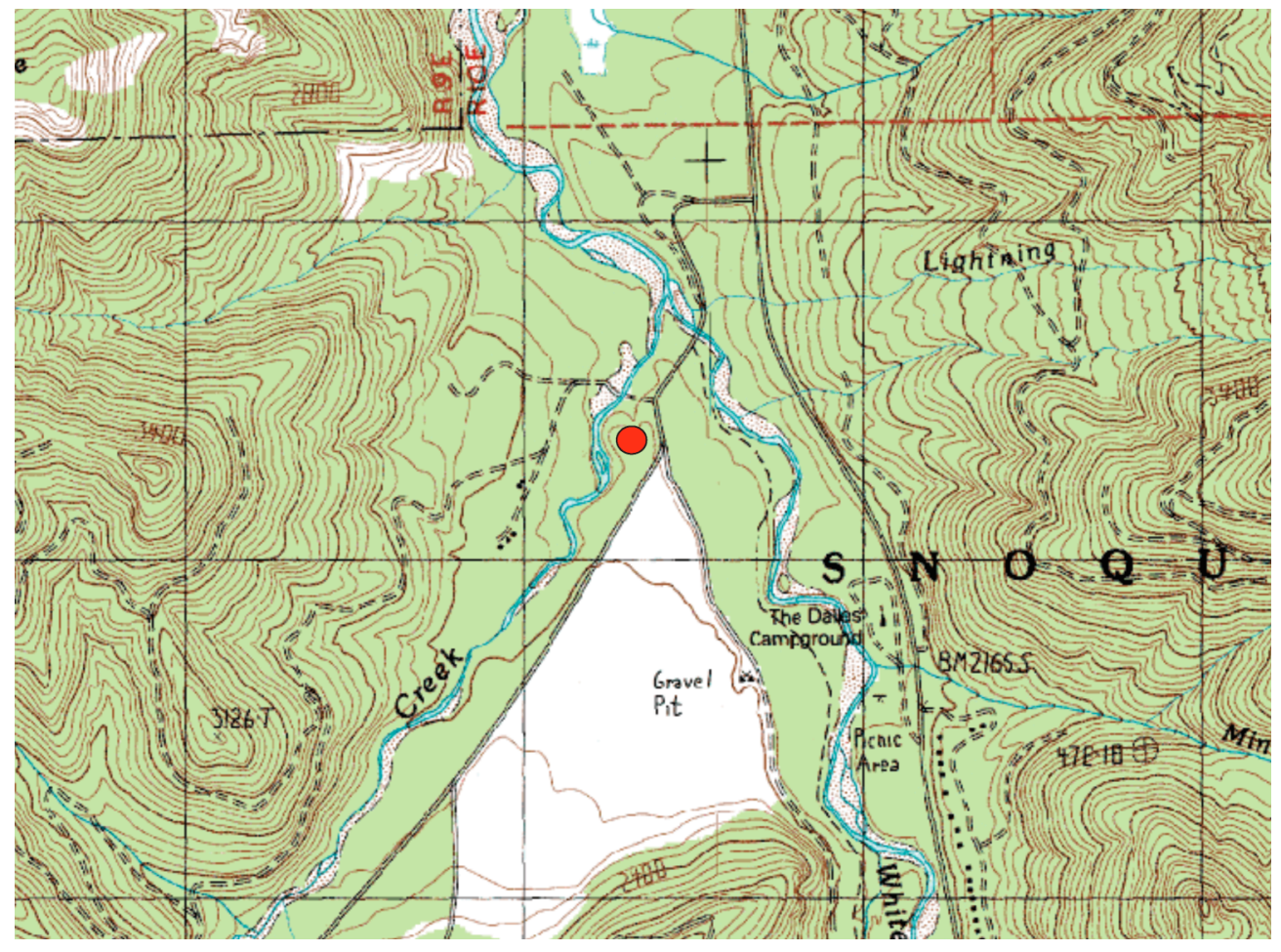

Figure 9: Osceola mudflow collection site, indicated by red circle. Located on Huckleberry Creek, on the northeast side of Mt. Rainier, south of Greenwater, WA. 


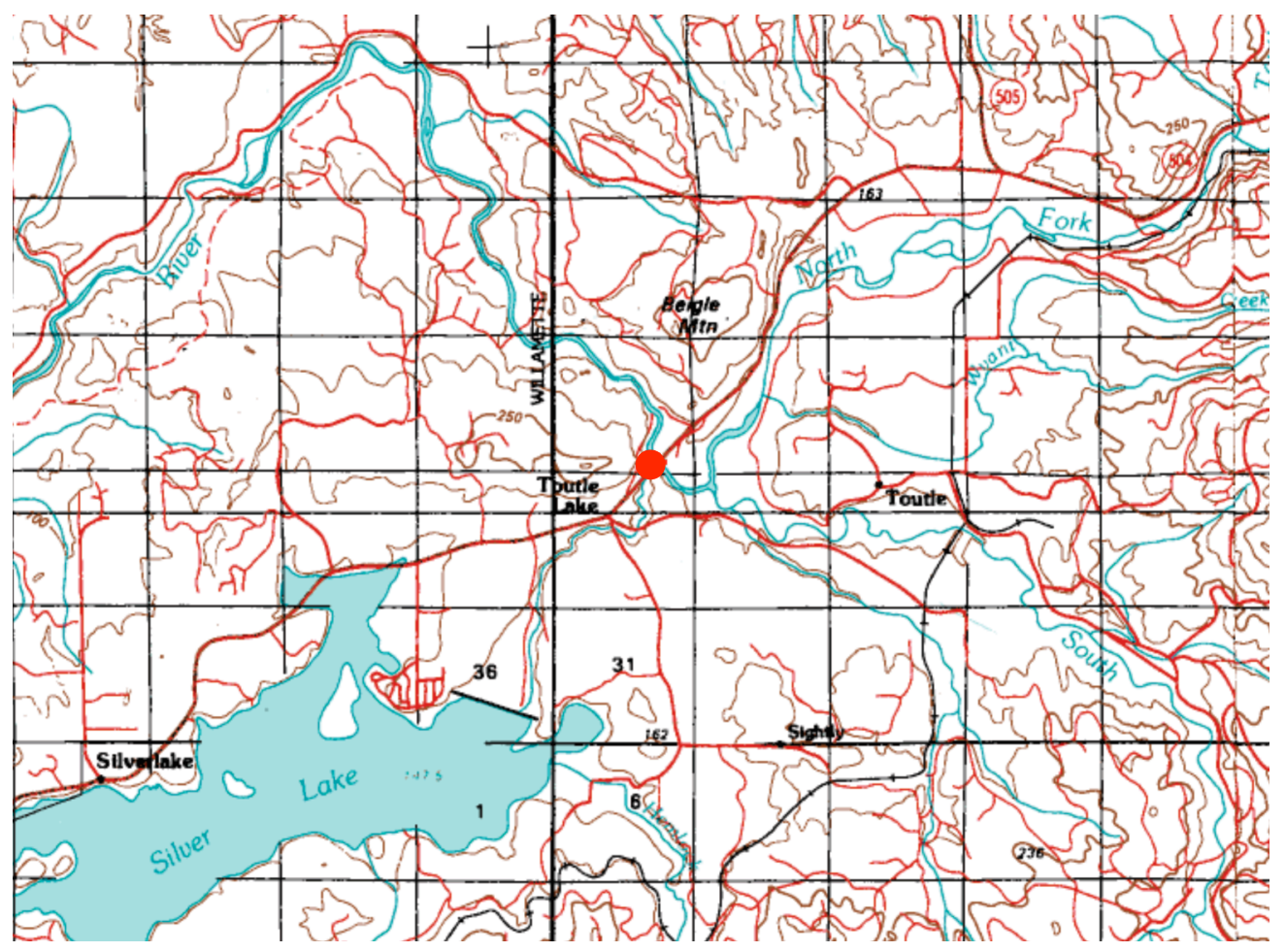

Figure 10: Toutle River mudflow from Mount St. Helen's 1980 eruption. The collection site is near the Kidd Valley Bridge on Highway 504. The sediment collection site is represented by the red circle in the graphic. Sediment was collected at about 3 meters above the Toutle River. 


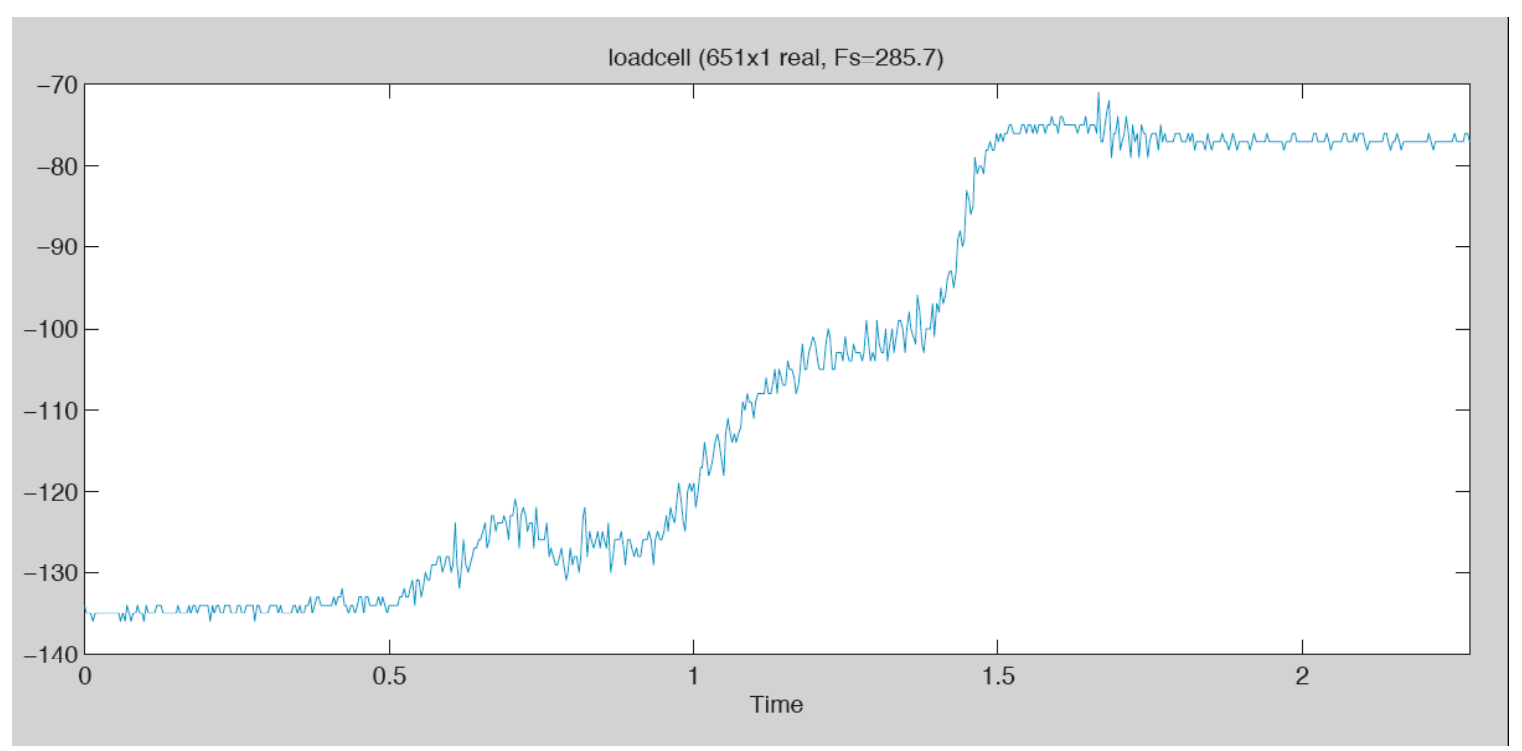

Figure 11: Example of noisy raw data. The x-axis is time in seconds and the $y$-axis is analog digital units (adu). The example shows the load cell sensor during the lift portion of the experiment. Note that from $0-.5$ and from $\sim 1.7$-end noise is easily identified as oscillating around a mean value.

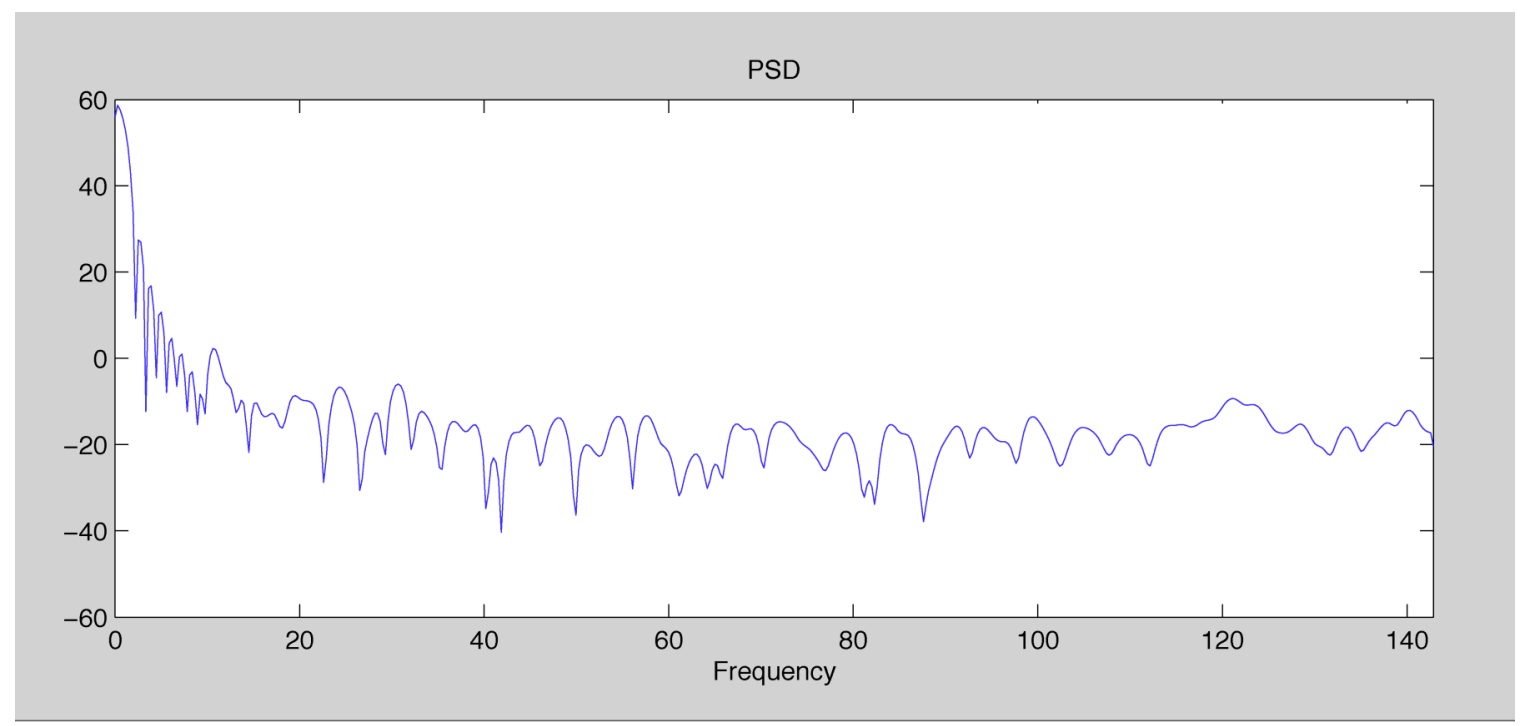

Figure 12: Example of power spectral density plots showing sinusoids identifying the primary signal and noise. The y axis represents decibel units $(\mathrm{dB})$. The primary signal is in the low frequency range $(<20 \mathrm{~Hz})$. The noise in the signal oscillates around a mean of about $-20 \mathrm{~dB}$ and is identified by the relative plane in which it resides, i.e., a horizontal line can be drawn through the sinusoids. This example plot is representative of all PSD's for the experiments. 


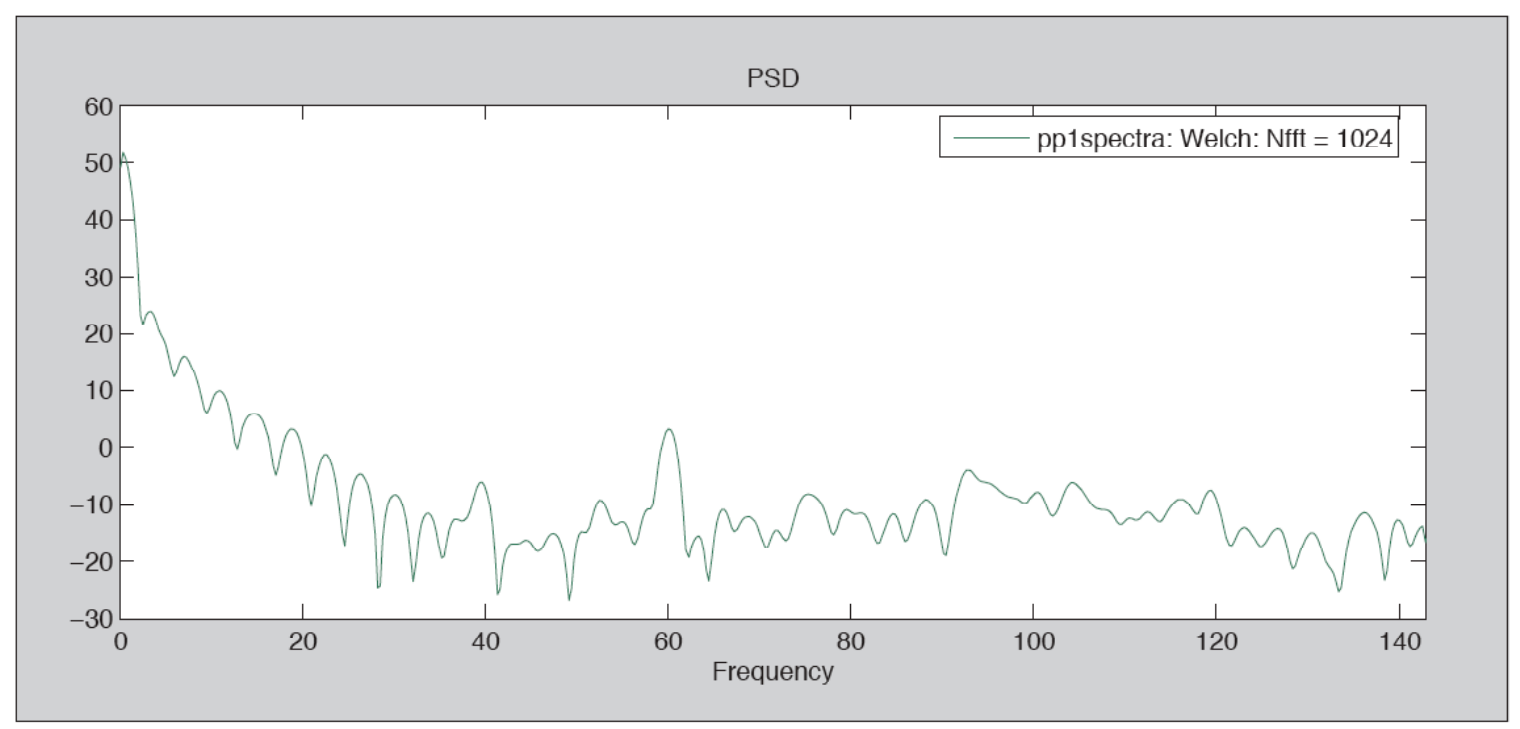

Figure 13: Power spectral density plot showing frequency peaks at $60 \mathrm{~Hz}$ and $120 \mathrm{~Hz}$. The $37.15 \mathrm{~Hz}$ peak is presumably caused by aliasing of the $3^{\text {rd }}$ harmonic of the power spectrum.

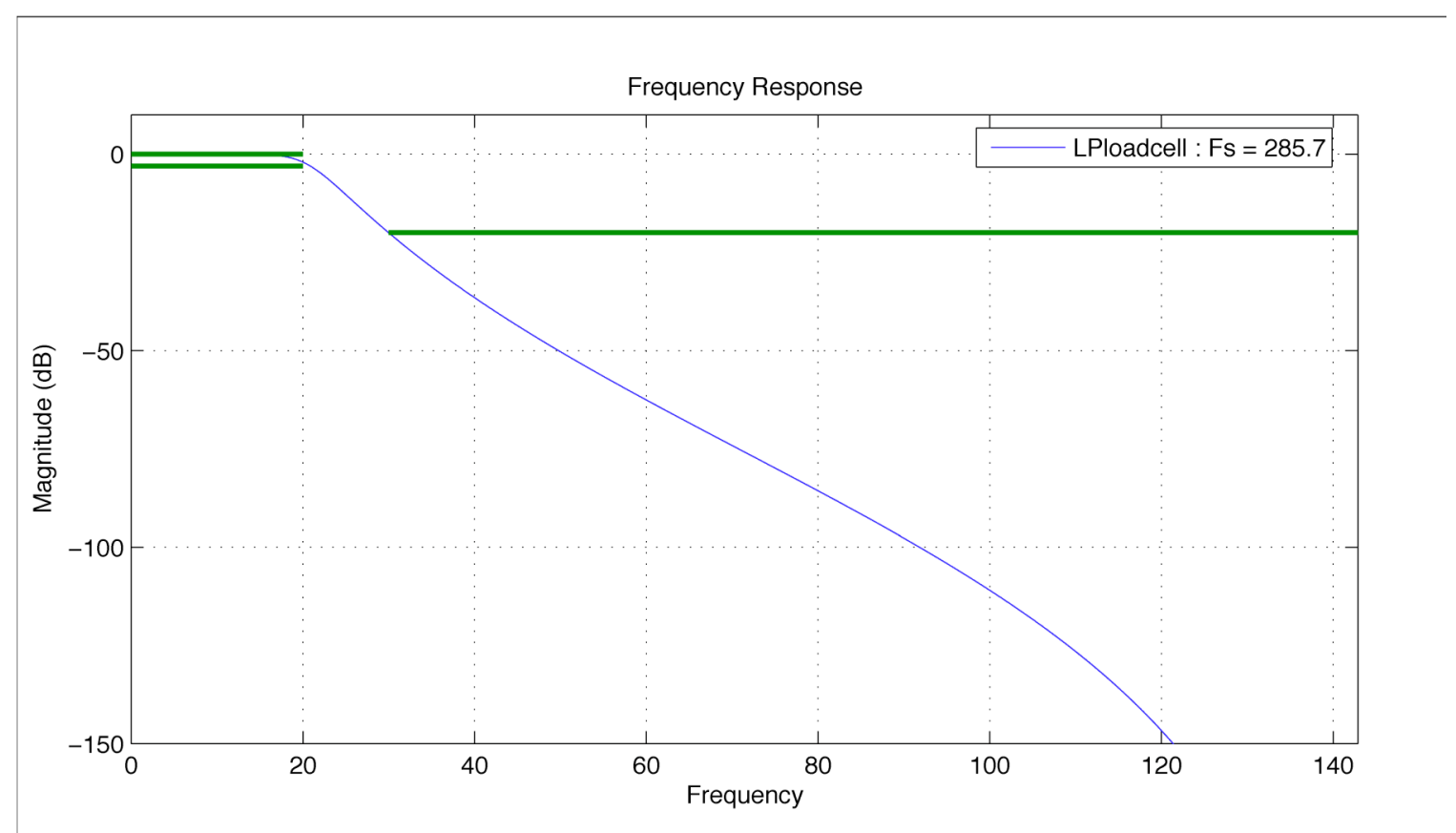

Figure 14: Example of lowpass Butterworth filter. The green horizontal double lines define the maximum and minimum desired values for the frequency response across the passband. The vertical separation of the lines indicates the magnitude of the passband ripple, the larger the ripple the further apart the bands. The single green horizontal line defines the stopband. The blue line defines the frequency response and plots the magnitude of the filter's frequency response in decibels $\left(20^{*} \log 10\right.$ (magnitude)). 


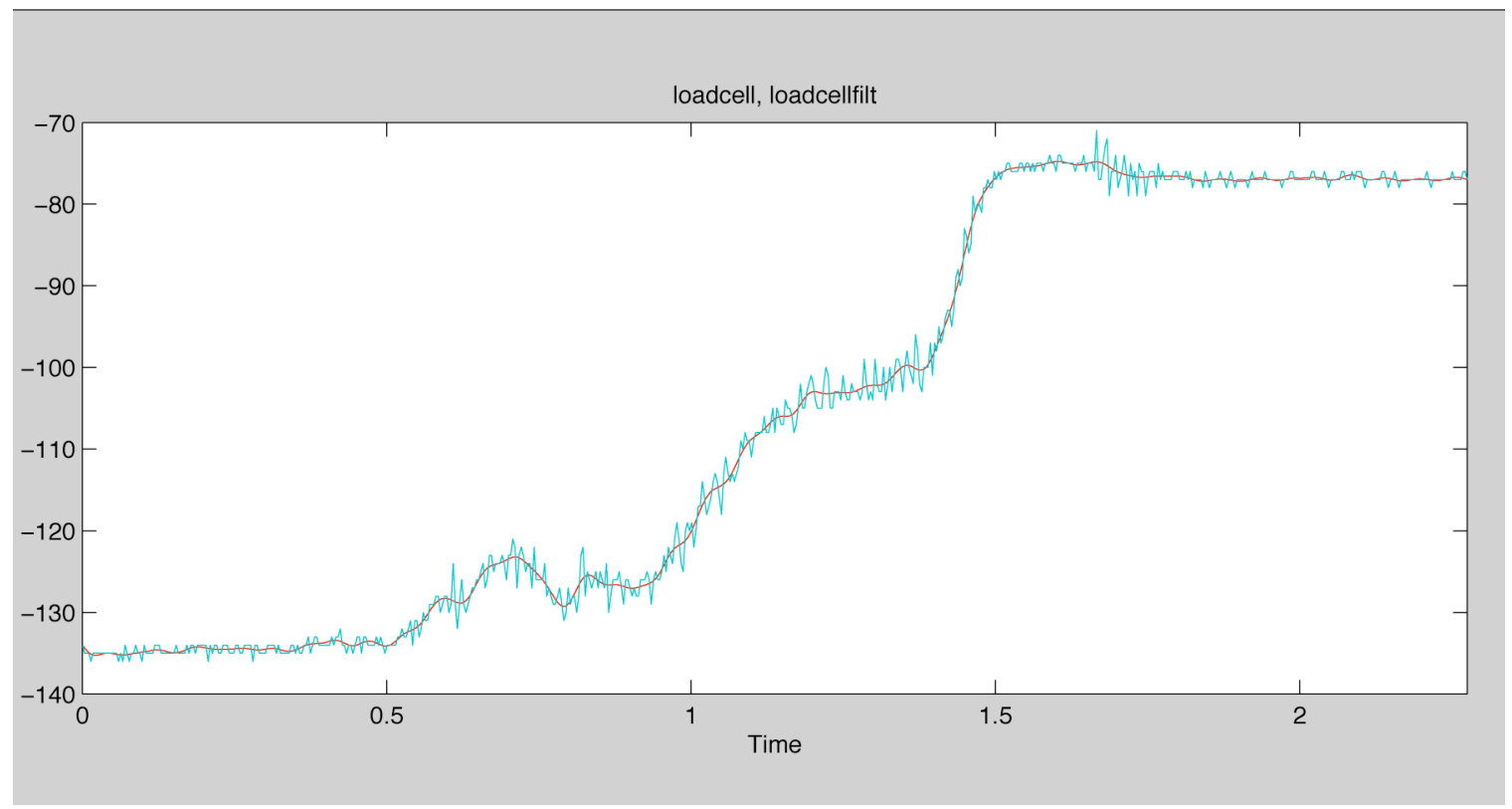

Figure 15: Example of comparison plot showing the filtered and raw data. The raw data are shown in light blue and the filtered data are in red. The y axis represents analog digital units and the $\mathrm{x}$ axis is time in seconds. This example is representative of all filtering that is done for both the load cell and the pressure sensors. 


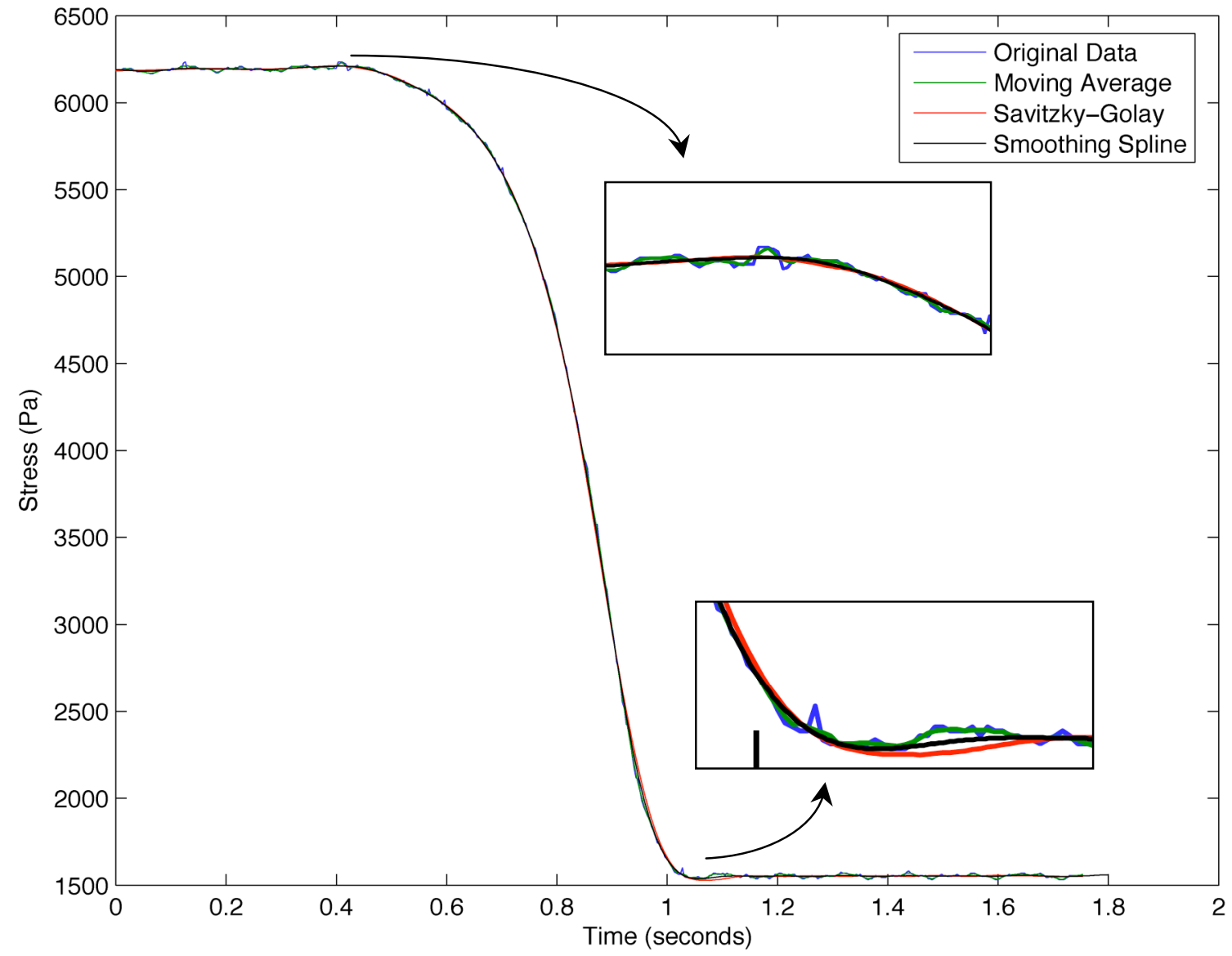

Figure 16: Example of curve fitting laser data. Several curves were fit to the data before settling on the smoothing spline. The inset plots show detail at the start of flow and the end of the flow. This example is representative of all curve fitting of the laser data for all experiments. 
Dodson $\rho_{b}=1939 \frac{\mathrm{kg}}{\mathrm{m}^{3}}, h_{i}=0.33 \mathrm{~m}, w c=43 \%$
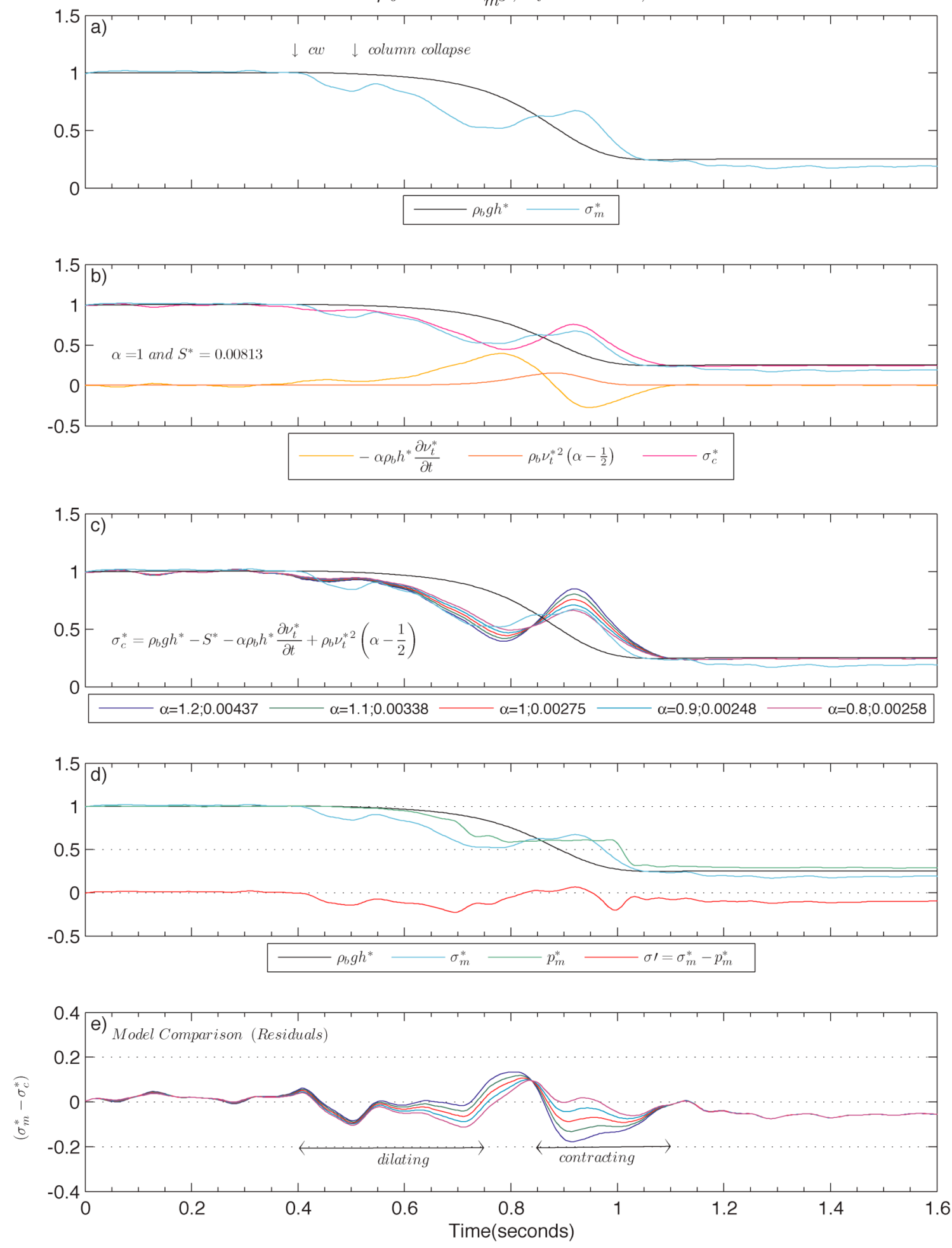

Figure 17: The figure shows a subplot with five plots, a-b-c-d-e. The header of the plot defines the sediment name, bulk density, initial height, and water content. The y-axis are normalized and represents stress for plots a-d. Plot (a) shows the measured normal stress compared to the 
simple hydrostatic pressure. In the plot (a) "cw" represents when the counter weight was applied to the system and "column collapses" represents when the sediment column started to collapse. Plot (b) is an overlay of plot (a) showing the individual terms of the fundamental equation plotted independently. Plot (c) shows the model with various values defined for $\alpha$ and the measured bed-normal stress. Plot (d) shows the measured bed-normal stress and the measured pore-fluid pressure plotted with the hydrostatic stress and the resulting effective stress. Plot (e) shows the residual (difference) between the measured bed-normal stress and the calculated bed-normal stress. As the residual lines approach 0 , the model fits the measured bed-normal stress values better. The double-ended arrows represent the general trend of the sediment mass as it dilates and contracts. 

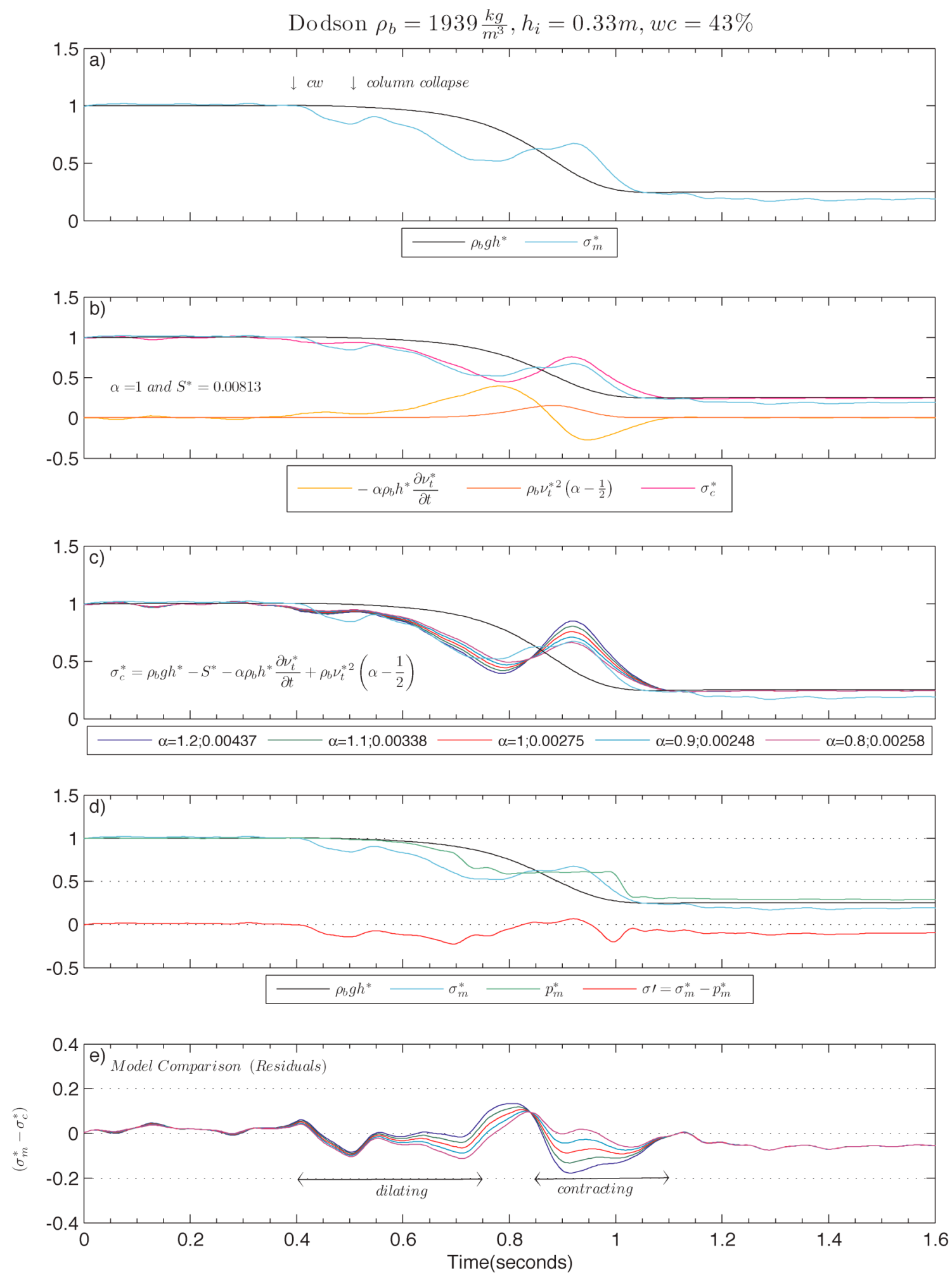

Figure 18: Experiment \#1 - Dodson debris flow, Dodson, Oregon, Columbia River Gorge, 1997. The sediment mixture has a water content of $43 \%$, initial column height of $.33 \mathrm{~m}$, and bulk density 
of $1939 \mathrm{~kg} / \mathrm{m}^{3}$. Plot a) shows the simple hydrostatic pressure $\left(\rho_{b} g h^{*}\right)$ compared to the measured centerline bed-normal stress $\left(\sigma_{m}^{*}\right)$. A counter weight applied to the cylinder to enable lifting, shown on the plot as 'cw'. The sediment column collapse is shown as 'column collapses'. This is the time when the sediment mass begins to flow out of the cylinder. Plot $b$ ) this plot shows the same data from plot a) but with the addition of the calculated bed-normal stress $\left(\sigma_{c}^{*}\right)$ (the model) and $\alpha$ set equal to 1 . This plot is used to compare the measured values to the model (calculated) values. This plot also shows the individual terms of the model equation so that a comparison can be made between the momentum term $\left(\rho_{b} v_{t}^{* 2}\left(\alpha-\frac{1}{2}\right)\right)$ and the acceleration term $\left(\alpha \rho_{b} h^{*} \frac{\partial v_{t}^{*}}{\partial t}\right)$. Plot c) overlays plot a) showing the model solutions with five independent values of $\alpha$ and the mean square error associated with the use of each $\alpha$ as compared to the measured bed-normal stress. Plot d) again overlays plot a) with the measured centerline porefluid pressure $\left(p_{m}^{*}\right)$ and the measured bed-normal stress $\left(\sigma_{m}^{*}\right)$. The difference of the two is the effective stress $\left(\sigma^{\prime}\right)$. Plot e) shows the calculated bed-normal stress $\left(\sigma_{c}^{*}\right)$ (or model) evaluated with each of the five $\alpha$ values and then subtracted from the measured bed-normal stress $\left(\sigma_{m}^{*}\right)$. Each line represents that difference or residual. The lines that intersect 0 represent when the measured values and the calculated values are equal. The $\alpha$ values are shown in the legend at the bottom of the plot (c). When $\alpha$ is greater than 1 the sediment mass is dilating and $\alpha$ less than 1 means the sediment mass is contracting; highlighted with the double-ended arrows. 
Dodson $\rho_{b}=1876 \frac{\mathrm{kg}}{\mathrm{m}^{3}}, h_{i}=0.43 \mathrm{~m}, w c=47 \%$
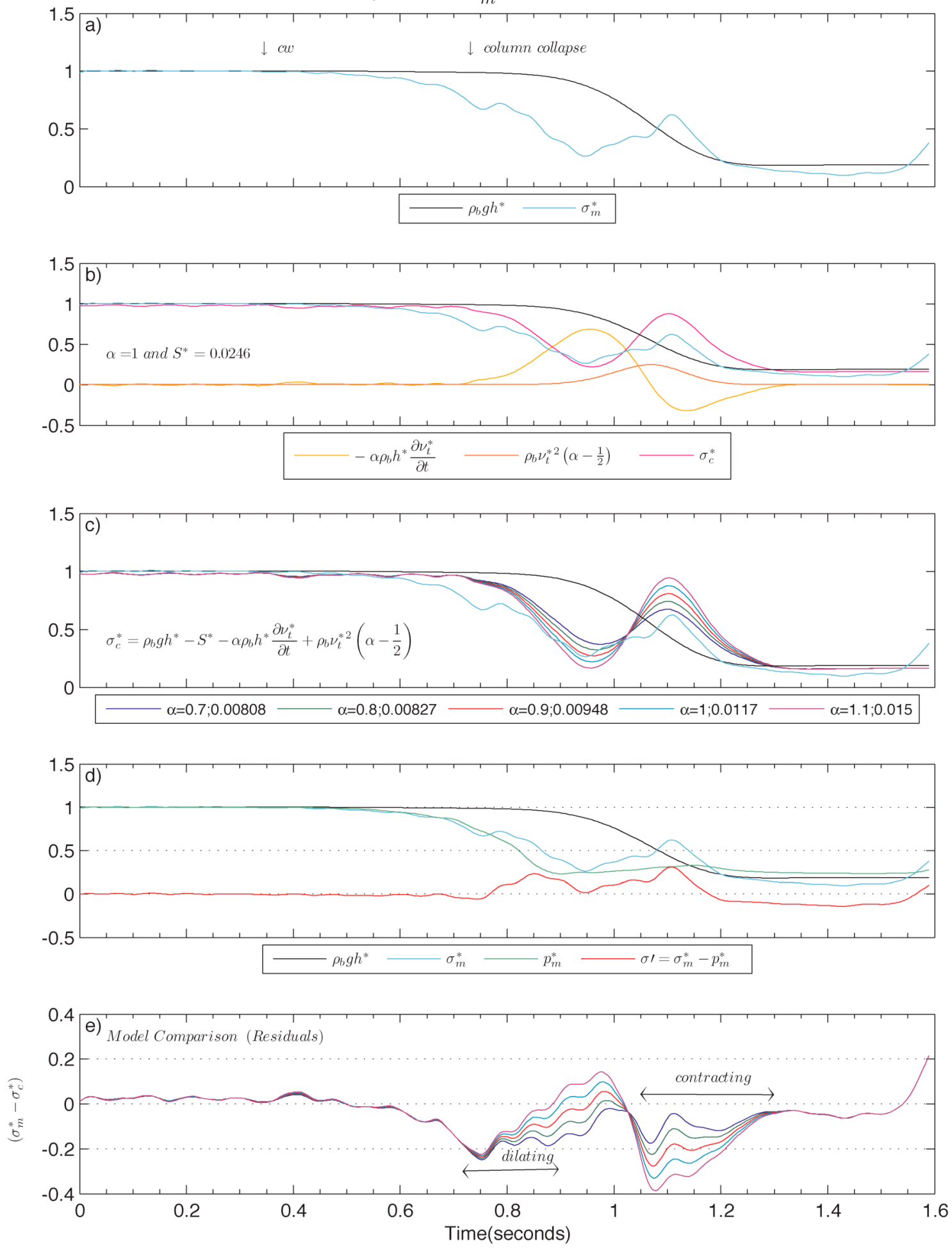

Figure 19: Experiment \#2 - Dodson debris flow, Dodson, Oregon, Columbia River Gorge, 1997.

The sediment mixture has a water content of $47 \%$, initial column height of $.43 \mathrm{~m}$, and bulk density of $1876 \mathrm{~kg} / \mathrm{m}^{3}$. Refer to Figure 18 for plot details. 
Osceola $\rho_{b}=1993 \frac{\mathrm{kg}}{\mathrm{m}^{3}}, h_{i}=0.43 \mathrm{~m}, w c=40 \%$
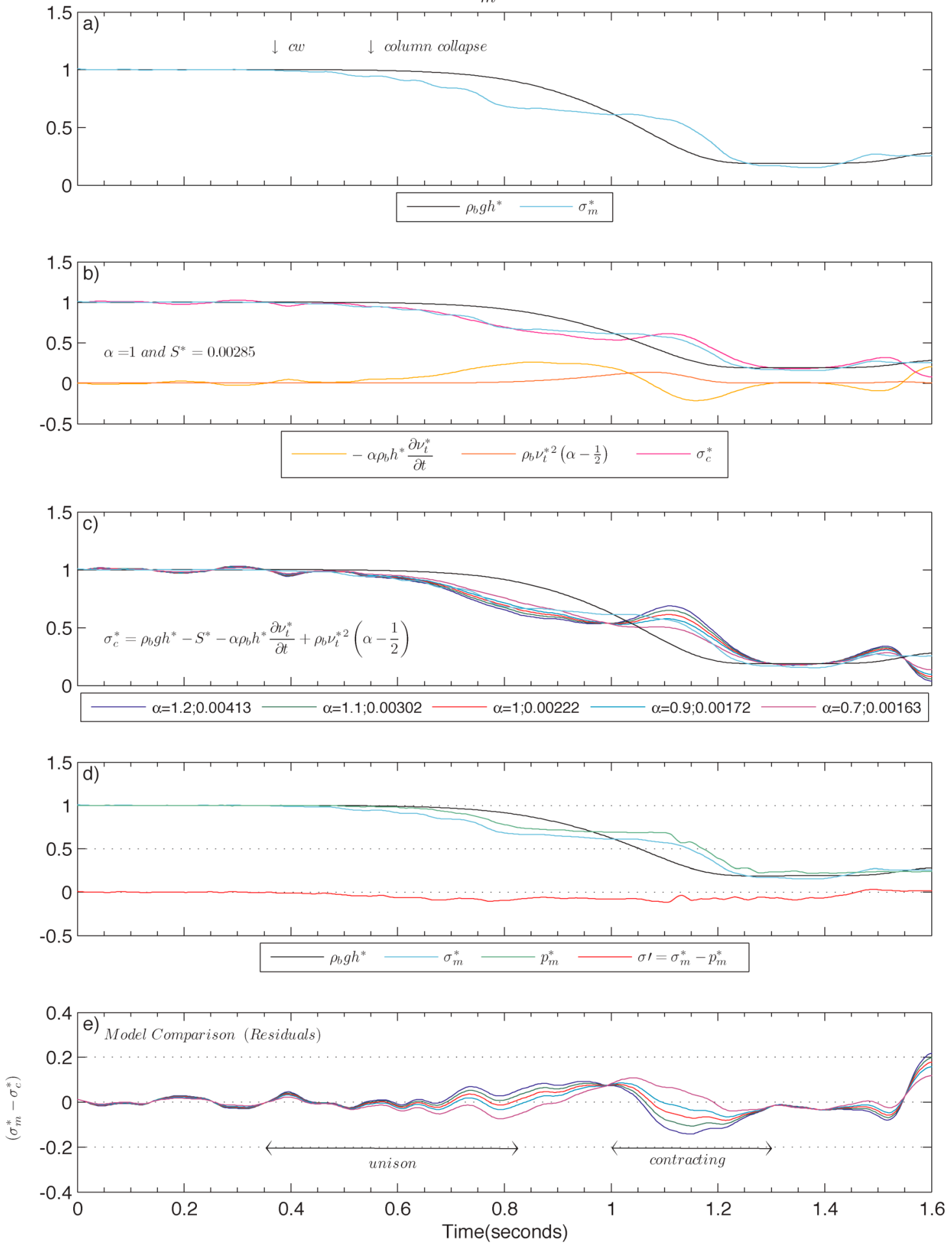

Figure 20: Experiment \#1 - Osceola mudflow, Mt. Rainier, WA, 5600 years ago. The sediment mixture has a water content of $40 \%$, initial column height of $.43 \mathrm{~m}$, and bulk density of 1993 $\mathrm{kg} / \mathrm{m}^{3}$. Refer to Figure 18 for plot details. 
Osceola $\rho_{b}=1943 \frac{\mathrm{kg}}{\mathrm{m}^{3}}, h_{i}=0.39 \mathrm{~m}, w c=43 \%$
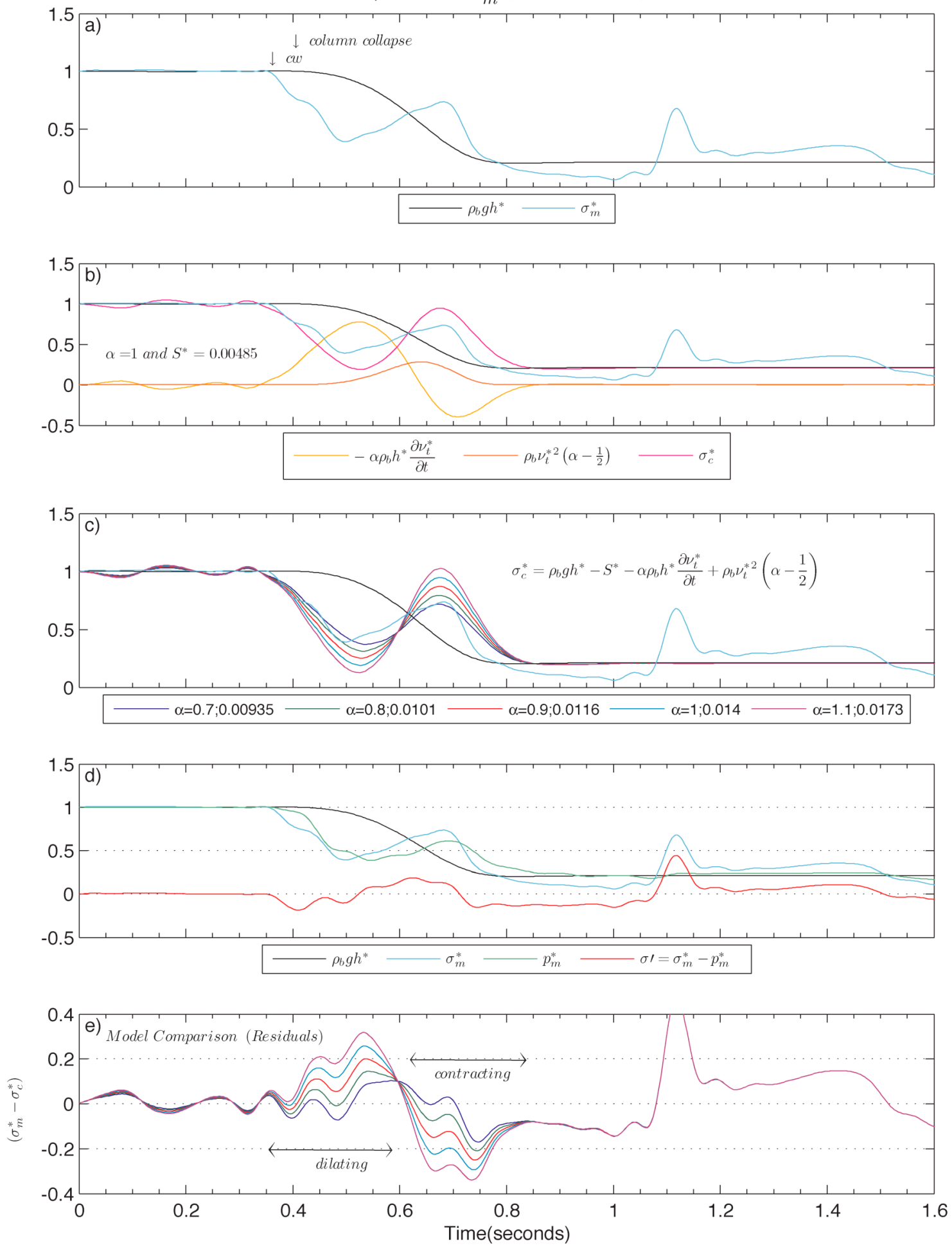

Figure 21: Experiment \#2 - Osceola mudflow, Mt. Rainier, WA, 5600 years ago. The sediment mixture has a water content of $43 \%$, initial column height of $.39 \mathrm{~m}$, and bulk density of 1943 $\mathrm{kg} / \mathrm{m}^{3}$. Refer to Figure 18 for plot details. 
Toutle $\rho_{b}=1891 \frac{\mathrm{kg}}{\mathrm{m}^{3}}, h_{i}=0.37 \mathrm{~m}, w c=44 \%$
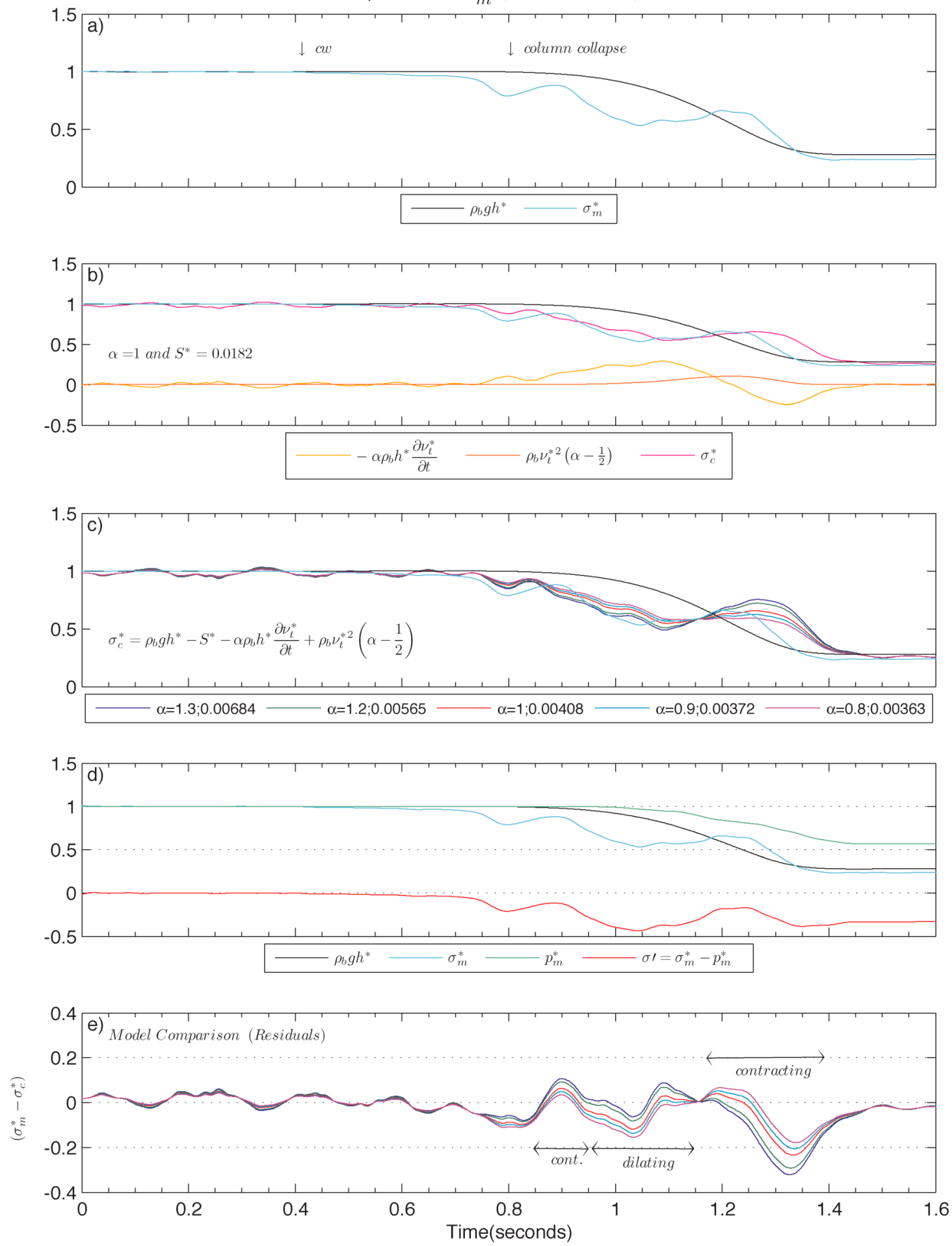

Figure 22: Experiment \#1 - North Fork Toutle River mudflow, Mount St. Helens, WA, 1980. The sediment mixture has a water content of $44 \%$, initial column height of $.37 \mathrm{~m}$, and bulk density of $1891 \mathrm{~kg} / \mathrm{m}^{3}$. Refer to Figure 18 for plot details. 
Toutle $\rho_{b}=1841 \frac{\mathrm{kg}}{\mathrm{m}^{3}}, h_{i}=0.4 \mathrm{~m}, w c=47 \%$
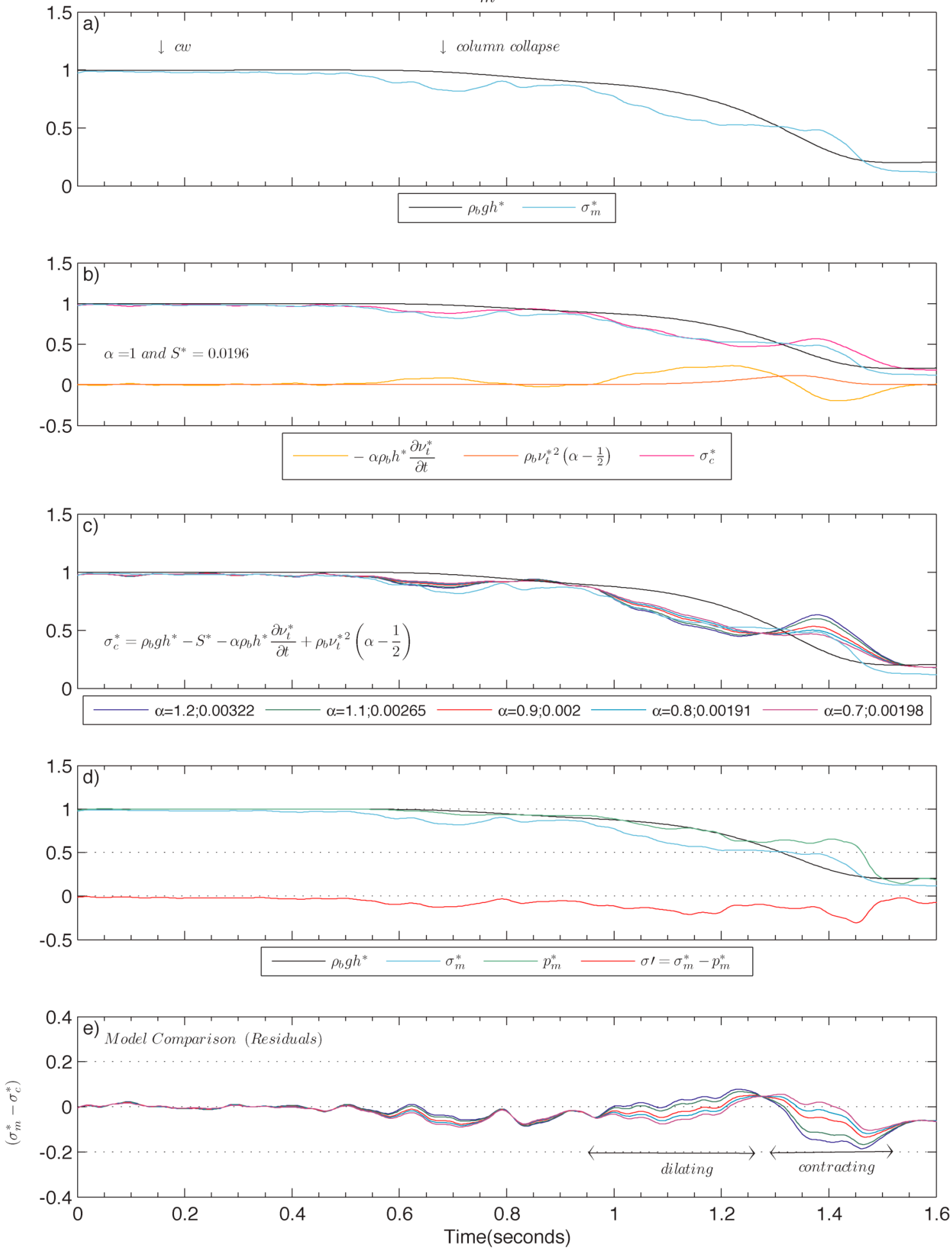

Figure 23: Experiment \#2 - North Fork Toutle River mudflow, Mount St. Helens, WA, 1980. The sediment mixture has a water content of $47 \%$, initial column height of $.40 \mathrm{~m}$, and bulk density of $1841 \mathrm{~kg} / \mathrm{m}^{3}$. Refer to Figure 18 for plot details. 
Sand-Gravel Mix $\rho_{b}=2211 \frac{\mathrm{kg}}{\mathrm{m}^{3}}, h_{i}=0.58 \mathrm{~m}, w c=29 \%$
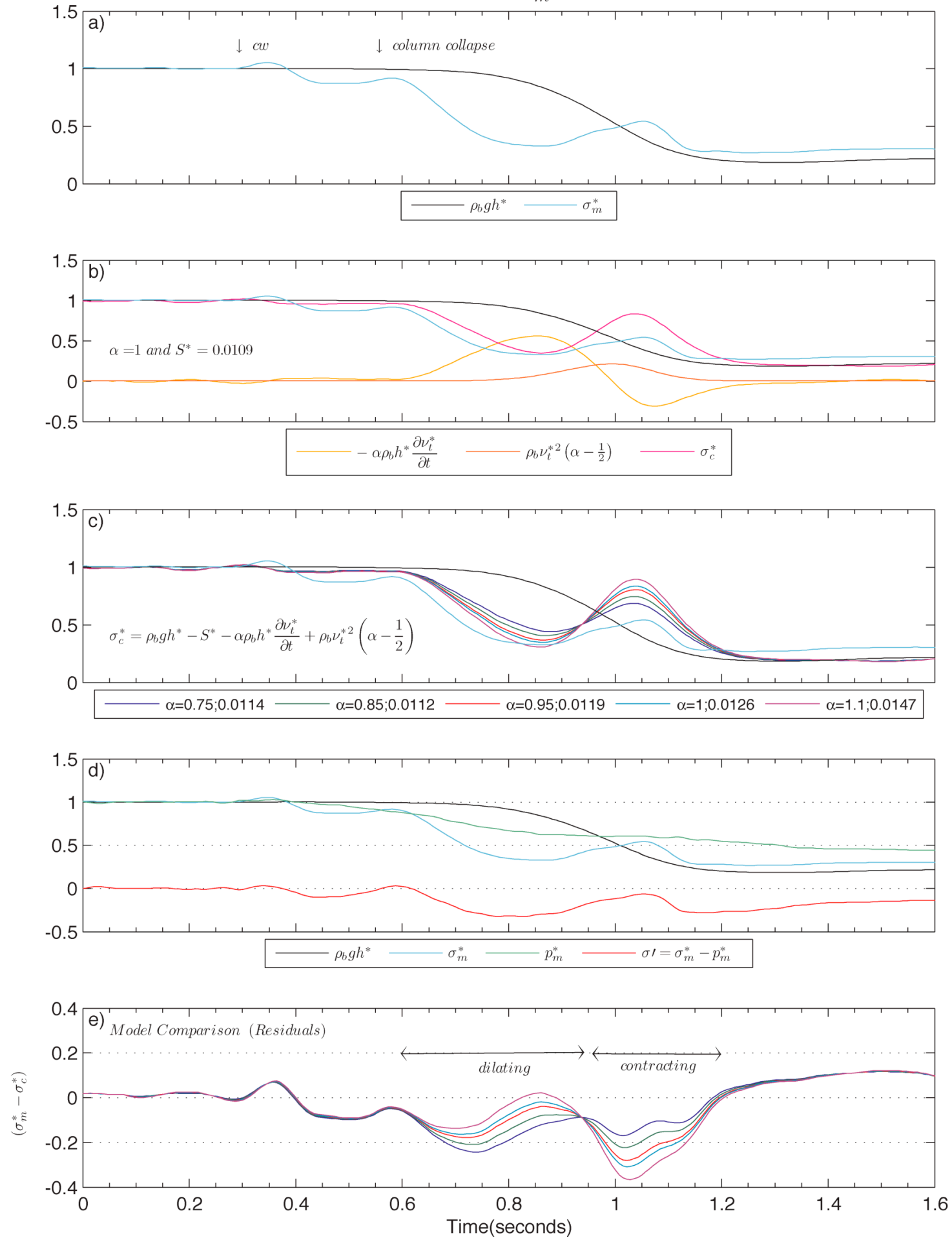

Figure 24: Experiment \#1 - Commercial sand and gravel mixture. The sediment mixture has a water content of $29 \%$, initial column height of $.58 \mathrm{~m}$, and bulk density of $2211 \mathrm{~kg} / \mathrm{m}^{3}$. Refer to Figure 18 for plot details. 
Sand-Gravel-Loam Mix $\rho_{b}=2000 \frac{\mathrm{kg}}{\mathrm{m}^{3}}, h_{i}=0.31 \mathrm{~m}, w c=39 \%$
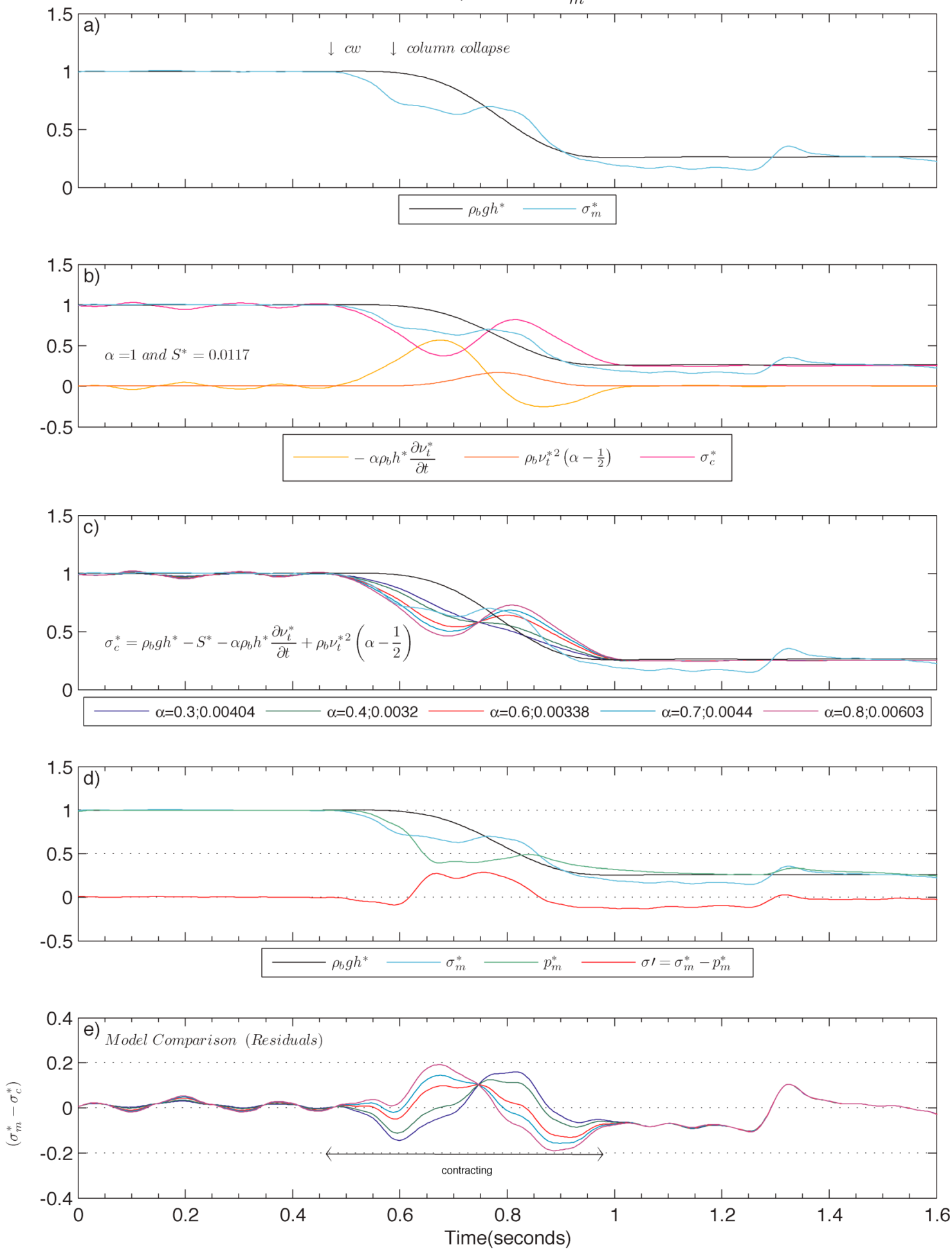

Figure 25: Experiment \#1 - Commercial sand, gravel, and loam mixture. The sediment mixture has a water content of $39 \%$, initial column height of $.31 \mathrm{~m}$, and bulk density of $2000 \mathrm{~kg} / \mathrm{m}^{3}$. Refer to Figure 18 for plot details. 


\section{Appendix A. Experiment Details}

\section{Experimental Apparatus}

The experimental apparatus consists of a holding container and a cylinder. A modified 55-gallon drum with a mean diameter of $.575 \mathrm{~m}$ and a height of $.395 \mathrm{~m}$ acts as the holding container. Inside of that a cylinder sits in the center and is manufactured from smooth stainless steel with a mean diameter of $.253 \mathrm{~m}$ and a height of $1.0 \mathrm{~m}$. The cylinder is smooth walled and centered within the container (Figure 3). The container is fitted with six pressure transducers and one load cell. The load cell and one pressure transducer reside at the centerline of the cylinder, while the remaining pressure transducers are affixed to both the base and sidewall of the container along a line radiating from its center (Figure $4 \mathrm{a}, \mathrm{b}$ ). A wooden framework is fastened to the rim of the container, which houses the cylinder, thus ensuring no rotation or lateral movement when lifting the cylinder vertically. The base of the cylinder is fitted with a flange and sealed with a gasket, to prevent sediment from leaking prior to lifting. The experimental apparatus is isolated its surroundings, and the mass of material is known at the onset of the experiment and remains constant throughout. In dynamic experiments, the data acquisition system records the digital counts (or analog digital units (adu)) for all pressure transducers, the load cell, and the laser.

\section{Data Acquisition System}

A laptop running Labtech Notebook/XE version 8.0 is used to collect binary data at various sampling rates (Table 2). The sensors are connected to the data acquisition system via insulated cables to a self-contained multi-channel output box that is then connected to the laptop computer through a PCM-DAS08 ${ }^{3}$ card (PCMCIA), using a 16-bit analog-to-digital conversion. The binary

\footnotetext{
${ }^{3}$ Computer Boards, Inc., 125 High Street, Mansfield, MA 02048, (508)261-1123.
} 
data are stored on the hard drive of the laptop before transferring to removable media. Conversion of binary data to ASCII format is done with the Streamer software package.

\section{Sensors}

The load cell is a 5.1-cm-wide, 7-cm-high S-beam type which resides below a 5-cm-diameter steel plate in the centerline of the holding container (Figure 4, c). The centerline pressure transducer is mounted in the center of the steel plate.

There are six piezoelectric pressure transducers, four on the base of the container and two on the sidewall. The pressure transducers are housed in PVC tubing filled with a plastic membrane to reduce vibration on the sensors (Figure $4, b$ ). The sensors are protected from fine particles by a 230-mesh screen.

A DynaVision SPR-02 Intelligent Single Point Sensor (670 nm visible light laser) detects motion of the surface of the sediment column as it flows from the cylinder into the container. The laser is focused on the center of the surface of the sediment column. The laser can accurately measure a surface located. $4064 \mathrm{~m}$ to $1.016 \mathrm{~m}$ from its viewing windows. The laser is not capable of accurately measuring material that is brown to black in color because of the similarity of the laser's beam color. Empirical experimentation showed that a white viewing surface produced the most accurate measurements, so a dampened white cloth was laid on the surface of the sediment column for each experiment. The cloth was dampened so that it would adhere to the surface and accurately track the flow.

\section{Calibration of Sensors}

This calibration procedure used static water columns, containing no sediment. The procedure was repeated for various column heights $(.381 \mathrm{~m}, .501 \mathrm{~m}, .605 \mathrm{~m}$, and $.674 \mathrm{~m})$. A minimum 
water-column height of $.05 \mathrm{~m}$ was required for accurate pressure sensor readings. The data acquisition system recorded the water flowing into the holding container until it came to rest. Given known water-column heights of calibration experiments, values of total stress (and total pore pressure) could be calculated from

$\sigma=\rho_{f} g h$

where $\rho_{f}$ is the density of water $\left(1,000 \mathrm{~kg} / \mathrm{m}^{3}\right), g$ is gravitational constant $\left(9.8 \mathrm{~m} / \mathrm{s}^{2}\right)$, and $h$ is the water column height measured from the base of the container to the surface of the water. Such calculated stress and pressure values were compared to measured counts, and conversions from digital counts (adu) directly to pressure and stress, were determined.

\section{Preparation of Sediment}

The first step in sediment preparation was to dry the sediment samples, either outdoors under the sun or in an oven. Large samples of sand and gravel were dried in the sun. Samples were then weighed using a spring scale and 5-gallon bucket. The dry sediment was added to a large industrial mixer and turned to break up dry clumps. Additional working with a shovel was necessary to disaggregate clumps in most cases. The water was then weighed using the same bucket and scale. As water was added to the sediment in the industrial mixer, additional shoveling was necessary to achieve uniformly saturated sediment.

Once mixing was complete, the saturated sediment was transferred from the mixer to the cylinder by bucket loads (usually three). Each bucket load of sediment mixture was weighed individually.

Sediment samples collected from the field were re-used and dried between experiments. The commercial sediment mixtures were available in large quantity and were not re-used. 


\section{Bulk Density and Water Content}

The bulk density for each of the sediment mixtures was measured by independently weighing the water and sediment prior to mixing. The water content is calculated using the measured bulk density and the following equation,

$v_{f}=\frac{\left(\rho_{s}-\rho_{b}\right)}{\left(\rho_{s}-\rho_{f}\right)}$

and,

$\rho_{b}=\rho_{f} v_{f}+\rho_{s} v_{s}$

where $\rho_{f}$ is the fluid density, $v_{f}$ is the fluid volume fraction, $\rho_{s}$ is the solid density, $v_{s}$ is the solid volume fraction. The fluid phase for the sediments is water with density $1,000 \mathrm{~kg} / \mathrm{m}^{3}$. The density of the solid phase ranged from 2,600 to $2,700 \mathrm{~kg} / \mathrm{m}^{3}$ for the sediments (Table 1).

\section{Procedure for Experiments}

To ensure consistency throughout of the all experiments a procedure was developed and is outlined below:

1) Each of the pressure transducers was connected with clear tubing filled with water to the experimental apparatus. The water-filled tubing showed whether fine particles penetrated the protective mesh. These tubes were inspected and cleaned between each experiment.

2) Sediment was thoroughly dried prior to use.

3) Sediment and water masses were independently weighed before mixing together.

4) Sediment mixture masses were weighed prior to filling the cylinder. 
5) Lifting of the cylinder was recorded on video and deposits photographed for supporting qualitative analysis. 


\section{Appendix B. Normalization and Dimensional Analysis}

To verify the units for each term and to check for correctness of the equation dimensional analysis is performed for each term. The fundamental equation is normalized by dividing all

terms by the characteristic stress, $\rho g H$, where $H$ is the initial height in meters of the sediment column for each experiment.

The fundamental equation,

$\sigma=\rho_{b} g h-S-\alpha \rho_{b} h \frac{\partial v_{t}}{\partial t}+\rho_{b} v_{t}^{2}\left(\alpha-\frac{1}{2}\right)$

Normalization and dimensional analysis,

$$
\sigma^{*} \rightarrow \frac{\sigma}{\rho_{b} g H}=\frac{\frac{(M)}{(L)(T)^{2}}}{\frac{(M)}{(L)(T)^{2}}}
$$

$$
h^{*} \rightarrow \frac{\rho_{b} g h}{\rho_{b} g H}=\frac{\frac{(M)}{(L)(T)^{2}}}{\frac{(M)}{(L)(T)^{2}}}
$$

$$
S^{*} \rightarrow \frac{\rho_{b} g h-\sigma}{\rho_{b} g H}=\frac{\frac{(M)}{(L)^{3}} \frac{(L)}{(T)^{2}} \frac{(L)}{1}-\frac{(M)}{(L)(T)^{2}}}{\frac{(M)}{(L)(T)^{2}}}=\frac{\frac{(M)}{(L)(T)^{2}}}{\frac{(M)}{(L)(T)^{2}}}
$$




$$
\begin{gathered}
\alpha \rho_{b} h^{*} \frac{\partial v_{t}^{*}}{\partial t} \rightarrow \frac{\alpha \rho_{b} h \frac{\partial v_{t}}{\partial t}}{\rho_{b} g H}=\frac{\left(\frac{(M)}{(L)^{3}}\right)\left(\frac{(L)}{1}\right)\left(\frac{(L)}{(T)^{2}}\right)}{\frac{(M)}{(L)(T)^{2}}}=\frac{\frac{(M)}{(L)(T)^{2}}}{\frac{(M)}{(L)(T)^{2}}} \\
\rho_{b} v_{t}^{* 2}\left(\alpha-\frac{1}{2}\right) \rightarrow \frac{\rho_{b} v_{t}^{2}\left(\alpha-\frac{1}{2}\right)}{\rho_{b} g H}=\frac{\frac{(M)}{(L)^{3}} \frac{(L)}{(T)} \frac{(L)}{(T)}}{\frac{(M)}{(L)(T)^{2}}}=\frac{\frac{(M)}{(L)(T)^{2}}}{\frac{(M)}{(L)(T)^{2}}}
\end{gathered}
$$

The resulting normalized equation is,

$$
\sigma^{*}=\rho_{b} g h^{*}-S^{*}-\alpha \rho_{b} h^{*} \frac{\partial v_{t}^{*}}{\partial t}+\rho_{b} v_{t}^{* 2}\left(\alpha-\frac{1}{2}\right) .
$$




\section{Appendix C. Matlab Code}

The mathematical computations and plotting were performed using Matlab. Programming $\mathrm{m}$-files to perform the tasks was the most efficient means to complete a considerable amount of plots in a consistent manner. The $\mathrm{m}$-file code is included here. There are two separate $\mathrm{m}$-files, one which contains known variables and defines annotations for plots and the other calls the first and then performs mathematical computations, plotting, file saving, and printing.

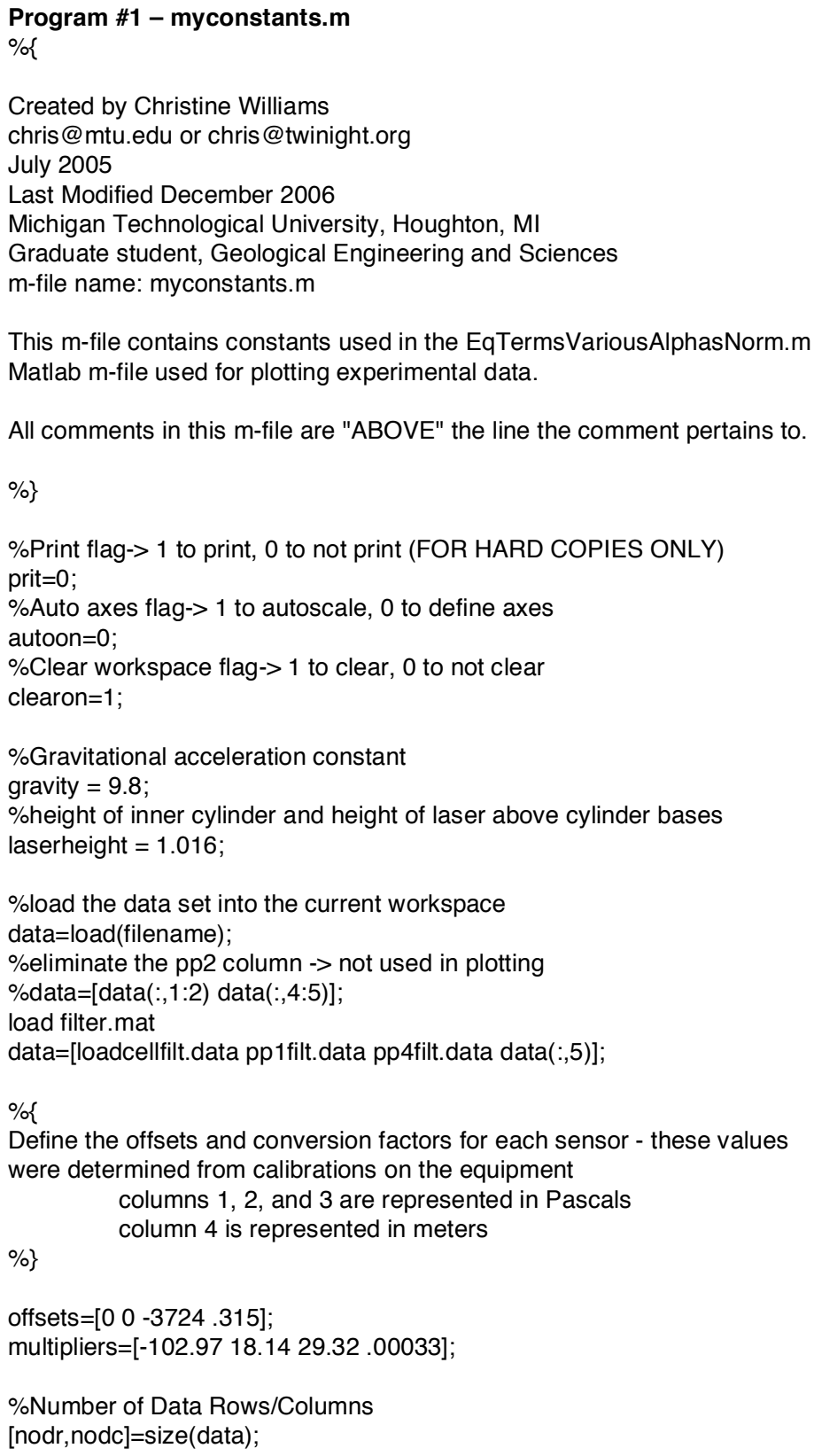


\%multiply data by multipliers

data $=$ data. ${ }^{*}$ (ones $([\text { nodr }, 1])^{*}$ multipliers);

$\%$ add the offsets to the data

data $=$ data $+\left(\right.$ ones $([\text { nodr }, 1])^{\star}$ offsets $)$;

\%calculate the changing sediment column height

sedheight=laserheight-data(:,4);

\%calculate the initial height read by the laser

initialheight=sedheight(1:1);

$\%$ Create the titles for plots, legends, and annotated text

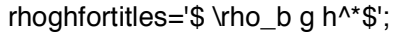

fluidrhoghfortitles='\$rho_f $\mathrm{g} \mathrm{h} \mathrm{h}^{\wedge} \$$

sigmacalc $=$ '\$lsigma ${ }^{\wedge *}{ }^{\star} \mathrm{c} \$$;

pp1calc $=' \$ p^{\wedge \star} \_c \$$;

sigmameasured $=' \$ \backslash$ sigma ${ }^{\wedge}{ }^{\star}-\mathrm{m} \$$;

pp1meastitle $=\$ p^{\wedge \star} \_m \$^{\prime}$;

counterweight='\$ldownarrow $\backslash \mathrm{cw} \$$ ';

collapse='\$ldownarrow $\backslash$ column $\backslash$ collapse $\$$;

effectivestresstitle $=$ ' $\$$ sigma $\backslash$ prime $=\backslash$ sigma $\_m^{\wedge *}-\backslash \backslash p \_m^{\wedge *} \$$;

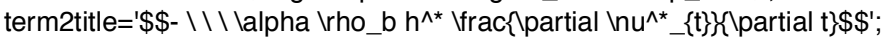

fluidterm2title='\$\$- $\backslash \backslash \backslash \backslash$ alpha $\backslash$ rho_f $h^{\wedge *} \backslash$ frac $\left\{\right.$ partial $\left.\backslash n u^{\wedge *}\{t\}\right\}$, Ypartial $\left.t\right\} \$ \$$;

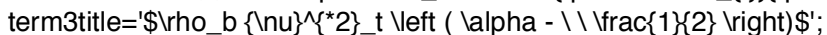

fluidterm3title='\$rho_f $\{$ nu $\} \backslash\left\{{ }^{*} 2\right\} \_t$ Veft ( Valpha - $\backslash \backslash$ Vfrac $\left.\{1\} 2\right\} \backslash$ vight) $\$$ ';

Ictitle='\$lsigma centerline $\$$ ';

pp1title='\$p\$';

pp4title='\$Sidewall Pore-fluid Pressure $\$$;

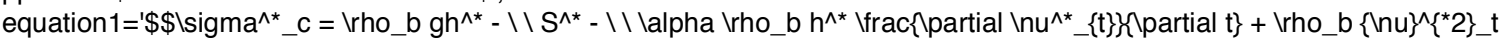

Veft( \alpha - \\ \frac $\{1\} 2\}$ \right)\$\$;

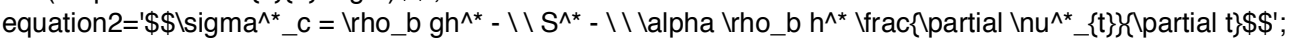

modelcomparison='\$Modell Comparison\Veft( Residuals Vight)\$';

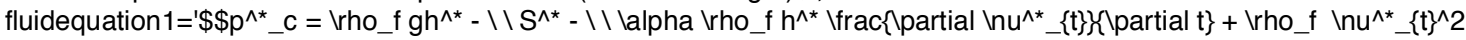

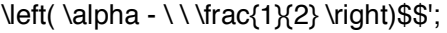

fluidequation2 $=\$ \$ \$ p^{\wedge \star} \_c=\backslash r h o \_f g h^{\wedge \star}-\backslash \backslash S^{\wedge \star}-\backslash \backslash$ lalpha $\backslash r h o \_f h^{\wedge \star} \backslash$ frac $\left\{\right.$ partial $\left.\backslash n u^{\wedge \star}\{t\}\right\} \backslash$ partial $\left.t\right\} \$ \$$

filttext='\$Blackline represents filtered data $\$$;

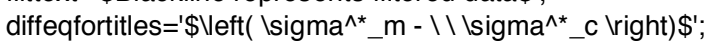

fluiddiffeqfortitles='\$Veft(

contracting='\$contracting $\$$ ';

dilating='\$dilating $\$$ ';

alphagreater='\$lalpha> $1 \$$

alphalesser='\$lalpha $<1 \$$;

$\%$ Convert initialheight value to a string with 2 significant digits

hint=num2str(initialheight,2);

$\%\{$

The following switch case is used to determine which set of constants are

defined depending upon which data set has been loaded.

The variables defined in this section are outlined below:

"density" is a calculated number, represents bulk density of sediment $(\mathrm{kg}) /\left(\mathrm{m}^{\wedge} 3\right)$

"fluiddensity" is the density of the fluid in the pore spaces of the sediment mass. It is set to $1200 \mathrm{~kg} / \mathrm{m}^{\wedge} 3$ for fines-rich seds and $1000 \mathrm{~kg} / \mathrm{m}^{\wedge} 3$ for fines-poor seds.

"ti" is the time interval, this is calculated from the sampling frequency and the number of channels, ie: $\mathrm{Fs}=2000 \mathrm{~Hz}$ and channels $=7$

then $7 / 2000=.0035 \mathrm{sec}$

"initialpressure" is the theoretical pressure if the sediment column is saturated and at equilibrium, $P=r h 0^{*} g^{*} h$

"measuredpressure" and "pp1measured" are the experimental values returned from the loadcell and the centerline pressure sensor for each experiment, 
but only the value at the very beginning and without any offsets applied

"pp4offset" is the offset value is the amount needed to add to the sensor to force a start at $0 \mathrm{~Pa}$

"wc" this is the water content for each experiment, percentage of total material in the sediment column

"plottitle" is the string given to each plot

"impact" is the value in seconds on the $x$ axis when the sediment column impacts the sidewall of the outer cylinder

"myalpha" are values for fits of the theoretical equation with varying values of alpha set.

"lifttime" is the time at which the cylinder is lifted.

"freetime" is the amount of time it takes for the sediment to evacuate the cylinder.

"collapsetime" is the amount of time it takes the sediment column to completely collapse and come to rest in the holding container.

"fluidalphas" are the values of alpha when solving the equation for pore pressure and not total stress.

"fluidplottitle" is the title used when solving for pore-fluid pressure.

$\%\}$

switch(shortfilename)

case 'dod_sat_liftonly'

density=1876;

measuredpressure $=14500$;

$\mathrm{ti}=.0035$;

plottitle=['Dodson $\$ \backslash r h o \_b=1876 \backslash$ frac $\left.\{\mathrm{kg}\} \mathrm{m}^{\wedge} 3\right\}, \mathrm{h} \_\mathrm{i}=$ ',hint,' $\mathrm{m}, \mathrm{wc}=47 \mathrm{\backslash} \% \$$ '];

fluidplottitle=['Dodson $\$ \backslash$ rho_f $=1200 \backslash$ frac $\left\{\mathrm{kg}_{\left\{\mathrm{m}^{\wedge} 3\right\}}\right\}$, h_i = ',hint,'m, wc = $471 \% \$$ '];

pp1 measured $=8620$;

pp4offset=2924;

impact $=1.101$;

fluiddensity $=1200$;

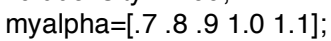

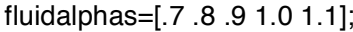

lifttime $=.339$; collapsetime $=.725$; ;reetime $=.784$;

case 'osc_sat_liftonly'

density=1943;

measuredpressure $=13700$;

$\mathrm{ti}=.0035$;

plottitle=['Osceola \$irho_b = $1943 \backslash$ frac $\left.\{k g\} \mathrm{m}^{\wedge} 3\right\}$, h_i = ',hint,' $\mathrm{m}, \mathrm{wc}=43 \backslash \% \$$ '];

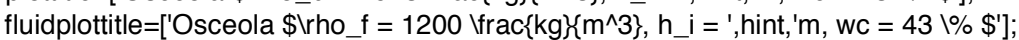

pp1 measured $=7710$;

pp4offset=3699;

impact $=.6589$;

fluiddensity $=1200$;

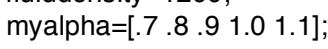

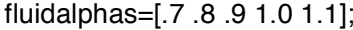

lifttime $=.353$; collapsetime $=.402$; freetime $=.427$;

case 'sgl_sat_liftonly'

density=2000;

measuredpressure $=12800$;

$\mathrm{ti}=.0035$;

plottitle=['Sand-Gravel-Loam Mix \$rho_b = $2000 \backslash$ frac $\left.\{\mathrm{kg}\} \mathrm{m}^{\wedge} 3\right\}, \mathrm{h} \_\mathrm{i}=$ ',hint,'m, wc = $39 \backslash \%$ \$'];

fluidplottitle=['Sand-Gravel-Loam Mix $\$ \backslash$ rho_f $=1000 \backslash$ frac $\left\{\mathrm{kg}_{\Omega}\left\{\mathrm{m}^{\wedge} 3\right\}, \mathrm{h} \_\mathrm{i}=\right.$ ',hint,'m, wc $=39 \mathrm{l} \%$ \$'];

pp1 measured $=6600$;

pp4offset=3800;

impact $=.8698$; 


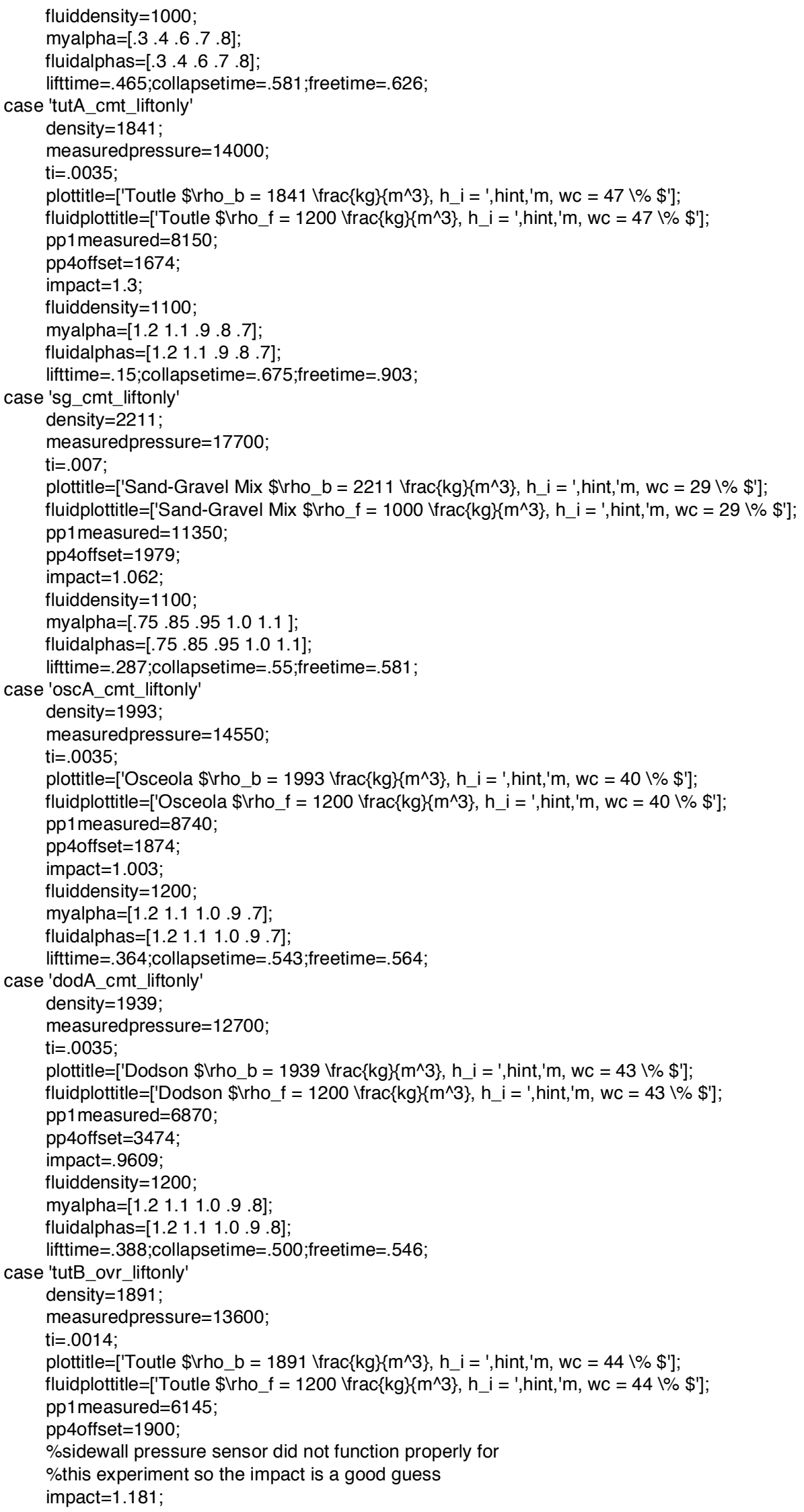




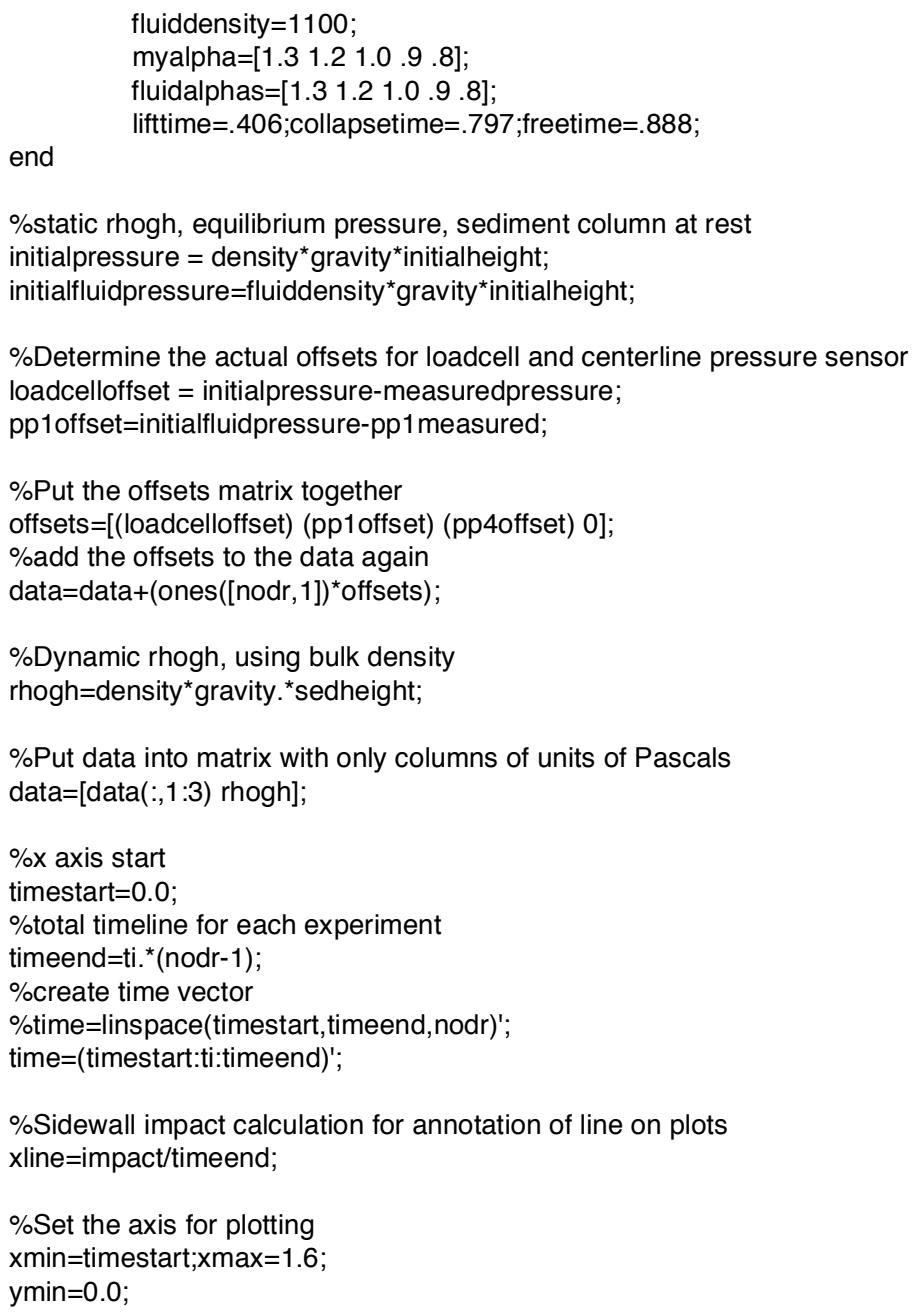

\section{Program \#2 - EqTermsVariousAlphasNorm.m}

$\%\{$

Created by Christine Williams

chris@mtu.edu or chris@twinight.org

Written July 2005

Last Modified December 2006

Michigan Technological University, Houghton, MI

Graduate student, Geological Engineering and Sciences

m-file name: EqTermsVariousAlphasNorm.m

Plot result: subplot of 5 plots

This $\mathrm{m}$-file is used to express the following:

a) Plot the simple hydrostatic pressure and the measured bed-normal stress.

b) Plot plot (a) above as well as plot each of the terms of the model equation individually on one plot setting alpha equal to 1 .

c) Plot plot (a) above as well as the model equation using various alpha values.

d) Plot plot (a) above as well as the measured bed-normal stress and measured pore-fluid pressure and calculated effective stress.

e) Plot the differences of the model equations with the various alpha values against the measured bed-normal stress.

All comments in this m-file are "ABOVE" the line the comment pertains to. 
The data represented by this $\mathrm{m}$-file is of the lift portion of the experiments and not the entire experiments duration.

$\%\}$

$\%$ GUI to select the file to read in and load

[filename, pathname] = uigetfile('*. asc', 'File to load');

\%filename no extention

shortfilename=filename( 1 :length(filename)-4);

$\%$ read in the $\mathrm{m}$-file that contains all the constants

myconstants

clc;

loadcell=data(:,1);

pressure $1=$ data $(:, 2)$;

$\%$ set the value of alpha

unison $=1$;

\%calculate the value of (S)

CalcS=rhogh-loadcell;

CalcS=[time CalcS];

for $i=1$ :nodr;

if $($ CalcS $(\mathrm{i},:)<$ lifttime) I (CalcS $(\mathrm{i},:)>$ freetime)

end

CalcS $(i,:)=0$;

end

CalcS=CalcS(:,2);

CalcS=mean(CalcS);

\%Normalize for comparison purposes

norm $=$ density ${ }^{*}$ gravity ${ }^{*}$ initialheight;

loadcell=loadcell./norm;

pressure $1=$ pressure $1 . /$ norm;

effectivestress=loadcell-pressure1;

rhogh=rhogh./norm;

CalcS $=$ CalcS $/$ norm;

\%Convert the values of $\mathrm{S}$ and alpha to strings

Stext=num2str(CalcS,3);

unisontext=num2str(unison,1);

$\%\{$

Smooth laser data using SmoothingSpline and take 1st and 2nd derivatives

of the result using the central difference method

$\%\}$

[fresult,gof,ouput]=fit(time,sedheight,'smoothingspline','SmoothingParam',0.9995);

[deriv1, deriv2]=differentiate(fresult,time);

$\%$ Positive direction defined as up, so vel and acc are negative

vel=-deriv1;

acc=-deriv2;

sedheight=feval(fresult,time);

\%Define the terms of the theoretical equation

term1 $=\left(\left(\right.\right.$ density ${ }^{*}$ gravity $) .{ }^{*}$ sedheight $) . /$ norm;

term2 $=\left(\left(\left(\right.\right.\right.$ unison ${ }^{*}$ density $) .{ }^{*}$ sedheight $) .{ }^{*}$ acc $) . /$ norm;

term3 $=\left(\left((\text { unison- }(1 / 2))^{*}\right.\right.$ density $) .{ }^{*}\left(\right.$ vel. $\left.\left.^{\wedge} 2\right)\right) . /$ norm;

$\%$ Put the equation together

sigma1=term1-CalcS-term2+term3;

\%Prepare the raw data for plotting against the calculated data

totalload=loadcell;

\%Plot the calculated and raw data for comparison

figure(1)

grid off

subplot $(5,1,1)$

ymin $=0 ; y \max =1.5$;

$\mathrm{y} 1=[$ term 1 totalload];

plot1 $=$ plot(time,y1); 
title([plottitle],'fontsize',12,'Interpreter','latex');

set(plot1(1),'Color',[[0 0 0]);'set(plot1(2),'Color',[.439 .877 .870]);

legend1=legend(\{rhoghfortitles,sigmameasured $\}, ' L o c a t i o n ', \ldots$

'southoutside','Fontname','helvetica','fontsize',8,'Orientation',...

'horizontal','Interpreter','latex');

axis([xmin xmax ymin ymax]);

text(lifttime, 1.2,\{counterweight\},'fontsize',8,'Interpreter','latex');

text(collapsetime, 1.2,\{collapse\},'fontsize',8,'Interpreter','latex');

grid off

subplot $(5,1,2)$

y2=[term2 term3 sigma1 term1 totalload];

plot2=plot(time,y2);

\%ylabel('Normalized Stress');

set(plot2(1),'Color',[1 .650 .029]);set(plot2(2),'Color',[1 .329 .121]);,..

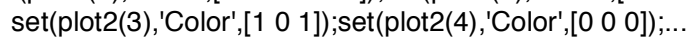

set(plot2(5),'Color',[.439.877.870]);

legend2=legend(\{term2title,term3title,...

sigmacalc\},'Location',...

'southoutside','Fontname','helvetica','fontsize', $8, \ldots$

'Orientation','horizontal','Interpreter','latex');

axis([xmin xmax ymin ymax]);

set(gca,'ylim',,[-.5 1.5]);

text $\left(.05, .4,\left\{\left[\right.\right.\right.$ '\$lalpha $=\$$ ', unisontext, '\$ $\backslash$ and $\backslash S^{\wedge \star}=\backslash \$$, Stext $]$, 'fontsize', $8, \ldots$

'Interpreter','latex');

$\%\{$

Define additional terms in the equation for plotting multiple

alpha values, loop for each alpha value and calculate the root mean square error between the model and the measured total load with and without the momentum term (term3).

$\%$

[nodr, nodc] $=$ size (totalload);

for $l i=1: 5$;

term2 $=\left(\left(\left(\right.\right.\right.$ myalpha(:,li) ${ }^{\star}$ density).${ }^{*}$ sedheight $) .{ }^{*}$ acc $) . /$ norm;

term3 $=\left(((\text { myalpha(:,li) })(1 / 2))^{\star}\right.$ density $) .{ }^{*}\left(\right.$ vel. $\left.\left.{ }^{\wedge} 2\right)\right) . /$ norm;

sigma1=term1-CalcS-term2+term3;

myalphatext=num2str(myalpha(:,li),3);

switch li

case 1

sigmabed $1=$ sigma 1 ;

myalphatex $1=$ myalphatext;

squareerr $=($ totalload-sigmabed 1$) .{ }^{\wedge} 2$;

sumerr=sum(squareerr);

MSE1=sumerr/nodr;

MSEtext1=num2str(MSE1,3);

case 2

sigmabed2=sigma1;

myalphatext2=myalphatext;

squareerr $=$ (totalload-sigmabed2). ${ }^{\wedge} 2$;

sumerr=sum(squareerr);

MSE2=sumerr/nodr;

MSEtext2=num2str(MSE2,3);

case 3

sigmabed3=sigma1;

myalphatext3=myalphatext;

squareerr=(totalload-sigmabed 3$). \wedge 2$;

sumerr=sum(squareerr);

MSE3=sumerr/nodr;

MSEtext3=num2str(MSE3,3);

case 4

sigmabed4=sigma1;

myalphatext4=myalphatext;

squareerr $=($ totalload-sigmabed 4$) . \wedge$;

sumerr=sum(squareerr);

MSE4=sumerr/nodr; 


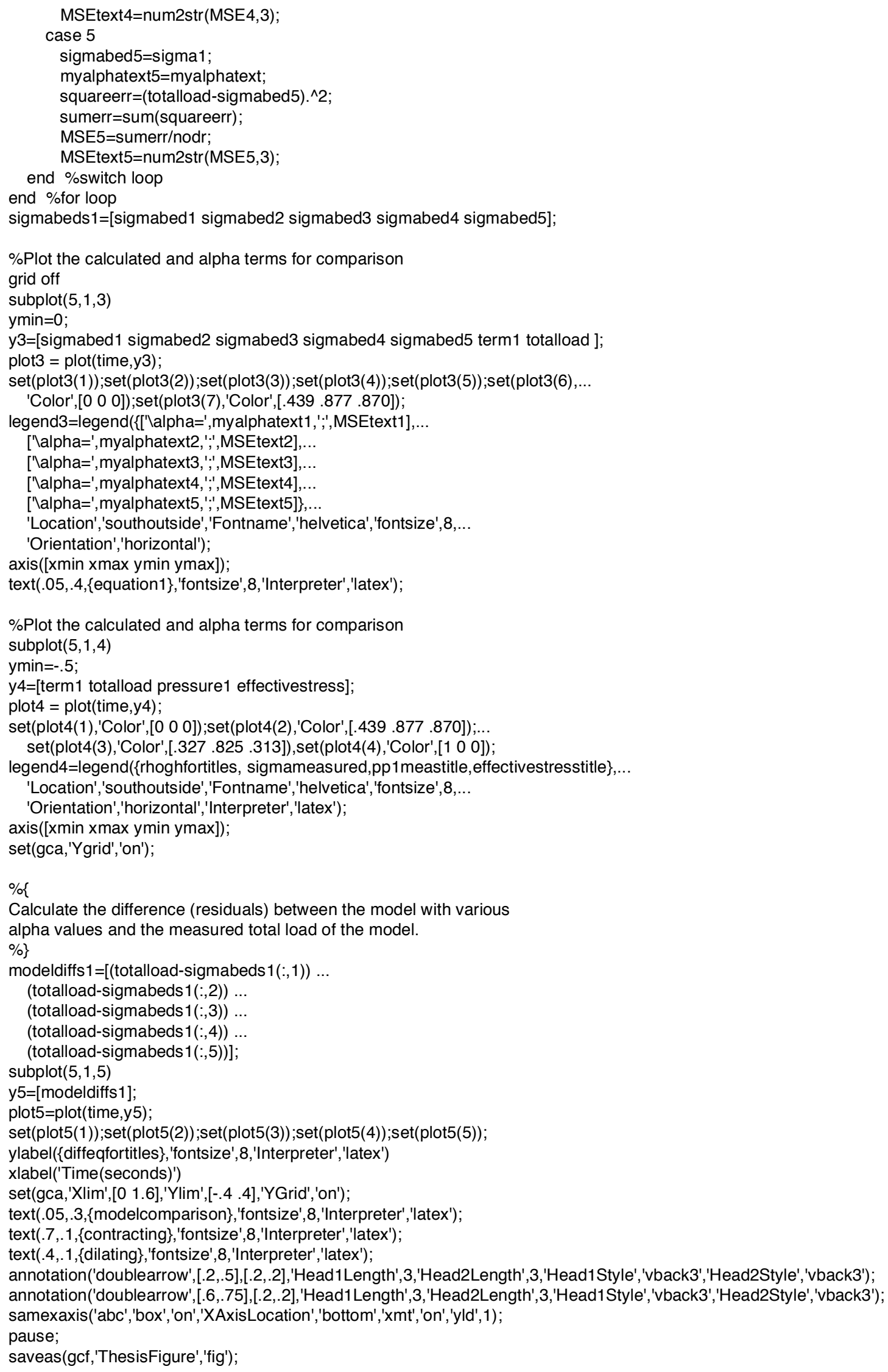




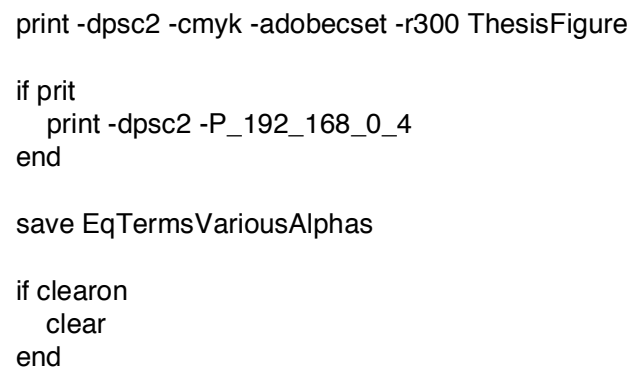




\section{Appendix D. Estimating Derivatives}

Matlab is used to estimate $1^{\text {st }}$ and $2^{\text {nd }}$ derivatives. The first derivative is calculated using the central difference quotient defined as

$y^{\prime}=\frac{y_{x+h}-y_{x-h}}{2 h}$,

where $x$ is the predictor value at which the derivative is calculated, $h$ is a small number, $y_{x+h}$ is fresult evaluated at $x+h$, and $y_{x-h}$ is fresult evaluated at $x-h$, and fresult is a fit result object in Matlab. The second derivative is calculated using the expression

$y^{\prime \prime}=\frac{y_{x+h}+y_{x-h}-2 y_{x}}{h^{2}}$. 


\section{Appendix E. Calculating the Mean Square Error (MSE)}

The mean square error is used to gauge the fit between measured bed-normal stress and calculated bed-normal stress. The MSE is calculated according to the following equation,

$M S E=\frac{\sum_{i=1}^{n}\left(\sigma_{m}-\sigma_{c}\right)^{2}}{n}$,

where $n$ represents the number of data points during a given time interval, $\sigma_{m}$ is the measured bed-normal stress and $\sigma_{c}$ the calculated bed-normal stress at each interval, $n$. 


\section{Appendix F. Velocity and Acceleration Plots}
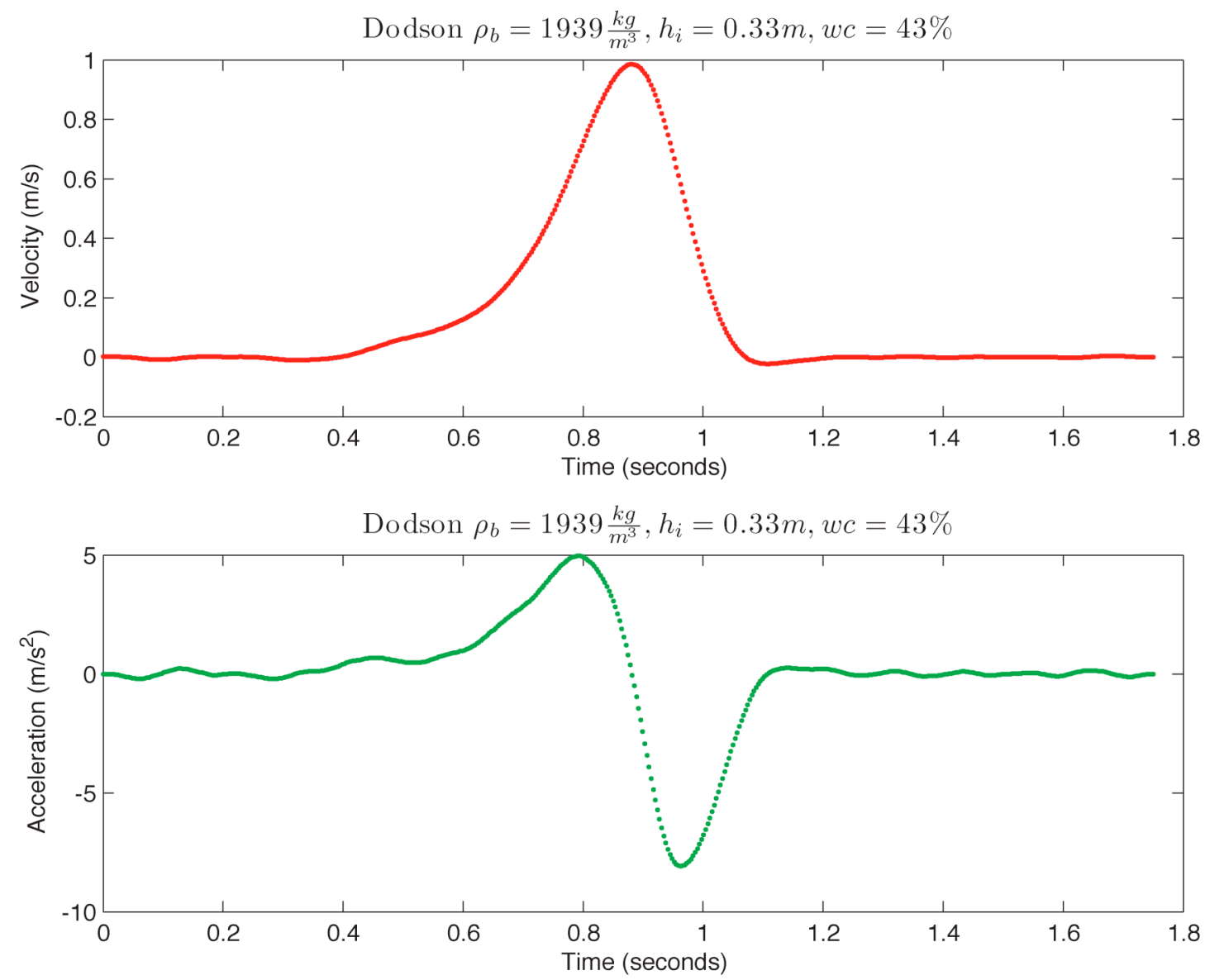

Figure 26: Experiment \#1 - Dodson debris flow, Dodson, Oregon, Columbia River Gorge, 1997.

The sediment mixture has a water content of $43 \%$, initial column height of $.33 \mathrm{~m}$, and bulk density of $1939 \mathrm{~kg} / \mathrm{m}^{3}$. 

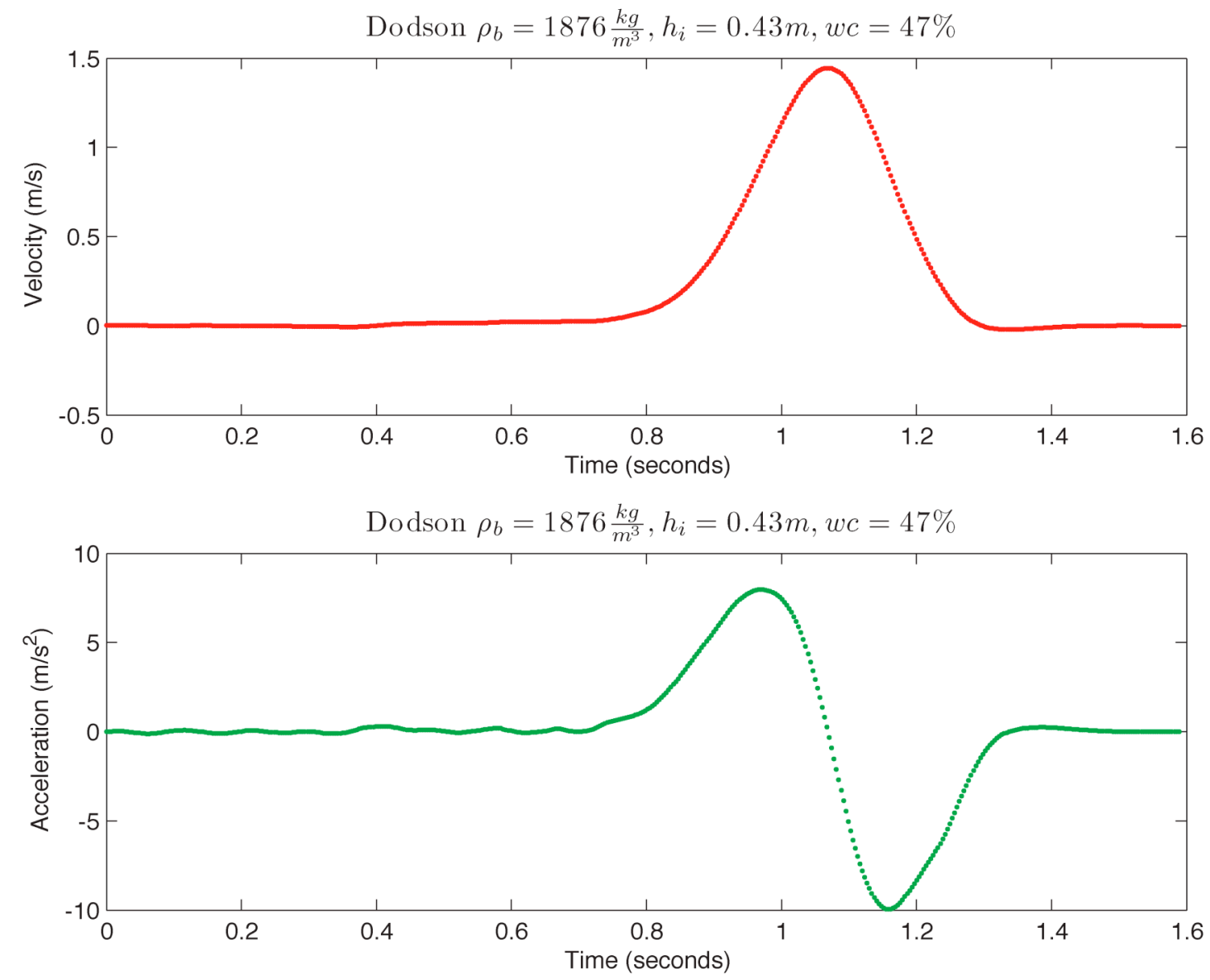

Figure 27: Experiment \#2 - Dodson debris flow, Dodson, Oregon, Columbia River Gorge, 1997. The sediment mixture has a water content of $47 \%$, initial column height of $.43 \mathrm{~m}$, and bulk density of $1876 \mathrm{~kg} / \mathrm{m}^{3}$. 

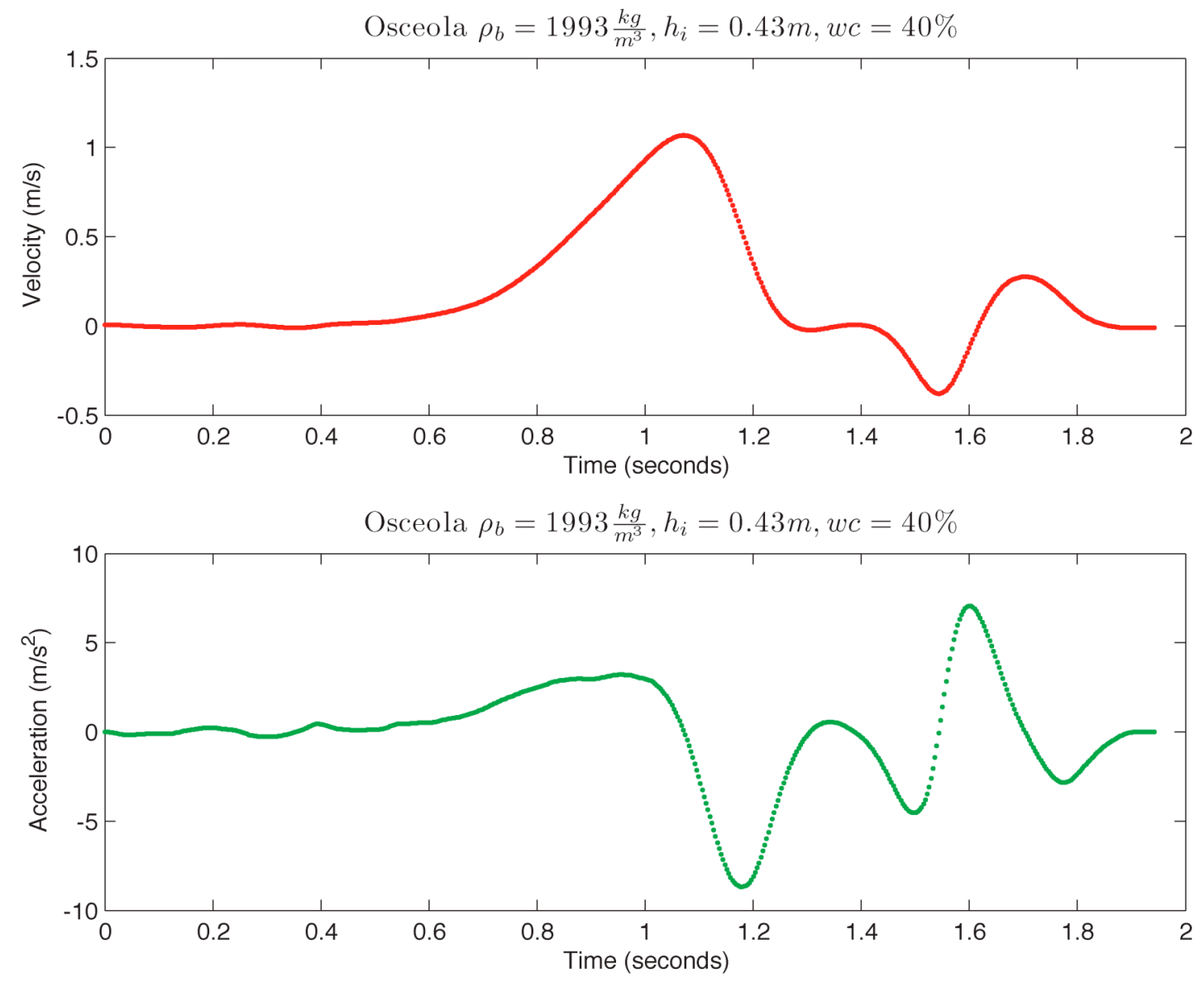

Figure 28: Experiment \#1 - Osceola mudflow, Mt. Rainier, WA, 5600 years ago. The sediment mixture has a water content of $40 \%$, initial column height of $.43 \mathrm{~m}$, and bulk density of 1993 $\mathrm{kg} / \mathrm{m}^{3}$. 


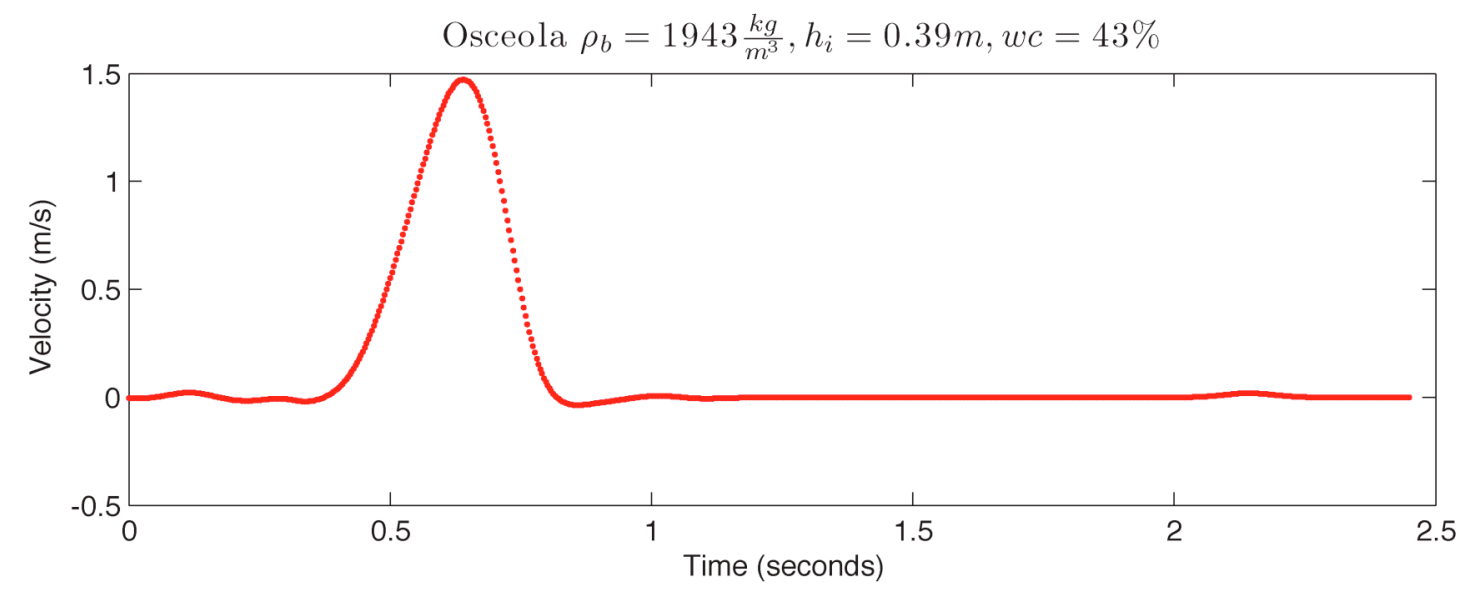

Osceola $\rho_{b}=1943 \frac{\mathrm{kg}}{\mathrm{m}^{3}}, h_{i}=0.39 \mathrm{~m}, w c=43 \%$

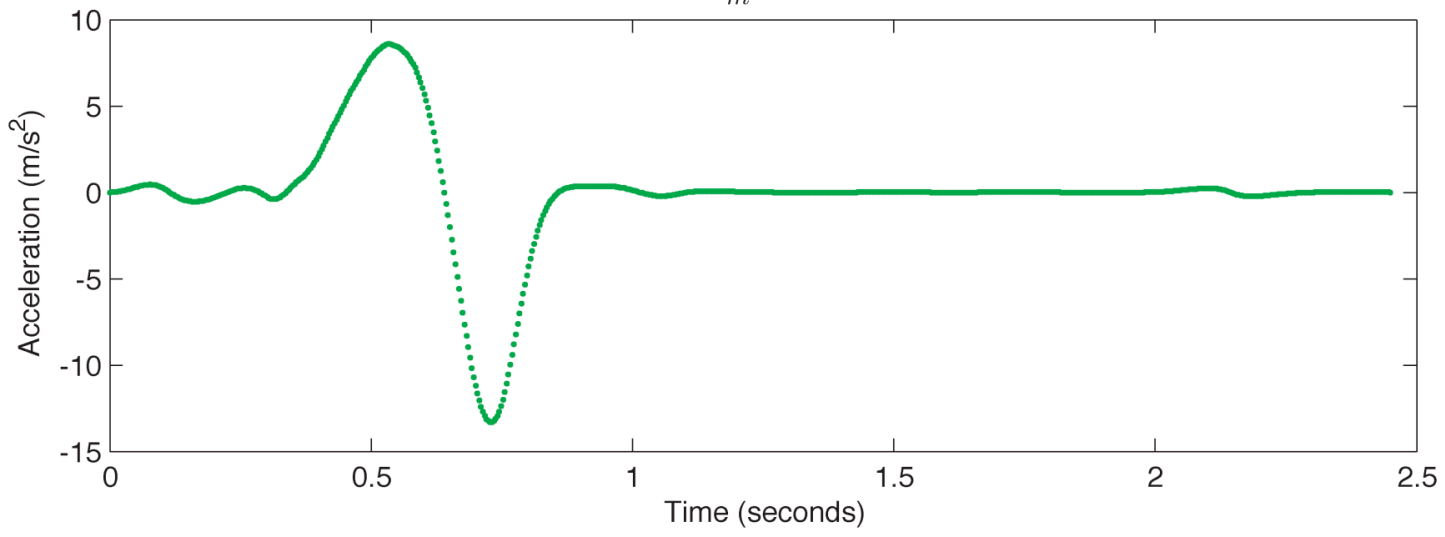

Figure 29: Experiment \#2 - Osceola mudflow, Mt. Rainier, WA, 5600 years ago. The sediment mixture has a water content of $43 \%$, initial column height of $.39 \mathrm{~m}$, and bulk density of 1943 $\mathrm{kg} / \mathrm{m}^{3}$. 
Toutle $\rho_{b}=1891 \frac{\mathrm{kg}}{\mathrm{m}^{3}}, h_{i}=0.37 \mathrm{~m}, w c=44 \%$

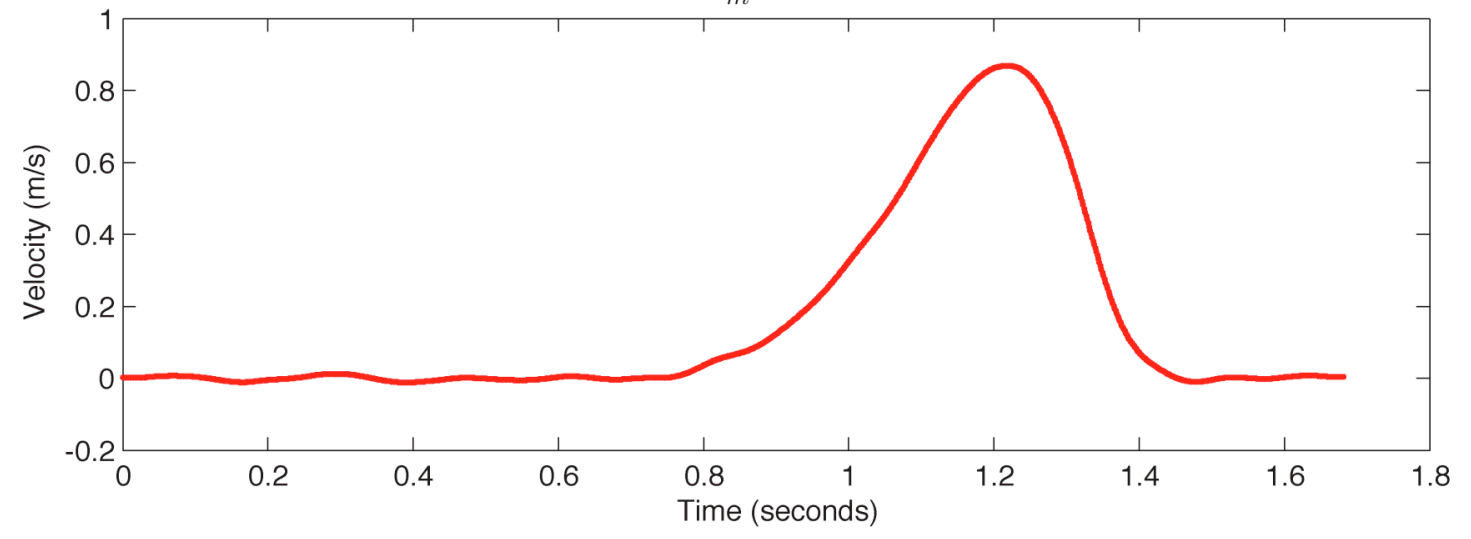

Toutle $\rho_{b}=1891 \frac{\mathrm{kg}}{\mathrm{m}^{3}}, h_{i}=0.37 \mathrm{~m}, w c=44 \%$

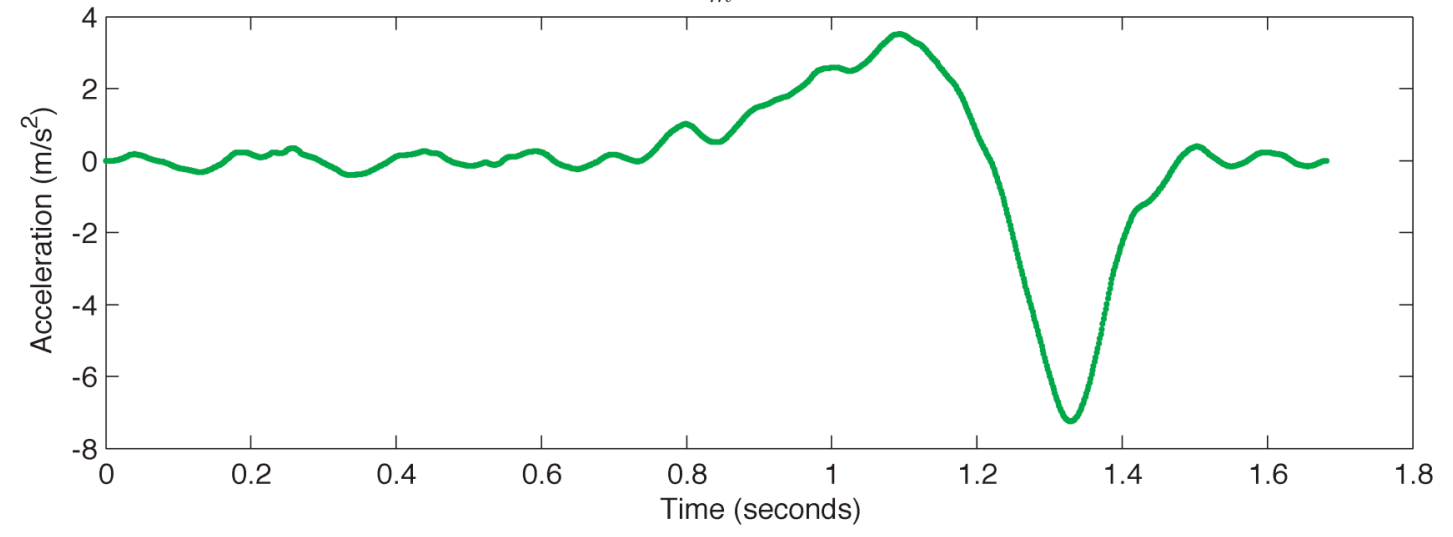

Figure 30: Experiment \#1 - North Fork Toutle River mudflow, Mount St. Helens, WA, 1980. The sediment mixture has a water content of $44 \%$, initial column height of $.37 \mathrm{~m}$, and bulk density of $1891 \mathrm{~kg} / \mathrm{m}^{3}$. 
Toutle $\rho_{b}=1841 \frac{\mathrm{kg}}{\mathrm{m}^{3}}, h_{i}=0.4 \mathrm{~m}, w c=47 \%$

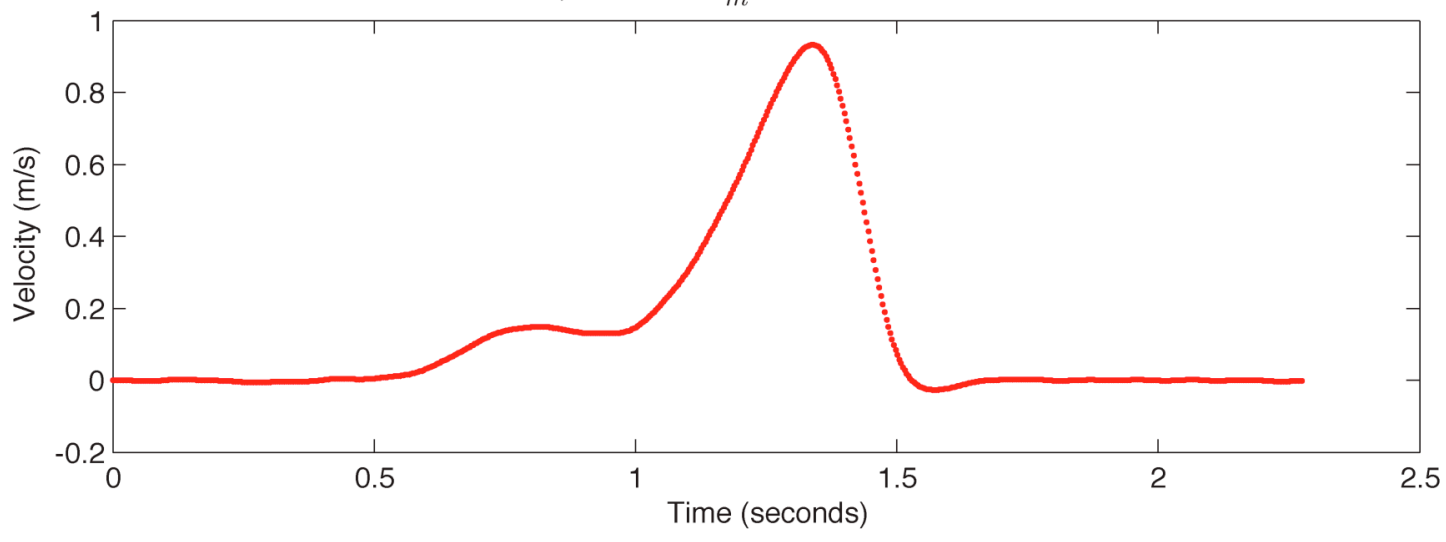

Toutle $\rho_{b}=1841 \frac{\mathrm{kg}}{\mathrm{m}^{3}}, h_{i}=0.4 \mathrm{~m}, w c=47 \%$

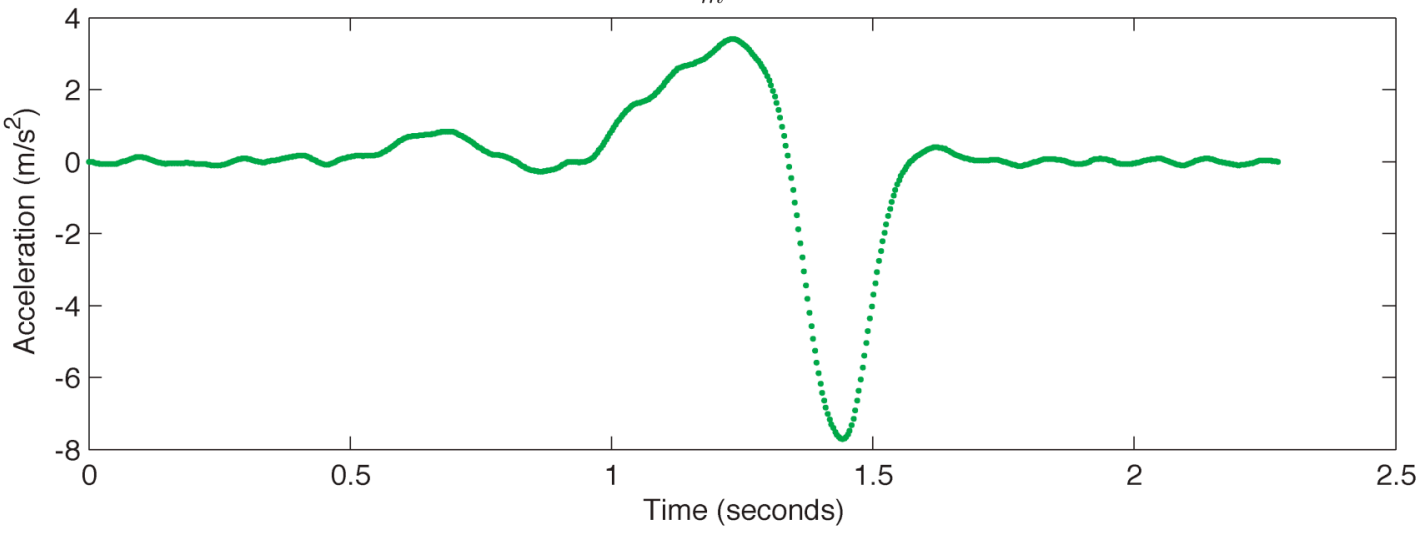

Figure 31: Experiment \#2 - North Fork Toutle River mudflow, Mount St. Helens, WA, 1980. The sediment mixture has a water content of $47 \%$, initial column height of $.40 \mathrm{~m}$, and bulk density of $1841 \mathrm{~kg} / \mathrm{m}^{3}$. 
Sand-Gravel Mix $\rho_{b}=2211 \frac{\mathrm{kg}}{\mathrm{m}^{3}}, h_{i}=0.58 \mathrm{~m}, w c=29 \%$

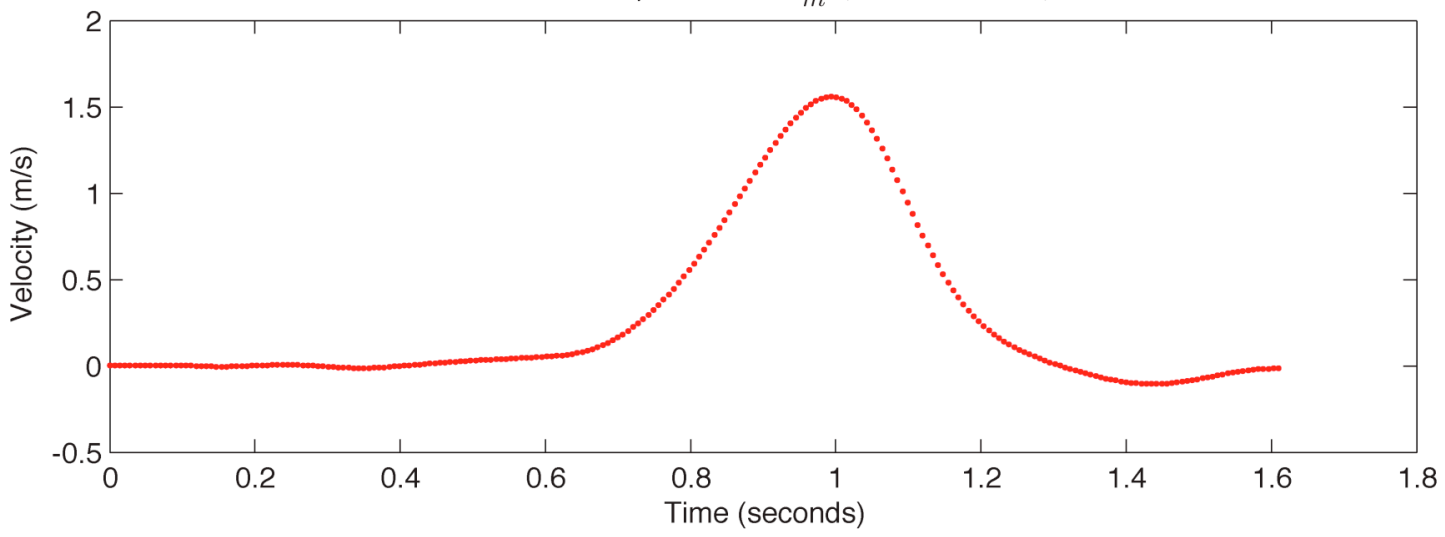

Sand-Gravel Mix $\rho_{b}=2211 \frac{\mathrm{kg}}{\mathrm{m}^{3}}, h_{i}=0.58 \mathrm{~m}, w c=29 \%$

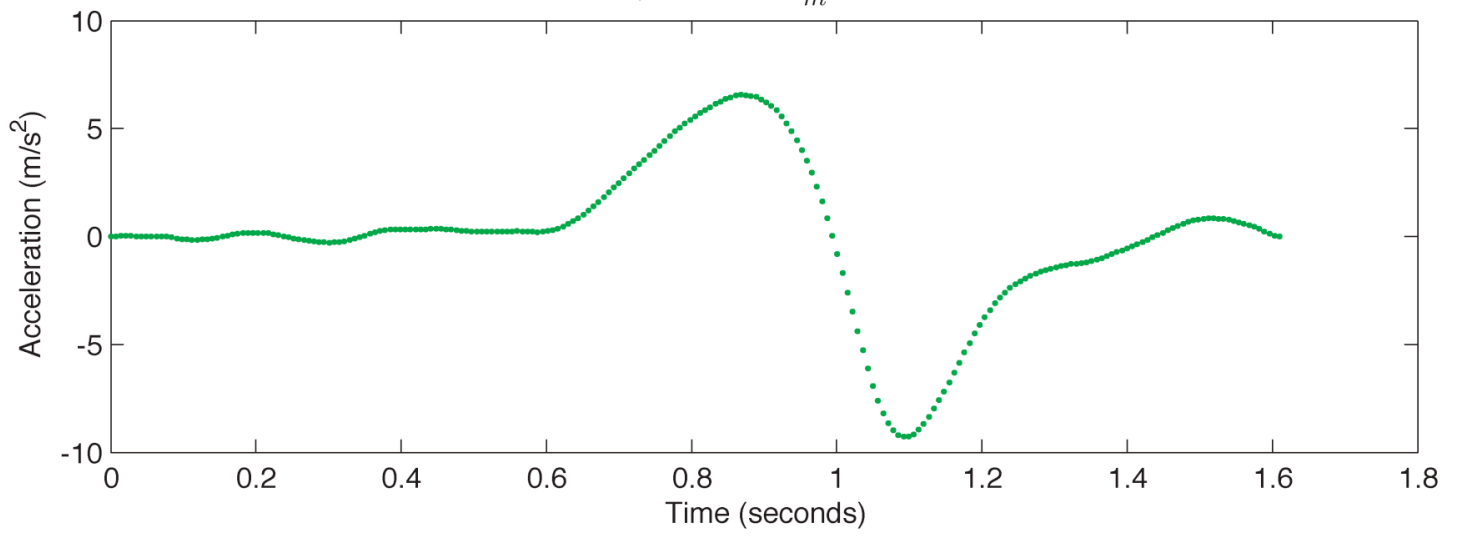

Figure 32: Experiment \#1 - Commercial sand and gravel mixture. The sediment mixture has a water content of $29 \%$, initial column height of $.58 \mathrm{~m}$, and bulk density of $2211 \mathrm{~kg} / \mathrm{m}^{3}$. 

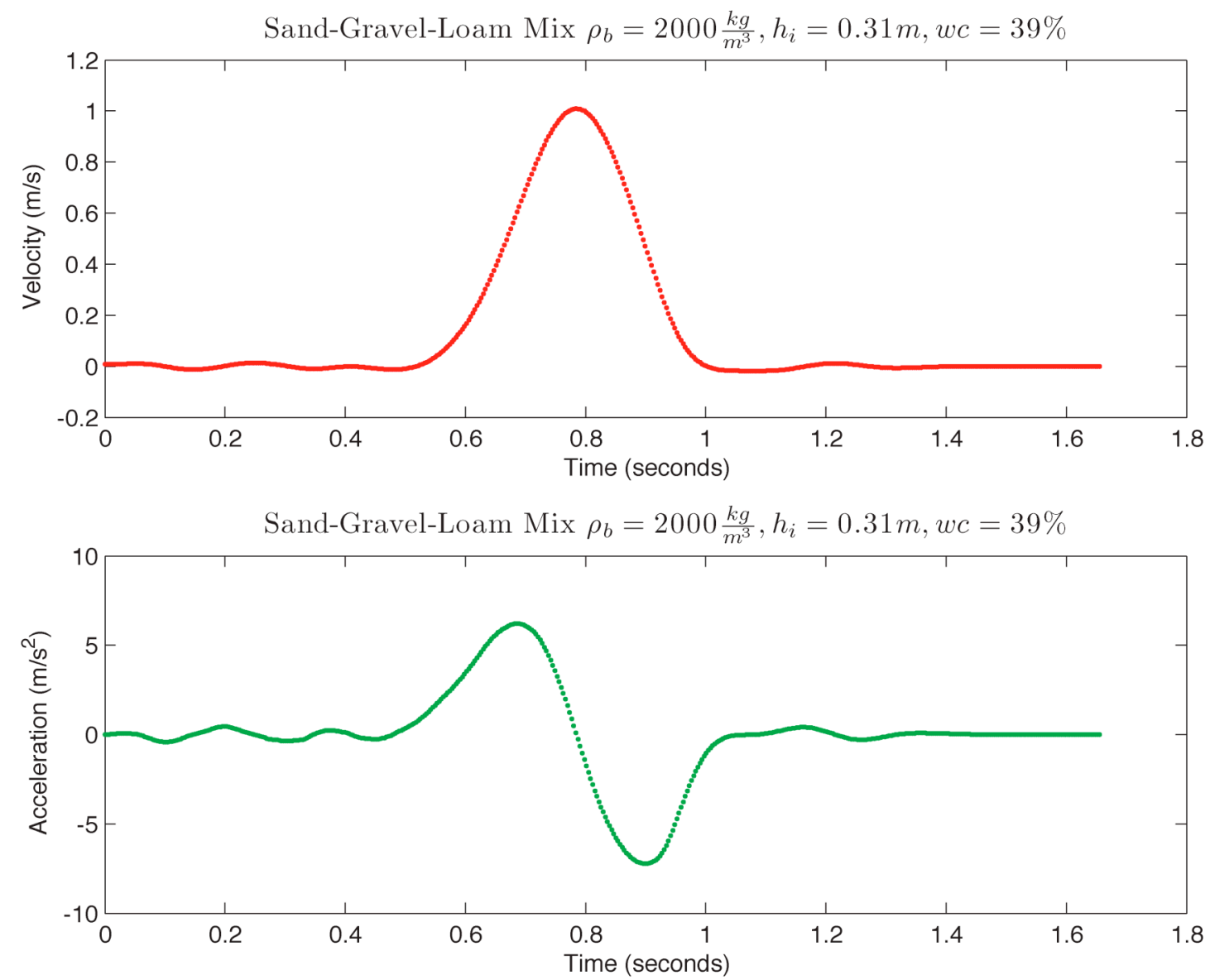

Figure 33: Experiment \#1 - Commercial sand, gravel, and loam mixture. The sediment mixture has a water content of $39 \%$, initial column height of $.31 \mathrm{~m}$, and bulk density of $2000 \mathrm{~kg} / \mathrm{m}^{3}$. 


\section{Appendix G. Plots of Raw Data}

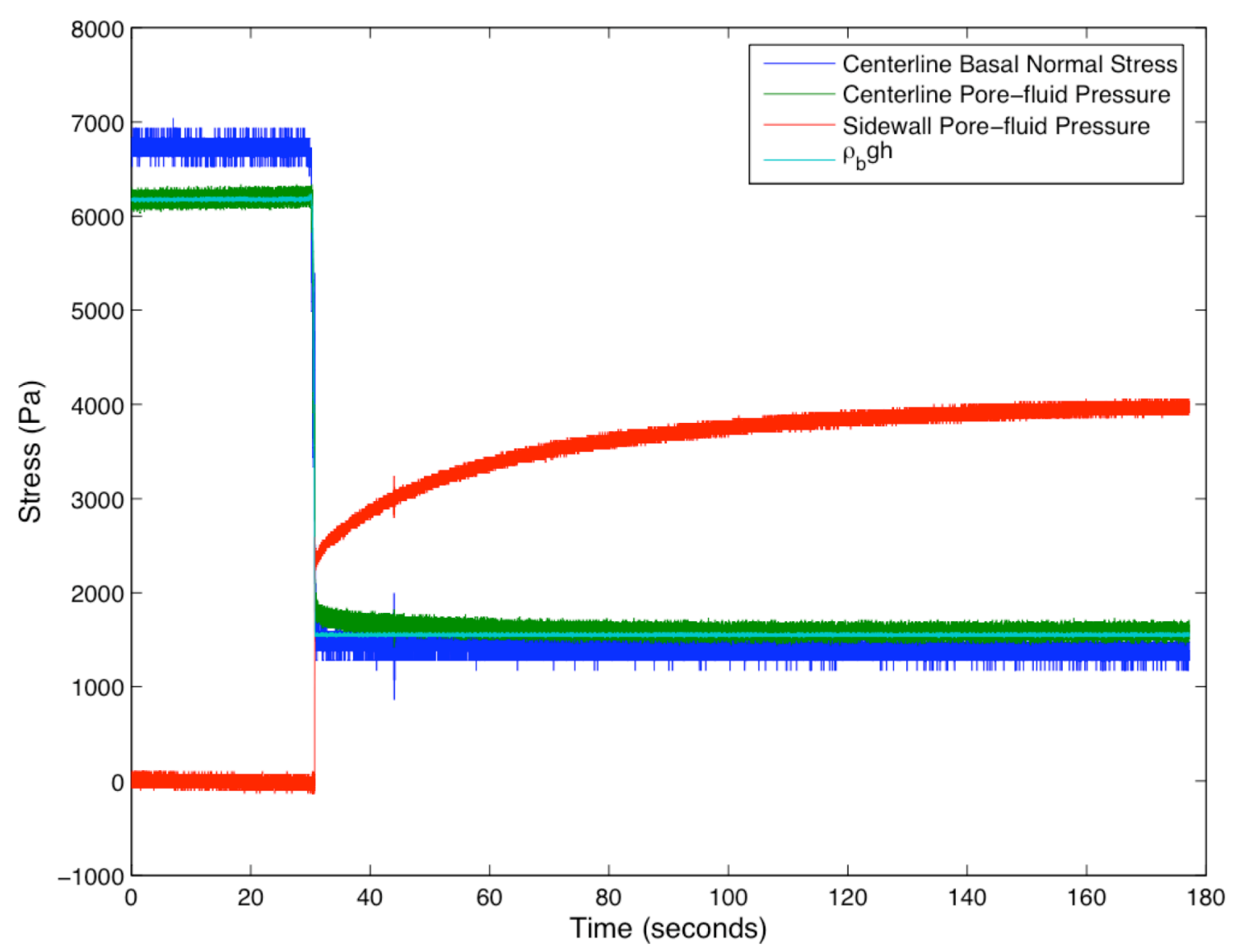

Figure 34: Dodson debris flow, Dodson, Oregon, Columbia River Gorge, 1997. The sediment mixture has a water content of $43 \%$, initial column height of $.33 \mathrm{~m}$, and bulk density of 1939 $\mathrm{kg} / \mathrm{m}^{3}$. The plot shows all sensors for the duration of the run. 


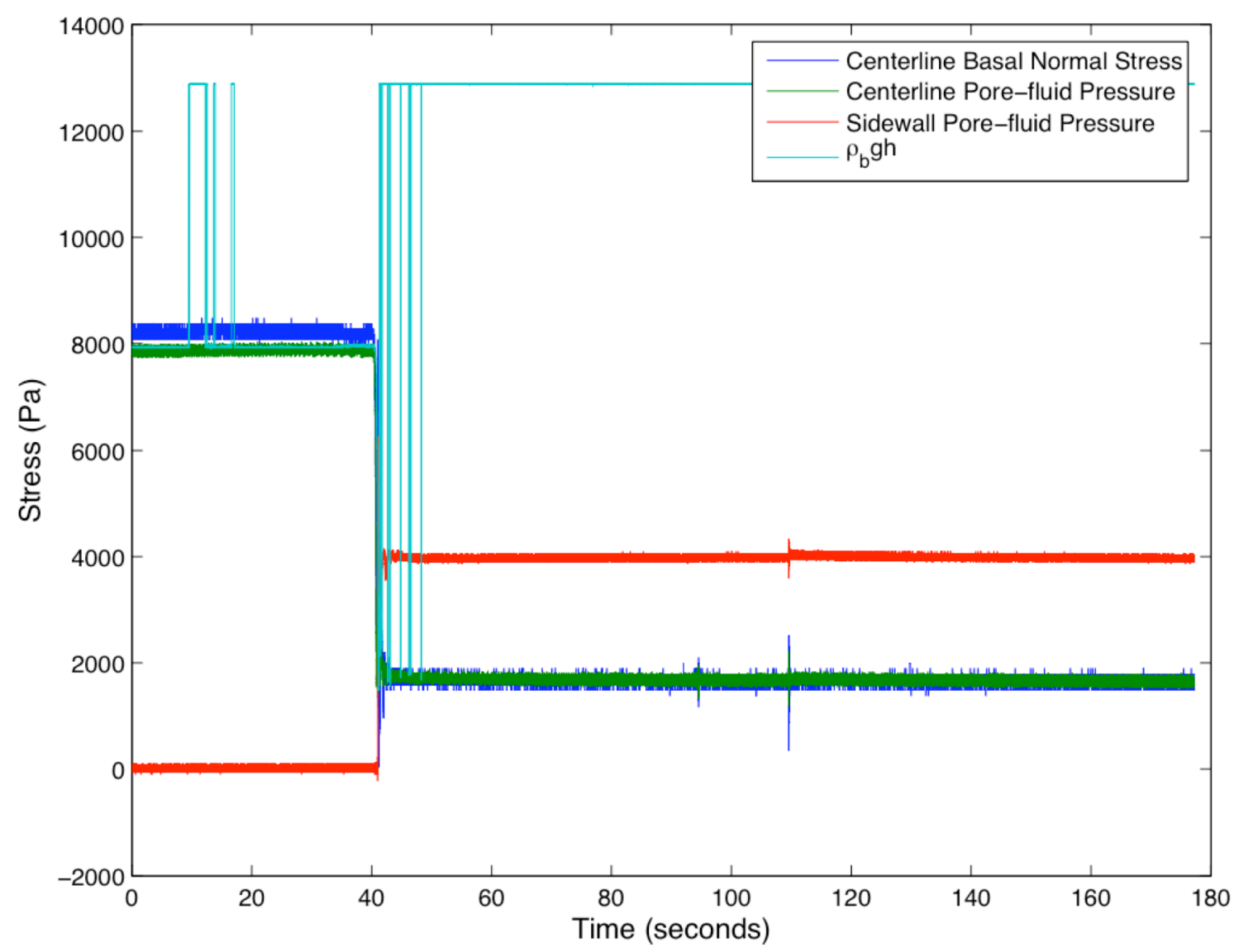

Figure 35: Dodson debris flow, Dodson, Oregon, Columbia River Gorge, 1997. The sediment mixture has a water content of $47 \%$, initial column height of $.43 \mathrm{~m}$, and bulk density of 1876 $\mathrm{kg} / \mathrm{m}^{3}$. The plot shows all sensors for the duration of the run. 


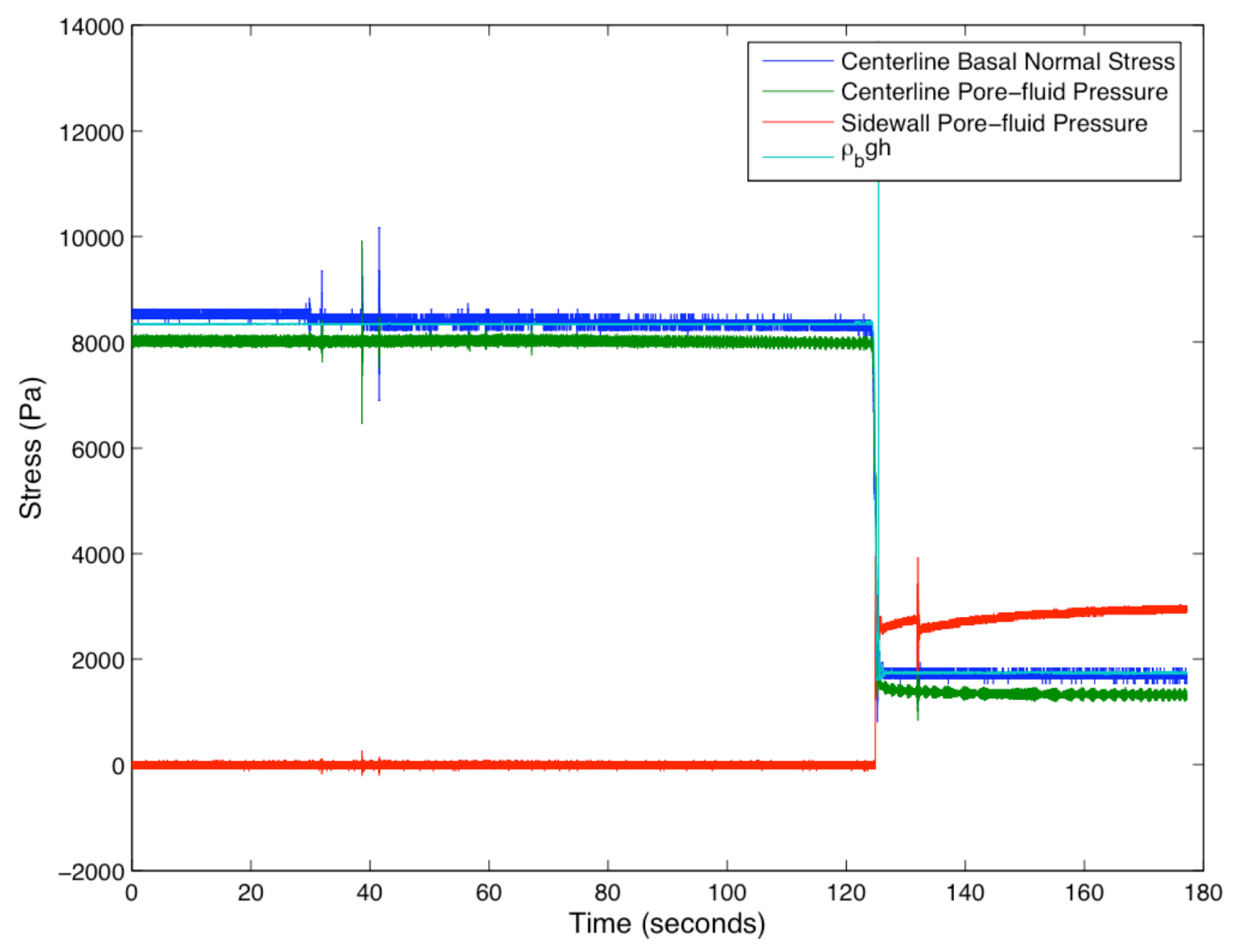

Figure 36: Osceola mudflow, Mt. Rainier, WA, 5600 years ago. The sediment mixture has a water content of $40 \%$, initial column height of $.43 \mathrm{~m}$, and bulk density of $1993 \mathrm{~kg} / \mathrm{m}^{3}$. The plot shows all sensors for the duration of the run. 


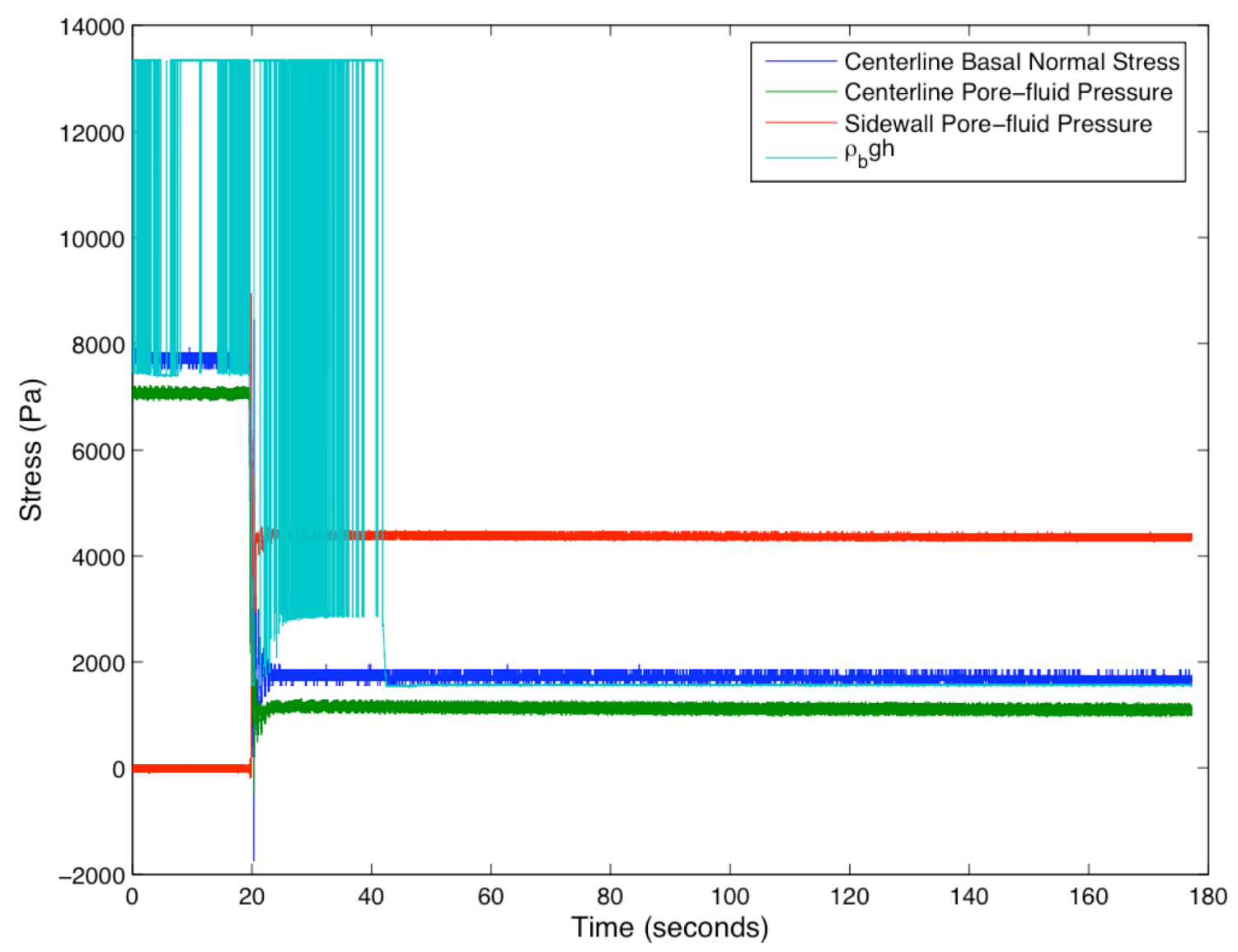

Figure 37: Osceola mudflow, Mt. Rainier, WA, 5600 years ago. The sediment mixture has a water content of $43 \%$, initial column height of $.39 \mathrm{~m}$, and bulk density of $1943 \mathrm{~kg} / \mathrm{m}^{3}$. The plot shows all sensors for the duration of the run. 


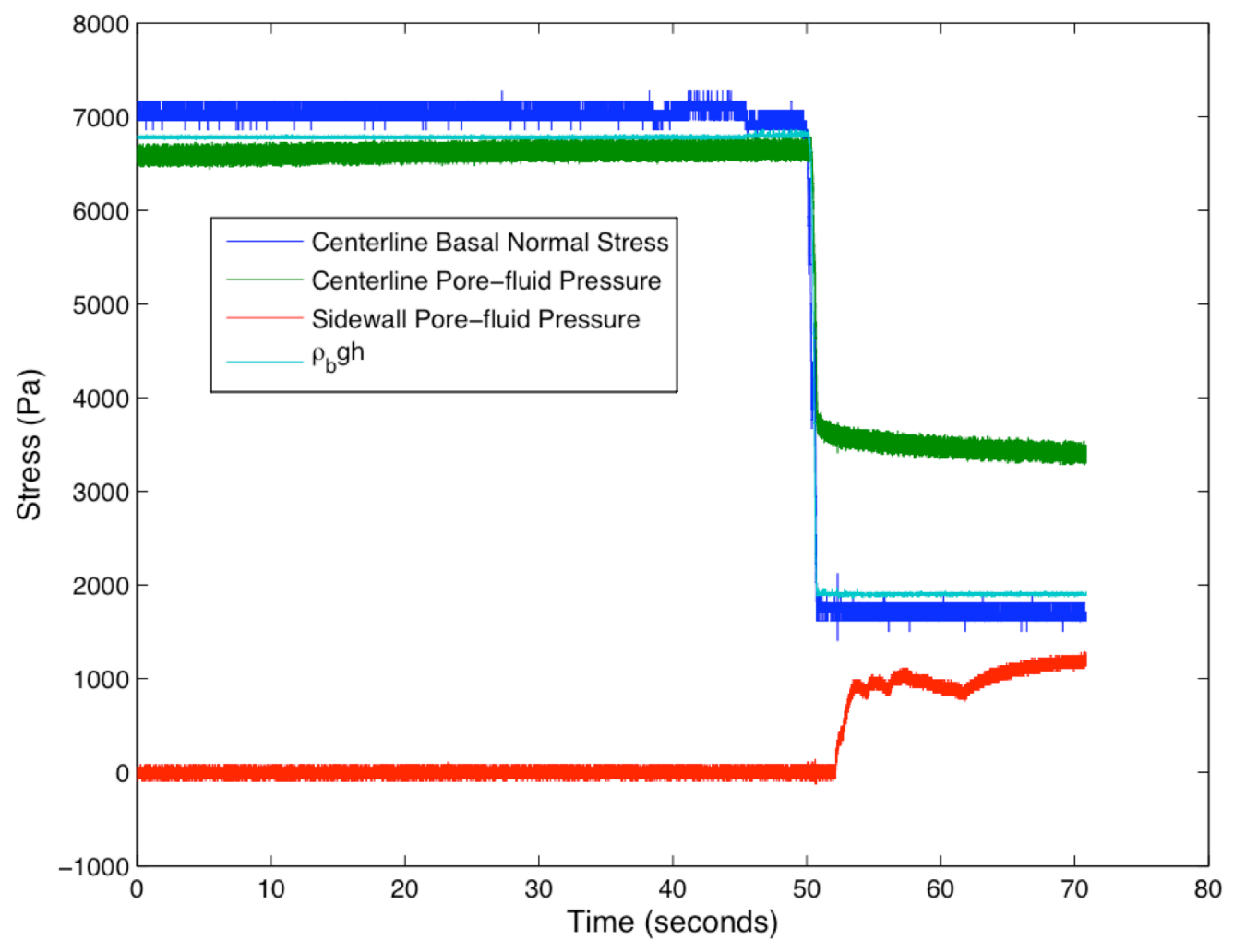

Figure 38: North Fork Toutle River mudflow, Mount St. Helens, WA, 1980. The sediment mixture has a water content of $44 \%$, initial column height of $.37 \mathrm{~m}$, and bulk density of $1891 \mathrm{~kg} / \mathrm{m}^{3}$. The plot shows all sensors for the duration of the run. 


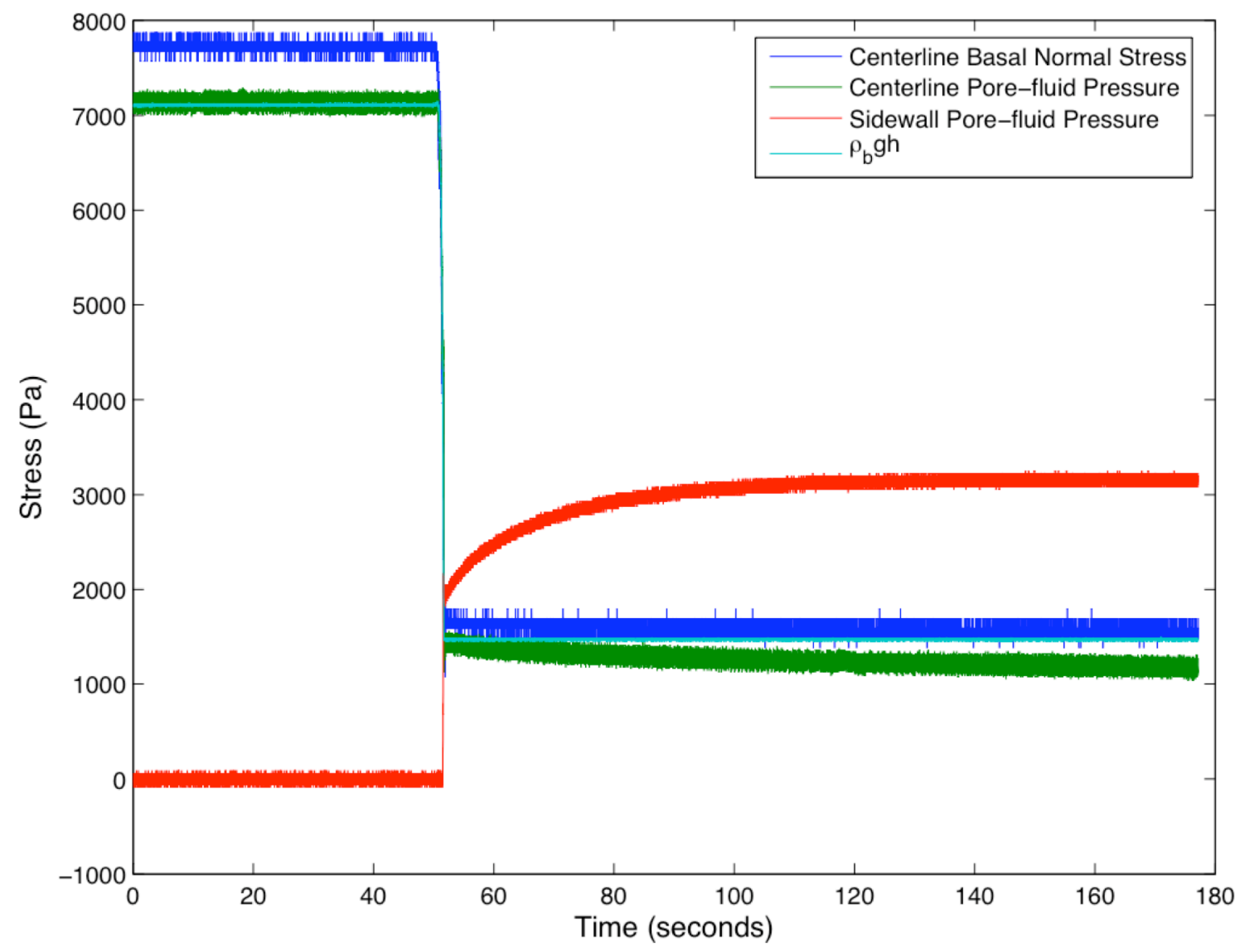

Figure 39: North Fork Toutle River mudflow, Mount St. Helens, WA, 1980. The sediment mixture has a water content of $47 \%$, initial column height of $.40 \mathrm{~m}$, and bulk density of $1841 \mathrm{~kg} / \mathrm{m}^{3}$. The plot shows all sensors for the duration of the run. 


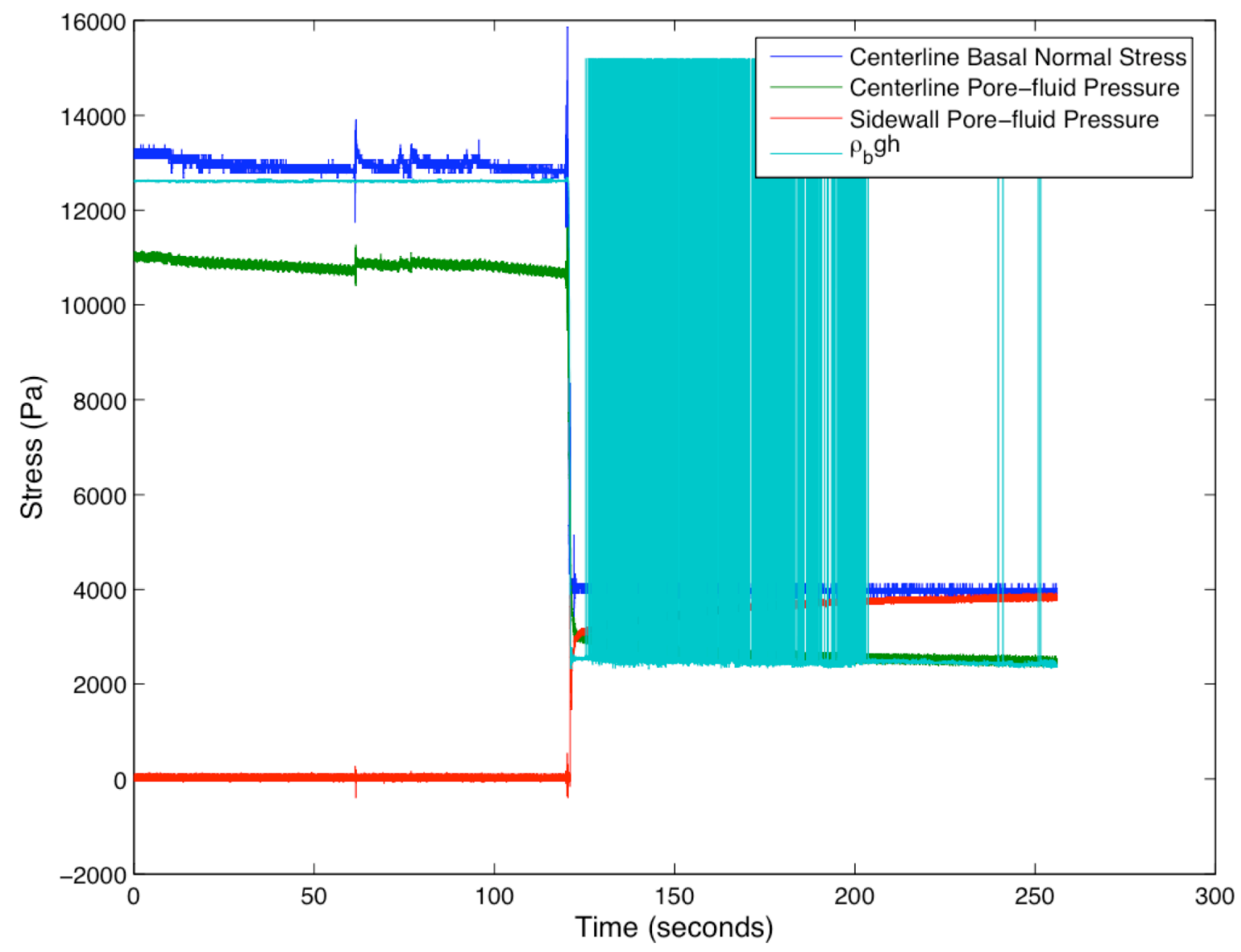

Figure 40: Commercial sand and gravel mixture. The sediment mixture has a water content of $29 \%$, initial column height of $.58 \mathrm{~m}$, and bulk density of $2211 \mathrm{~kg} / \mathrm{m}^{3}$. The plot shows all sensors for the duration of the run. 


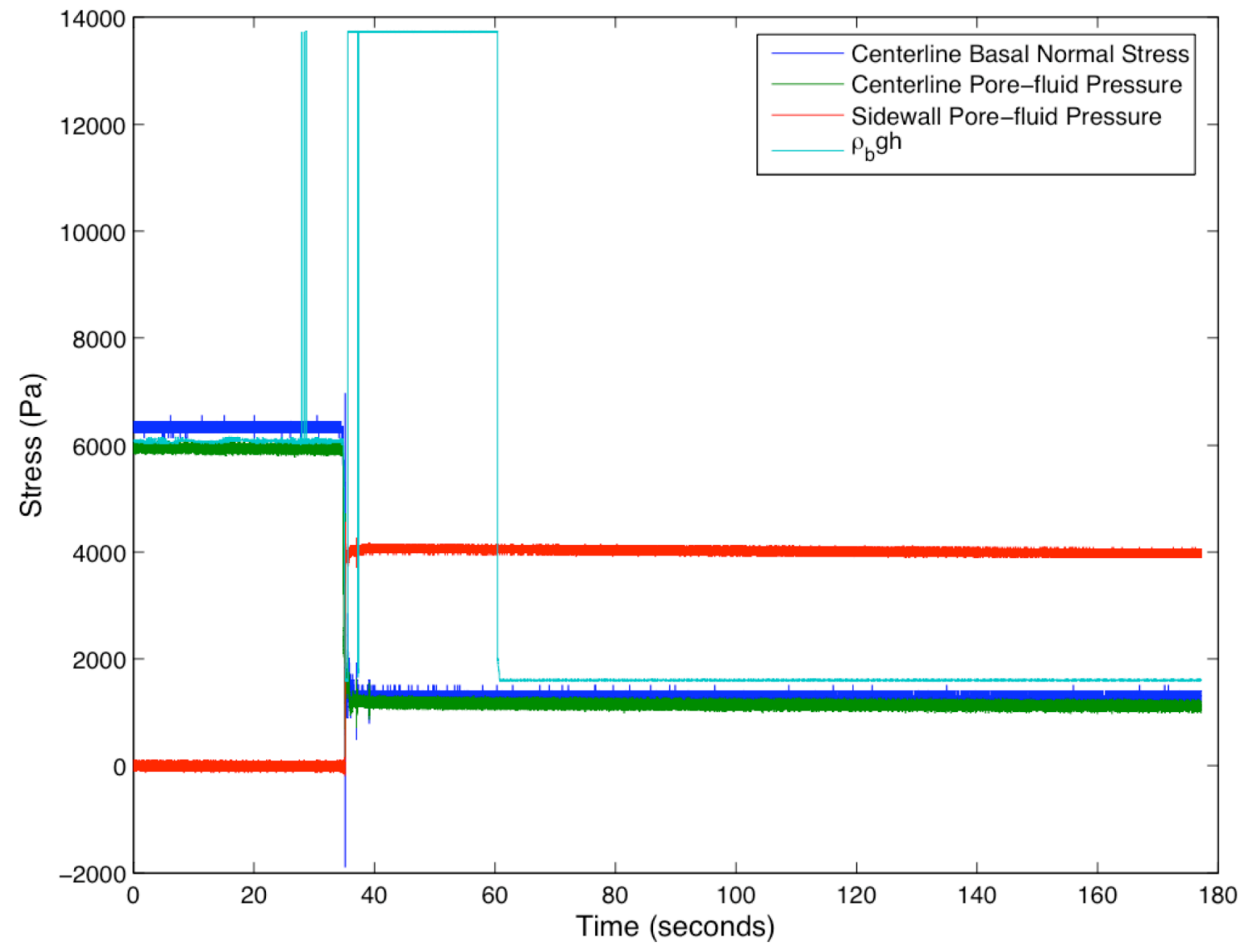

Figure 41: Commercial sand, gravel, and loam mixture. The sediment mixture has a water content of $39 \%$, initial column height of $.31 \mathrm{~m}$, and bulk density of $2000 \mathrm{~kg} / \mathrm{m}^{3}$. The plot shows all sensors for the duration of the run. 


\section{Appendix H. Sediment Analysis}

Grain size analysis is performed for all the sediments. The sieve method is used with sieve sizes (mm): $25.4,19.0,12.7,9.52,4.75,2.00, .850, .425, .250, .150$, and .075 . The analysis is done on sediments that have been oven dried.

Experiments that involved dry sediments are not included in this presentation of the analysis. In addition, the experiments with saturated gravel and saturated sand are omitted. 
\begin{tabular}{|l|l|}
\hline Sample \# & Dodson, sample 1 \\
\hline
\end{tabular}

\begin{tabular}{|c|c|}
\hline Weight in bag (g) & 2017.9 \\
\hline Weight of Sample Before (g) & 350.3 \\
\hline Weight of Sample After (g) & 350.4 \\
\hline Loose volume (cm3) & 1460 \\
\hline
\end{tabular}

\begin{tabular}{|cc|c|c|c|c|cc|}
\hline Sieve \# & Sieve Opening $(\mathrm{mm})$ & $\begin{array}{c}\text { Weight of } \\
\text { Empty Sieve } \\
(\mathrm{g})\end{array}$ & $\begin{array}{c}\text { Weight of } \\
\text { Soil+Sieve } \\
(\mathrm{g})\end{array}$ & $\begin{array}{c}\text { Weight } \\
\text { of Soil } \\
(\mathrm{g})\end{array}$ & $\begin{array}{c}\text { Percent } \\
\text { Retained on } \\
\text { Each Sieve }(\%)\end{array}$ & $\begin{array}{c}\text { Cumulative } \\
\text { Percent Retained } \\
(\%)\end{array}$ & $\begin{array}{c}\text { Percent Finer } \\
(\%)\end{array}$ \\
\hline $1^{\prime \prime}$ & 25.400 & & & 0.0 & 0.0 & 0.0 & 100.0 \\
\hline $.75 "$ & 19.000 & & & 0.0 & 0.0 & 0.0 & 100.0 \\
\hline $.5^{\prime \prime}$ & 12.700 & 549.1 & 561.9 & 12.8 & 3.7 & 3.7 & 96.3 \\
\hline $.375^{\prime \prime}$ & 9.520 & 540.4 & 546.0 & 5.6 & 1.6 & 5.3 & 94.7 \\
\hline 4 & 4.750 & 536.9 & 548.3 & 11.4 & 3.3 & 8.5 & 81.5 \\
\hline 10 & 2.000 & 701.2 & 734.2 & 33.0 & 9.4 & 17.9 & 70.3 \\
\hline 20 & 0.850 & 467.7 & 508.8 & 41.1 & 11.7 & 29.7 & 59.5 \\
\hline 40 & 0.425 & 422.1 & 460.2 & 38.1 & 10.9 & 40.5 & 49.9 \\
\hline 60 & 0.250 & 401.3 & 434.9 & 33.6 & 9.6 & 50.1 & 39.9 \\
\hline 100 & 0.150 & 386.2 & 421.2 & 35.0 & 10.0 & 60.1 & 28.8 \\
\hline 200 & 0.075 & 365.8 & 404.7 & 38.9 & 11.1 & 71.2 & 2 \\
\hline Pan & 0.000 & 355.6 & 456.5 & 100.9 & 28.8 & 100.0 & 0.0 \\
\hline
\end{tabular}

Grainsize Distribution, Dodson sample 1

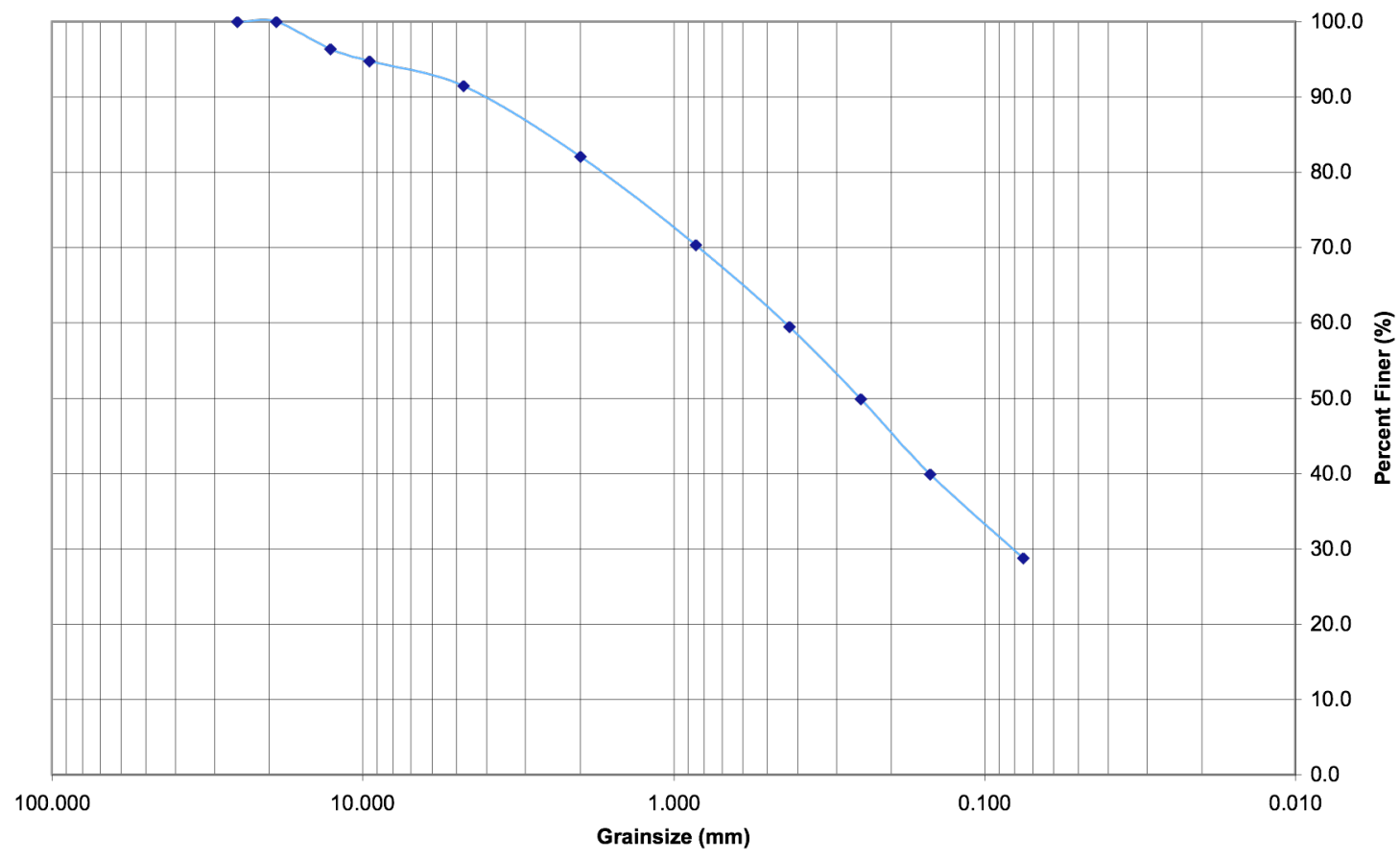




\begin{tabular}{|c|c|}
\hline Weight in bag (g) & 1723.7 \\
\hline Weight of Sample Before $(\mathrm{g})$ & 591 \\
\hline Weight of Sample After $(\mathrm{g})$ & 591 \\
\hline Loose volume (cm3) & 1070 \\
\hline
\end{tabular}

\begin{tabular}{|c|c|c|c|c|c|c|c|}
\hline Sieve \# & Sieve Opening $(\mathrm{mm})$ & $\begin{array}{c}\text { Weight of } \\
\text { Empty Sieve } \\
\text { (g) }\end{array}$ & $\begin{array}{c}\text { Weight of } \\
\text { Soil+Sieve } \\
\text { (g) }\end{array}$ & \begin{tabular}{|c|} 
Weight of \\
Soil $(\mathrm{g})$
\end{tabular} & $\begin{array}{c}\text { Percent } \\
\text { Retained on } \\
\text { Each Sieve } \\
(\%) \\
\end{array}$ & $\begin{array}{c}\text { Cumulative } \\
\text { Percent } \\
\text { Retained (\%) }\end{array}$ & Percent Finer (\%) \\
\hline $1 "$ & 25.400 & & & 33.0 & 5.6 & 5.6 & 94.4 \\
\hline $.75^{\prime \prime}$ & 19.000 & & & 62.0 & 10.5 & 16.1 & 83.9 \\
\hline $.5 "$ & 12.700 & & & 51.9 & 8.8 & 24.9 & 75.1 \\
\hline $.375^{\prime \prime}$ & 9.520 & 540.2 & 566.6 & 26.4 & 4.5 & 29.3 & 70.7 \\
\hline 4 & 4.750 & 537.0 & 579.6 & 42.6 & 7.2 & 36.5 & 63.5 \\
\hline 10 & 2.000 & 701.2 & 755.9 & 54.7 & 9.3 & 45.8 & 54.2 \\
\hline 20 & 0.850 & 467.6 & 521.9 & 54.3 & 9.2 & 55.0 & 45.0 \\
\hline 40 & 0.425 & 421.9 & 469.3 & 47.4 & 8.0 & 63.0 & 37.0 \\
\hline 60 & 0.250 & 401.1 & 439.1 & 38.0 & 6.4 & 69.4 & 30.6 \\
\hline 100 & 0.150 & 385.9 & 435.5 & 49.6 & 8.4 & 77.8 & 22.2 \\
\hline 200 & 0.075 & 366.0 & 413.3 & 47.3 & 8.0 & 85.8 & 14.2 \\
\hline Pan & 0.000 & 496.6 & 580.4 & 83.8 & 14.2 & 100.0 & 0.0 \\
\hline
\end{tabular}

Grainsize Distribution, Dodson sample 2

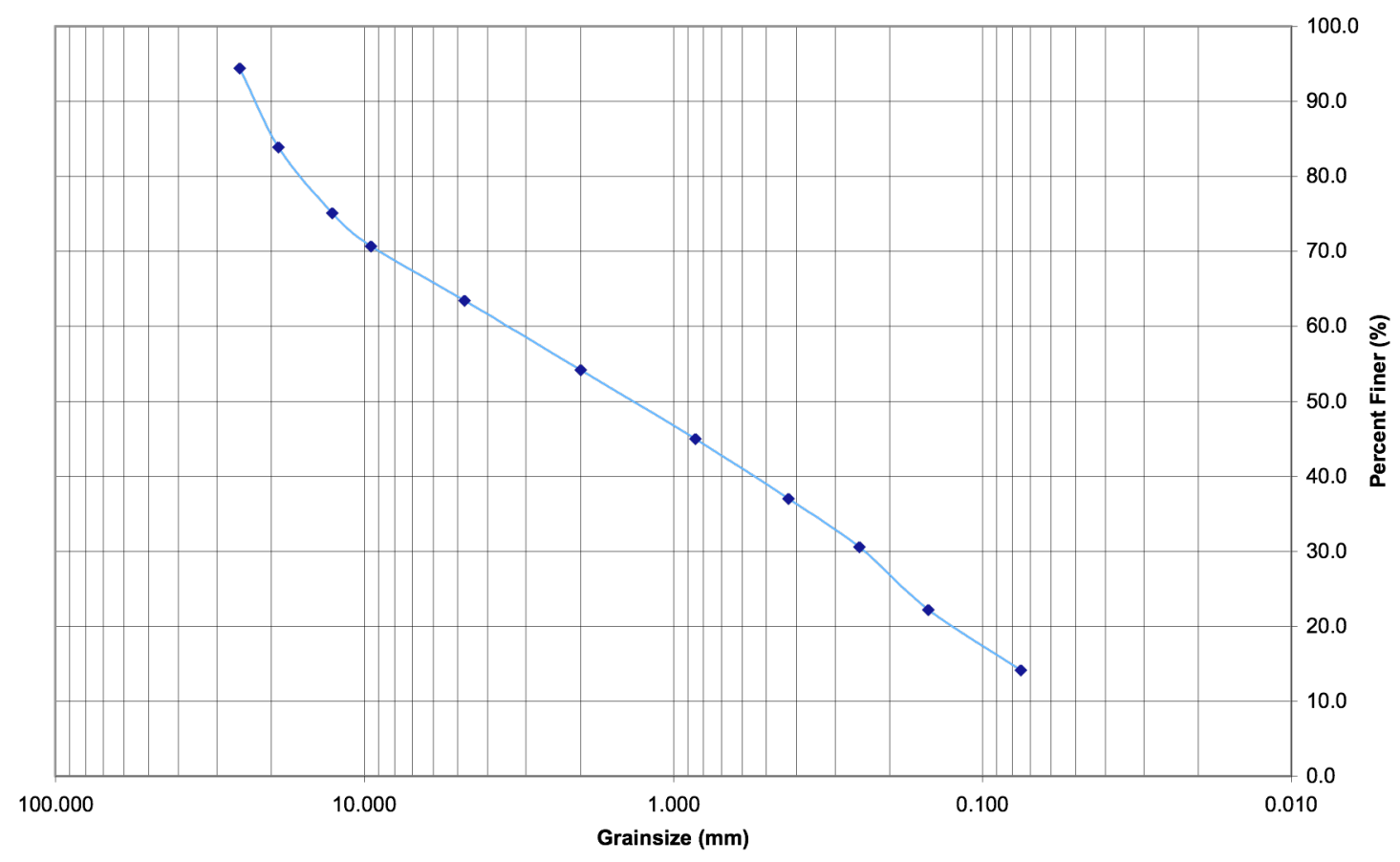




\begin{tabular}{|c|c|}
\hline Weight in bag (g) & 1493.4 \\
\hline Weight of Sample Before (g) & 559.1 \\
\hline Weight of Sample After (g) & 559.1 \\
\hline Loose volume (cm3) & 1020 \\
\hline
\end{tabular}

\begin{tabular}{|ccc|c|c|c|c|c|}
\hline Sieve \# & $\begin{array}{c}\text { Sieve Opening } \\
(\mathrm{mm})\end{array}$ & $\begin{array}{c}\text { Weight of } \\
\text { Empty Sieve } \\
(\mathrm{g})\end{array}$ & $\begin{array}{c}\text { Weight of } \\
\text { Soil+Sieve } \\
(\mathrm{g})\end{array}$ & $\begin{array}{c}\text { Weight of Soil } \\
(\mathrm{g})\end{array}$ & $\begin{array}{c}\text { Percent Retained } \\
\text { on Each Sieve } \\
(\%)\end{array}$ & $\begin{array}{c}\text { Cumulative } \\
\text { Percent Retained } \\
(\%)\end{array}$ & $\begin{array}{c}\text { Percent } \\
\text { Finer } \\
(\%)\end{array}$ \\
\hline $1^{\prime \prime}$ & 25.400 & & & 0.0 & 0.0 & 0.0 & 100.0 \\
\hline $.75^{\prime \prime}$ & 19.000 & & & 0.0 & 0.0 & 0.0 & 100.0 \\
\hline $.5^{\prime \prime}$ & 12.700 & 549.1 & 583.3 & 34.2 & 6.1 & 6.1 & 93.9 \\
\hline $.375^{\prime \prime}$ & 9.520 & 540.2 & 564.5 & 24.3 & 4.3 & 10.5 & 89.5 \\
\hline 4 & 4.750 & 537.0 & 583.5 & 46.5 & 8.3 & 18.8 & 81.2 \\
\hline 10 & 2.000 & 701.2 & 776.5 & 75.3 & 13.5 & 32.2 & 67.8 \\
\hline 20 & 0.850 & 467.6 & 528.2 & 60.6 & 10.8 & 43.1 & 56.9 \\
\hline 40 & 0.425 & 421.9 & 478.0 & 56.1 & 10.0 & 53.1 \\
\hline 60 & 0.250 & 401.1 & 444.7 & 43.6 & 7.8 & 60.9 & 36.9 \\
\hline 100 & 0.150 & 386.0 & 447.2 & 61.2 & 10.9 & 71.9 & 28.1 \\
\hline 200 & 0.075 & 366.0 & 413.8 & 47.8 & 8.6 & 80.4 \\
\hline Pan & 0.000 & 496.5 & 606.0 & 109.5 & 19.6 & 100.0 \\
\hline
\end{tabular}

Grainsize Distribution, Dodson sample 3

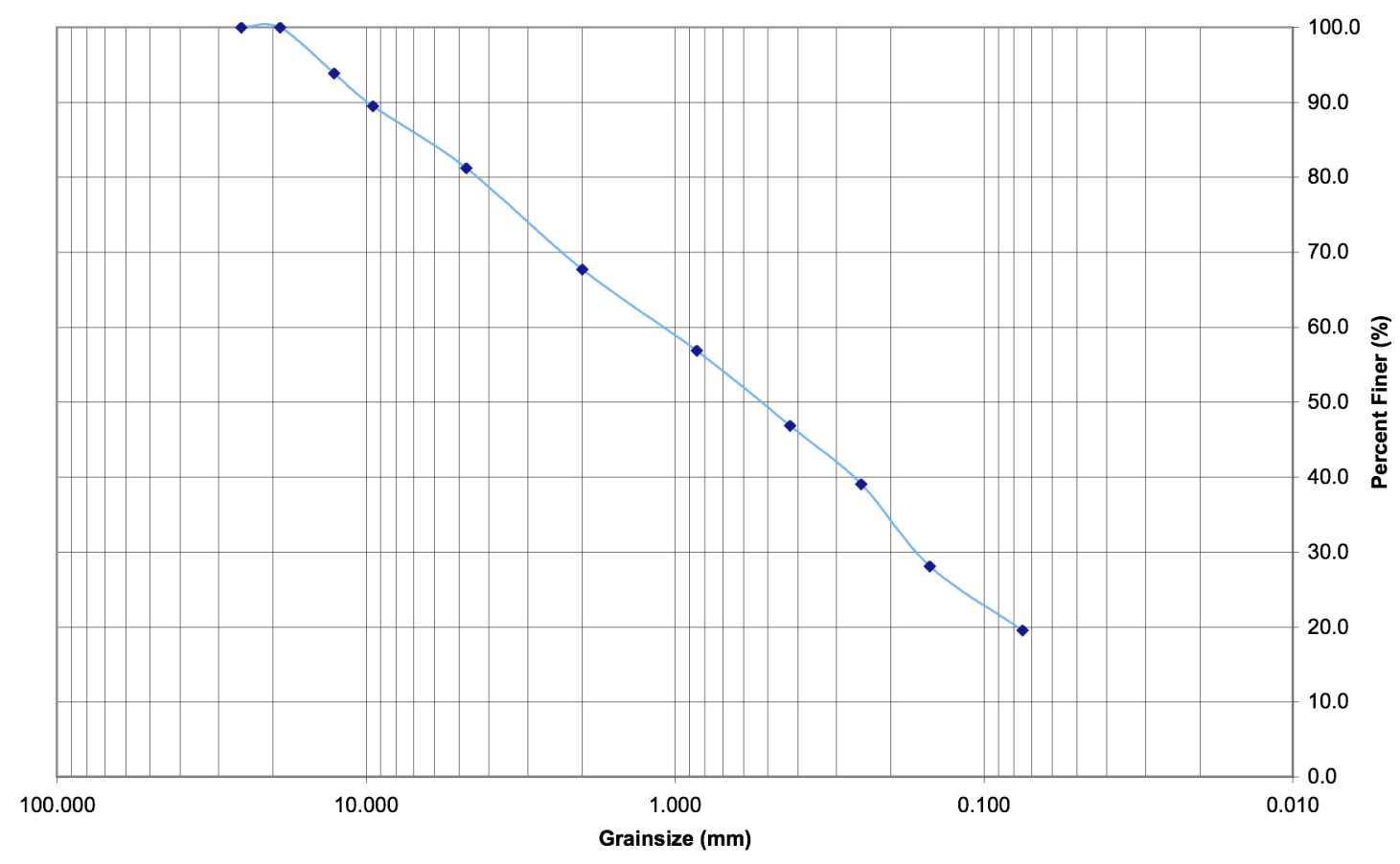




\begin{tabular}{|c|c|}
\hline Weight in bag (g) & 3064.9 \\
\hline Weight of Sample Before $(\mathrm{g})$ & 680.6 \\
\hline Weight of Sample After $(\mathrm{g})$ & 680.6 \\
\hline Loose volume $(\mathrm{cm} 3)$ & 1930 \\
\hline
\end{tabular}

\begin{tabular}{|c|c|c|c|c|c|c|c|}
\hline Sieve \# & Sieve Opening (mm) & $\begin{array}{c}\text { Weight of } \\
\text { Empty Sieve (g) }\end{array}$ & $\begin{array}{c}\text { Weight of } \\
\text { Soil+Sieve } \\
\text { (g) }\end{array}$ & Weight of Soil (g) & \begin{tabular}{|c|} 
Percent \\
Retained on \\
Each Sieve (\%) \\
\end{tabular} & \begin{tabular}{|c|} 
Cumulative \\
Percent \\
Retained (\%) \\
\end{tabular} & $\begin{array}{l}\text { Percent } \\
\text { Finer (\%) }\end{array}$ \\
\hline 1" & 25.400 & & & 0.0 & 0.0 & 0.0 & 100.0 \\
\hline $.75 "$ & 19.000 & & & 28.6 & 4.2 & 4.2 & 95.8 \\
\hline $.5 "$ & 12.700 & & & 26.5 & 3.9 & 8.1 & 91.9 \\
\hline $.375^{\prime \prime}$ & 9.520 & 540.2 & 556.7 & 16.5 & 2.4 & 10.5 & 89.5 \\
\hline 4 & 4.750 & 537.0 & 586.0 & 49.0 & 7.2 & 17.7 & 82.3 \\
\hline 10 & 2.000 & 701.2 & 763.5 & 62.3 & 9.2 & 26.9 & 73.1 \\
\hline 20 & 0.850 & 467.6 & 543.1 & 75.5 & 11.1 & 38.0 & 62.0 \\
\hline 40 & 0.425 & 421.9 & 509.3 & 87.4 & 12.8 & 50.8 & 49.2 \\
\hline 60 & 0.250 & 401.1 & 476.9 & 75.8 & 11.1 & 61.9 & 38.1 \\
\hline 100 & 0.150 & 386.1 & 465.1 & 79.0 & 11.6 & 73.6 & 26.4 \\
\hline 200 & 0.075 & 366.1 & 432.9 & 66.8 & 9.8 & 83.4 & 16.6 \\
\hline Pan & 0.000 & 496.6 & 609.8 & 113.2 & 16.6 & 100.0 & 0.0 \\
\hline
\end{tabular}

Grainsize Distribution, Osceola

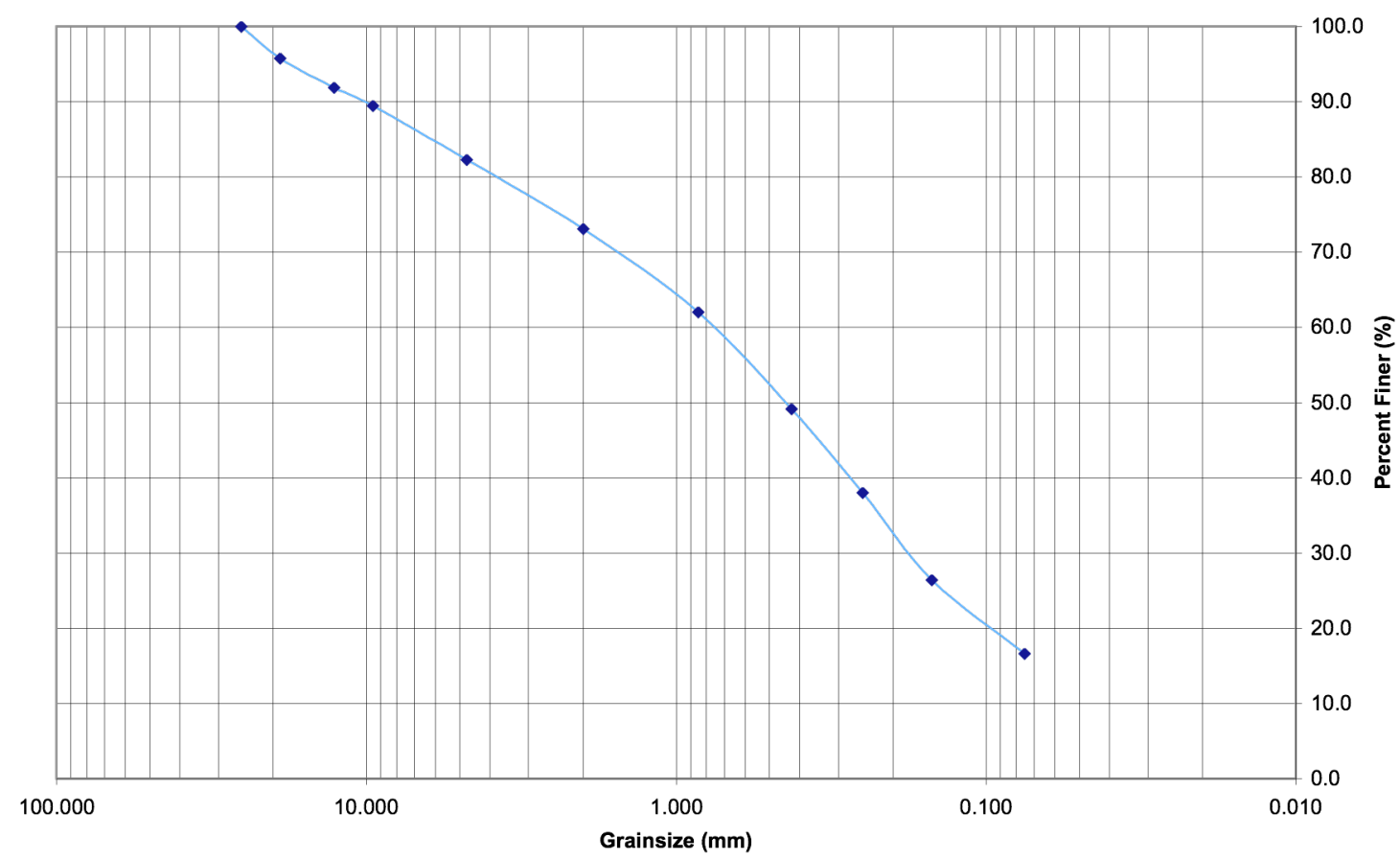




\begin{tabular}{|l|l|}
\hline Sample \# & Sand/Gravel/Loam \\
\hline
\end{tabular}

\begin{tabular}{|c|c|}
\hline Weight in bag (g) & 784.7 \\
\hline Weight of Sample Before (g) & 754.7 \\
\hline Weight of Sample After (g) & 754.8 \\
\hline Loose volume (cm3) & 460 \\
\hline
\end{tabular}

\begin{tabular}{|ccc|c|c|c|c|c|}
\hline Sieve \# & $\begin{array}{c}\text { Sieve Opening } \\
(\mathrm{mm})\end{array}$ & $\begin{array}{c}\text { Weight of } \\
\text { Empty Sieve } \\
(\mathrm{g})\end{array}$ & $\begin{array}{c}\text { Weight of } \\
\text { Soil+Sieve } \\
(\mathrm{g})\end{array}$ & $\begin{array}{c}\text { Weight } \\
\text { of Soil } \\
(\mathrm{g})\end{array}$ & $\begin{array}{c}\text { Percent Retained } \\
\text { on Each Sieve } \\
(\%)\end{array}$ & $\begin{array}{c}\text { Cumulative Percent } \\
\text { Retained }(\%)\end{array}$ & $\begin{array}{c}\text { Percent Finer } \\
(\%)\end{array}$ \\
\hline $1^{\prime \prime}$ & 25.400 & & & 0.0 & 0.0 & 0.0 & 100.0 \\
\hline $.75 "$ & 19.000 & & & 0.0 & 0.0 & 0.0 & 100.0 \\
\hline $5^{\prime \prime}$ & 12.700 & 1542.7 & 1613.5 & 70.8 & 9.4 & 9.4 & 90.6 \\
\hline $.375^{\prime \prime}$ & 9.520 & 1526.5 & 1562.2 & 35.7 & 4.7 & 14.1 & 85.9 \\
\hline 4 & 4.750 & 705.1 & 830.2 & 125.1 & 16.6 & 30.7 & 69.3 \\
\hline 10 & 2.000 & 483.4 & 606.3 & 122.9 & 16.3 & 47.0 & 53.0 \\
\hline 20 & 0.850 & 409.5 & 479.8 & 70.3 & 9.3 & 56.3 & 43.7 \\
\hline 40 & 0.425 & 384.2 & 478.8 & 94.6 & 12.5 & 68.8 & 31.2 \\
\hline 60 & 0.250 & 368.2 & 452.6 & 84.4 & 11.2 & 80.0 & 20.0 \\
\hline 100 & 0.150 & 348.9 & 403.0 & 54.1 & 7.2 & 87.2 & 12.8 \\
\hline 200 & 0.075 & 337.4 & 378.2 & 40.8 & 5.4 & 92.6 & 7.4 \\
\hline Pan & 0.000 & 375.3 & 431.4 & 56.1 & 7.4 & 100.0 & 0.0 \\
\hline
\end{tabular}

\section{Grainsize Distribution, Sand/Gravel/Loam}

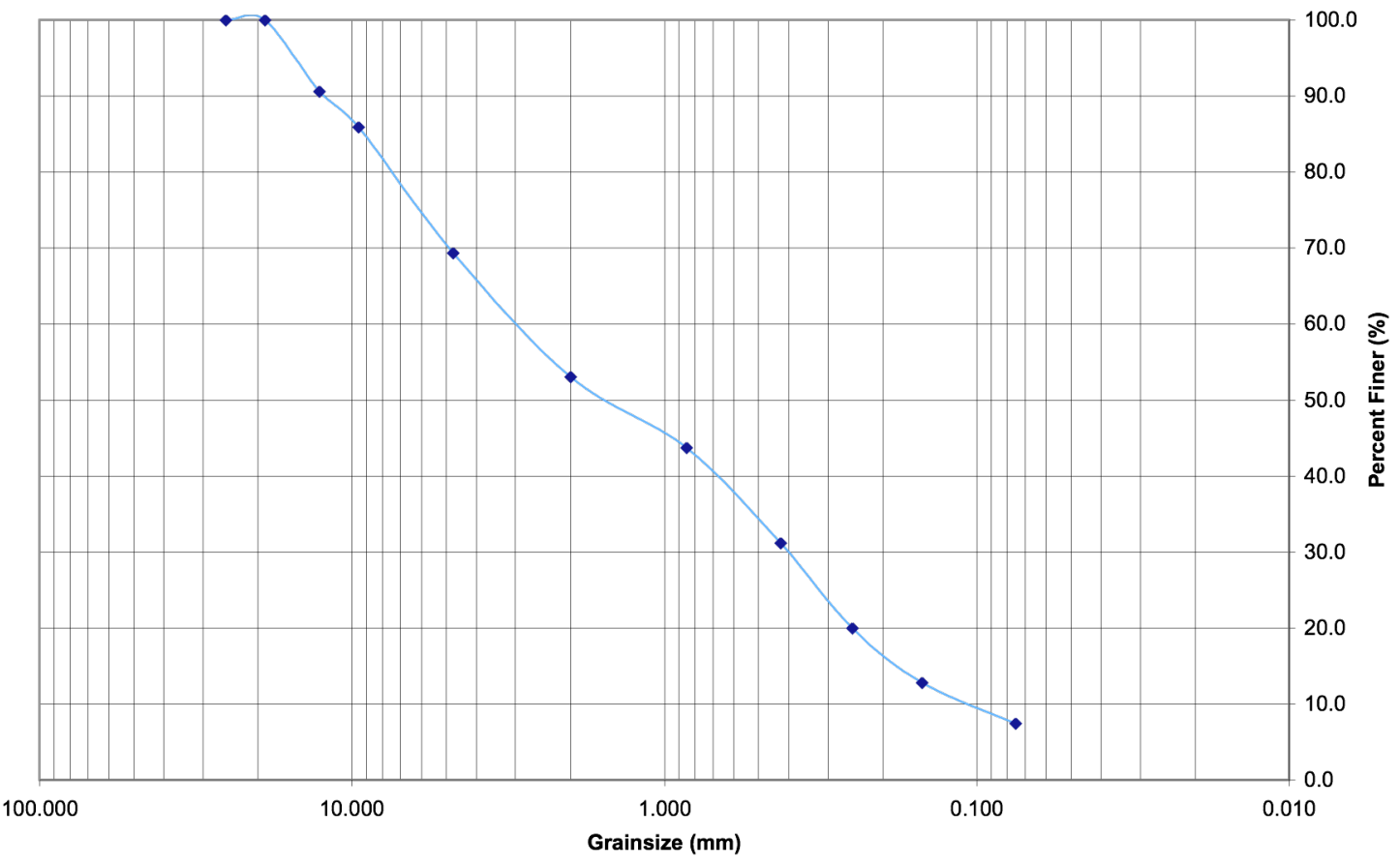




\begin{tabular}{|c|c|}
\hline Weight in bag (g) & 247.2 \\
\hline Weight of Sample Before (g) & 240.2 \\
\hline Weight of Sample After (g) & 240.1 \\
\hline Loose volume (cm3) & 150 \\
\hline
\end{tabular}

\begin{tabular}{|ccc|c|c|c|c|c|}
\hline Sieve \# & $\begin{array}{c}\text { Sieve Opening } \\
(\mathrm{mm})\end{array}$ & $\begin{array}{c}\text { Weight of } \\
\text { Empty Sieve } \\
(\mathrm{g})\end{array}$ & $\begin{array}{c}\text { Weight of } \\
\text { Soil+Sieve } \\
(\mathrm{g})\end{array}$ & $\begin{array}{c}\text { Weight } \\
\text { of Soil } \\
(\mathrm{g})\end{array}$ & $\begin{array}{c}\text { Percent Retained } \\
\text { on Each Sieve } \\
(\%)\end{array}$ & $\begin{array}{c}\text { Cumulative } \\
\text { Percent Retained } \\
(\%)\end{array}$ & $\begin{array}{c}\text { Percent Finer } \\
(\%)\end{array}$ \\
\hline $1^{\prime \prime}$ & 25.400 & & & 0.0 & 0.0 & 0.0 & 100.0 \\
\hline $.75 "$ & 19.000 & & & 13.2 & 5.5 & 5.5 & 94.5 \\
\hline $5^{\prime \prime}$ & 12.700 & & & 125.2 & 52.1 & 57.6 & 42.4 \\
\hline $.375^{\prime \prime}$ & 9.520 & 780.4 & 799.1 & 18.7 & 7.8 & 65.4 & 34.6 \\
\hline 4 & 4.750 & 707.7 & 723.1 & 15.4 & 6.4 & 71.8 & 28.2 \\
\hline 10 & 2.000 & 483.5 & 504.6 & 21.1 & 8.8 & 80.6 & 19.4 \\
\hline 20 & 0.850 & 410.1 & 421.5 & 11.4 & 4.7 & 85.4 & 14.6 \\
\hline 40 & 0.425 & 383.7 & 398.1 & 14.4 & 6.0 & 91.4 & 8.6 \\
\hline 60 & 0.250 & 368.0 & 378.2 & 10.2 & 4.2 & 95.6 & 4.4 \\
\hline 100 & 0.150 & 348.7 & 353.9 & 5.2 & 2.2 & 97.8 & 2.2 \\
\hline 200 & 0.075 & 337.4 & 339.8 & 2.4 & 1.0 & 98.8 & 1.2 \\
\hline Pan & 0.000 & 375.4 & 378.3 & 2.9 & 1.2 & 100.0 & 0.0 \\
\hline
\end{tabular}

Grainsize Distribution, Sand/Gravel

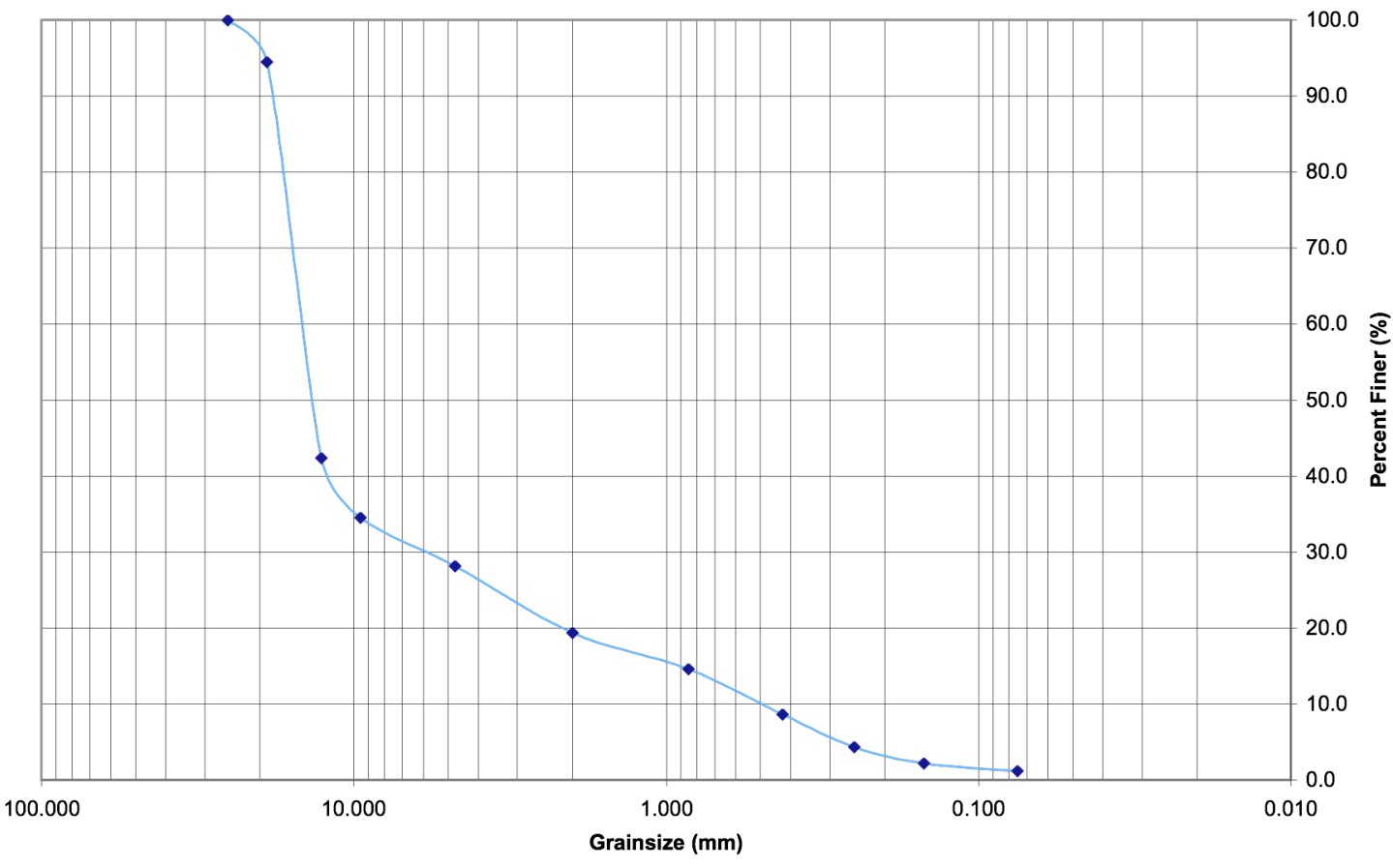




\begin{tabular}{|c|c|}
\hline Weight in bag (g) & 2862.9 \\
\hline Weight of Sample Before $(\mathrm{g})$ & 933.9 \\
\hline Weight of Sample After $(\mathrm{g})$ & 933.5 \\
\hline Loose volume $(\mathrm{cm} 3)$ & 2020 \\
\hline
\end{tabular}

\begin{tabular}{|c|c|c|c|c|c|c|c|}
\hline Sieve \# & $\begin{array}{l}\text { Sieve Opening } \\
\quad(\mathrm{mm})\end{array}$ & $\begin{array}{l}\text { Weight of Empty } \\
\text { Sieve }(\mathrm{g})\end{array}$ & $\begin{array}{c}\text { Weight of } \\
\text { Soil+Sieve }(\mathrm{g})\end{array}$ & Weight of Soil (g) & \begin{tabular}{|c|} 
Percent \\
Retained on \\
Each Sieve \\
$(\%)$ \\
\end{tabular} & \begin{tabular}{|c|} 
Cumulative \\
Percent \\
Retained (\%)
\end{tabular} & $\begin{array}{l}\text { Percent } \\
\text { Finer } \\
(\%)\end{array}$ \\
\hline $1 "$ & 25.400 & & & 0.0 & 0.0 & 0.0 & 100.0 \\
\hline $.75 "$ & 19.000 & 1652.1 & 1668.8 & 16.7 & 1.8 & 1.8 & 98.2 \\
\hline $.5^{\prime \prime}$ & 12.700 & 1542.7 & 1571.6 & 28.9 & 3.1 & 4.9 & 95.1 \\
\hline $.375^{\prime \prime}$ & 9.520 & 1526.5 & 1546.8 & 20.3 & 2.2 & 7.1 & 92.9 \\
\hline 4 & 4.750 & 705.1 & 755.8 & 50.7 & 5.4 & 12.5 & 87.5 \\
\hline 10 & 2.000 & 483.4 & 558.5 & 75.1 & 8.1 & 20.5 & 79.5 \\
\hline 20 & 0.850 & 409.5 & 553.9 & 144.4 & 15.5 & 36.0 & 64.0 \\
\hline 40 & 0.425 & 384.2 & 536.5 & 152.3 & 16.3 & 52.3 & 47.7 \\
\hline 60 & 0.250 & 368.2 & 478.5 & 110.3 & 11.8 & 64.1 & 35.9 \\
\hline 100 & 0.150 & 348.9 & 448.1 & 99.2 & 10.6 & 74.8 & 25.2 \\
\hline 200 & 0.075 & 337.4 & 440.0 & 102.6 & 11.0 & 85.8 & 14.2 \\
\hline Pan & 0.000 & 375.3 & 508.3 & 133.0 & 14.2 & 100.0 & 0.0 \\
\hline
\end{tabular}

Grainsize Distribution, Toutle

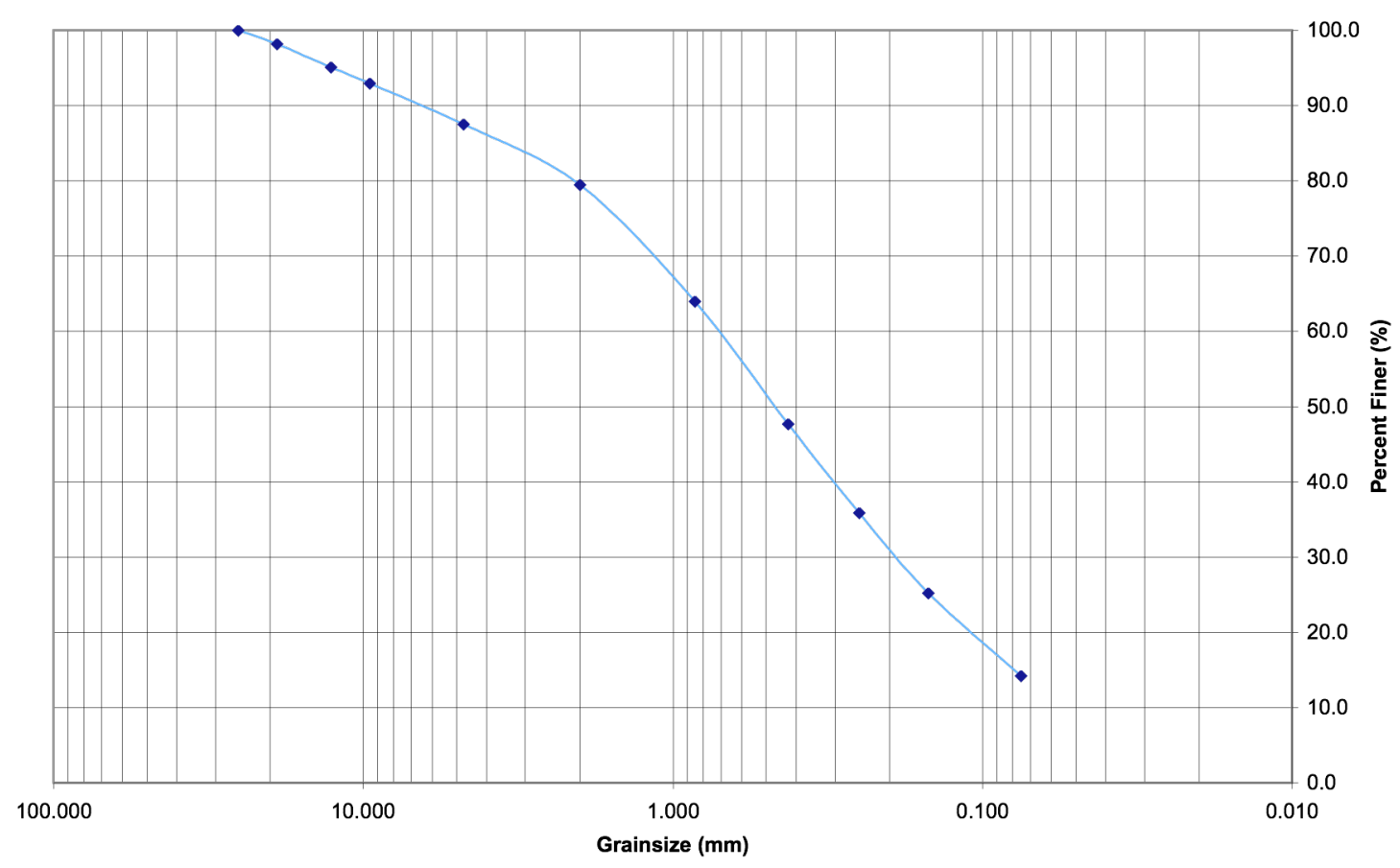

